\title{
The Perception of Young Drivers and Their Understanding of Graduated Drivers Licensing
}

Andrew Poszich

Follow this and additional works at: https://researchrepository.wvu.edu/etd

\section{Recommended Citation}

Poszich, Andrew, "The Perception of Young Drivers and Their Understanding of Graduated Drivers Licensing" (2016). Graduate Theses, Dissertations, and Problem Reports. 6439.

https://researchrepository.wvu.edu/etd/6439

This Thesis is protected by copyright and/or related rights. It has been brought to you by the The Research Repository @ WVU with permission from the rights-holder(s). You are free to use this Thesis in any way that is permitted by the copyright and related rights legislation that applies to your use. For other uses you must obtain permission from the rights-holder(s) directly, unless additional rights are indicated by a Creative Commons license in the record and/ or on the work itself. This Thesis has been accepted for inclusion in WVU Graduate Theses, Dissertations, and Problem Reports collection by an authorized administrator of The Research Repository @ WVU. For more information, please contact researchrepository@mail.wvu.edu. 


\title{
The Perception of Young Drivers and Their Understanding of Graduated Drivers Licensing
}

\author{
Andrew Poszich
}

Thesis submitted

to the Benjamin M. Statler College of Engineering and Mineral Resources

At West Virginia University

in partial fulfillment of the requirements for the degree of

Master of Science in

Civil Engineering

David R. Martinelli, Ph.D. Chair

Avinash Unnikrishnan, Ph.D.

Ronald Eck, Ph.D.

Department of Civil and Environmental Engineering

Morgantown, West Virginia

2016

Keywords: West, Virginia, Graduated, Driver, Licensing, Teenage, Safety Copyright 2016 Andrew Poszich 


\begin{abstract}
The Perception of Young Drivers and Their Understanding of Graduated

Drivers Licensing
\end{abstract}

\begin{abstract}
Andrew Poszich
New, young drivers are over three times more susceptible to crashes in their first 1,000 miles of on road driving. In order to reduce the number incident rate for teenage drivers, Graduated Drivers Licensing (GDL) programs have been implemented across the country. West Virginia, along with all other states, aims to further improve the effectiveness of this program. Currently, GDL effectiveness is steeply limited by the willingness of teenager drivers and their parents to comply with the laws in place. Across the country, programs are being implemented that help raise awareness of GDL and supplement some of the information already provided by the state. One key aspect where GDL is limited is the effect it has on the behavior and attitude of the teenagers passing through its process. Understanding why teenagers engage in certain high risk activities that go against the restrictions outlined by GDL is crucial to developing educational programs. A survey of high schools representing urban, suburban, and rural demographics has been designed to flush out elements that may affect students' perception of what risky driving habits are and what they would consider to be acceptable behavior. Using the insight developed from these surveys, programs will be recommended to better cater to the needs of the students of West Virginia; the most notable of which is "Teens in the Driver Seat" which promotes peer-led safe driving campaigns.
\end{abstract}




\section{Acknowledgements}

This research project is sponsored by the U.S. Department of Transportation, Federal Highway Administration, and the West Virginia Department of Transportation, Division of Highways. It was completed with the assistance of many individuals and organizations. The Principal Investigators wish to express thanks to those identified below, as well as all of the other individuals and organizations that supported the project.

The willingness of each of the cooperating schools, Clay-Battelle Middle/High School, Morgantown High School, and University High School, is encouraging and was greatly appreciated during the course of the study. The input each of the surveyed students provided is crucial for the development of programs and practices targeted towards the wellbeing of novice teenage drivers. The authors would like to extend a special thanks to the main correspondence from each of the schools: David Cottrell (Clay-Battelle), Paul Mihalko (Morgantown), Carol Muniz (Morgantown), Shari Burgess (University), John Conrad (University). 


\section{Table of Contents}

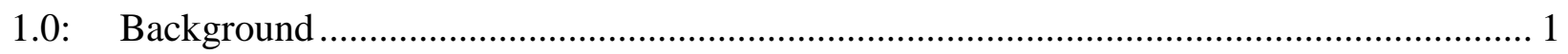

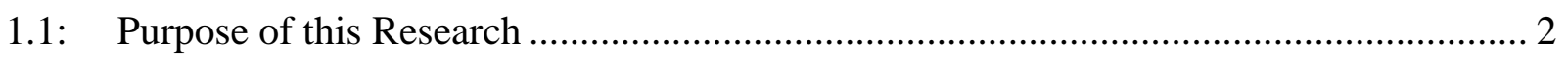

1.2: National Fatal Crash Statistics Involving Youth......................................................... 2

1.2.1: Alcohol Consumption around Young Drivers ....................................................... 4

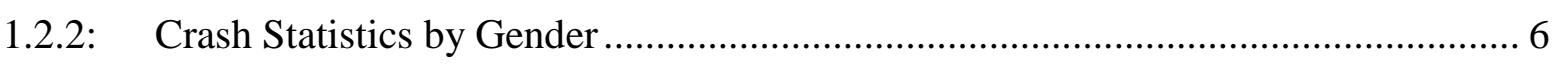

1.3: West Virginia Teenage Crash and Behavioral Statistics............................................... 7

1.3.1: Youth Risk Behavior Surveillance System (YRBSS) ………………………........ 8

1.4: Graduated Drivers Licensing ……………….................................................... 12

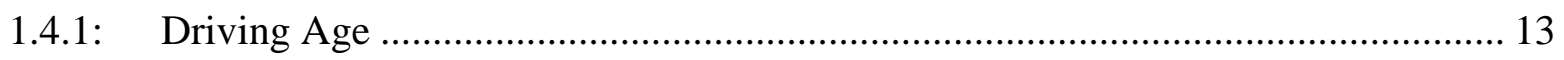

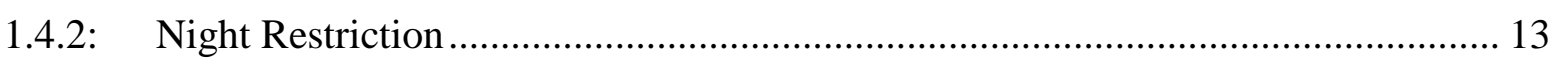

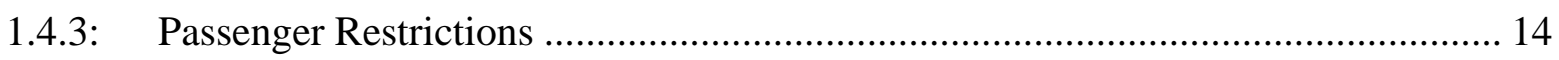

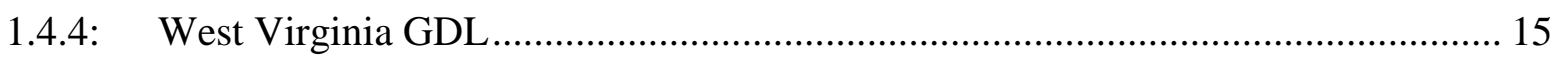

1.5: Previous Analysis of West Virginia's Graduated Driver Licensing Program ............... 16

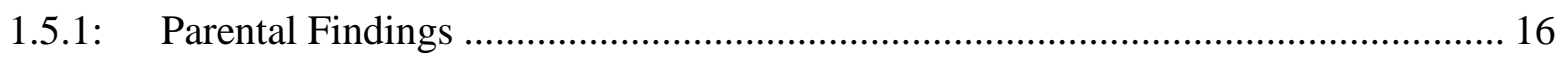

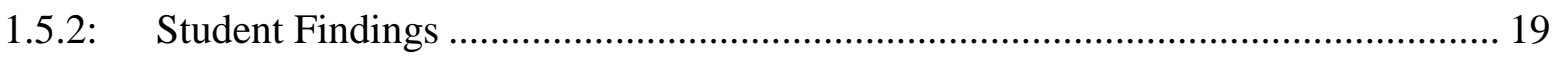

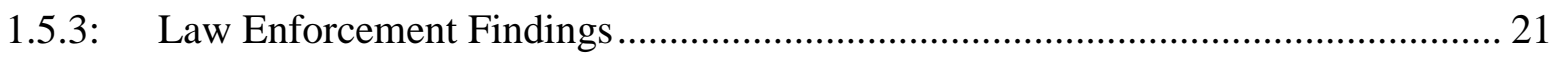

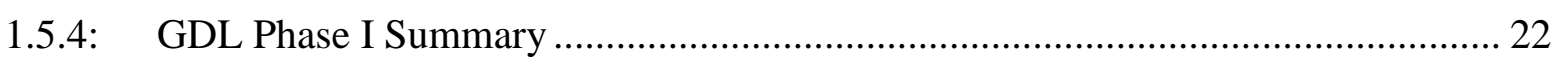

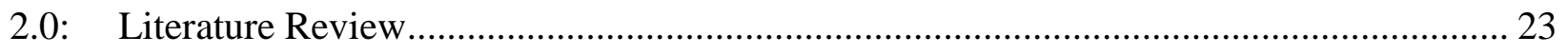

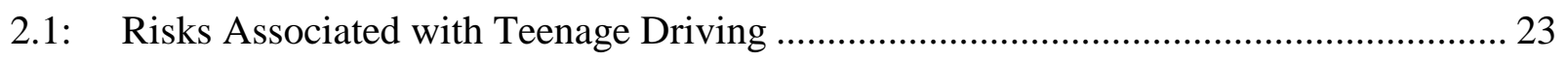

2.1.1: Analysis Methods for Evaluating Teenage Driving Statistics ................................ 23

2.1.2: Behavioral Analysis of Young Drivers .............................................................. 25

2.2: Existing Programs Targeted Towards Driver Safety ……………............................. 28

2.2.1: Early Education and Education Strategies .......................................................... 28

2.2.2: Post-Incident Intervention............................................................................ 33

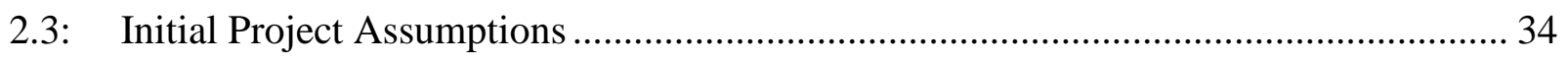

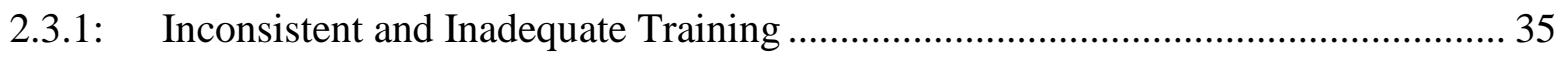

2.3.2: Limitation of GDL on Behavioral Influence ................................................... 36

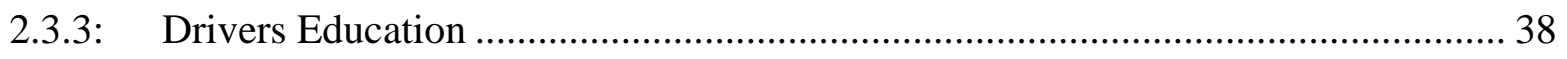

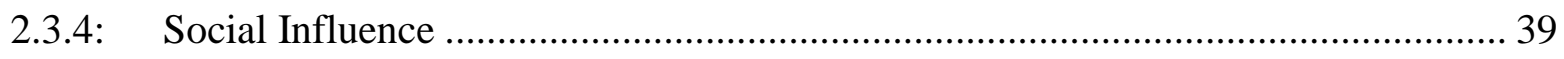

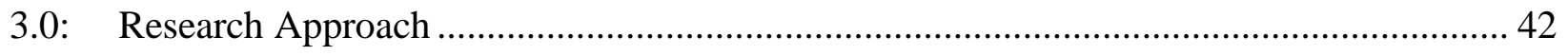

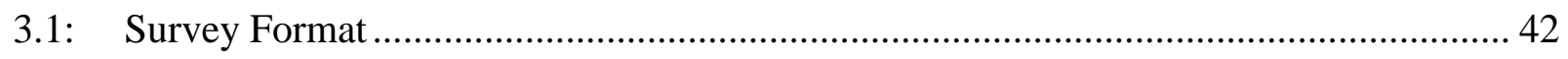

3.2: Driver Demographic ......................................................................................... 44

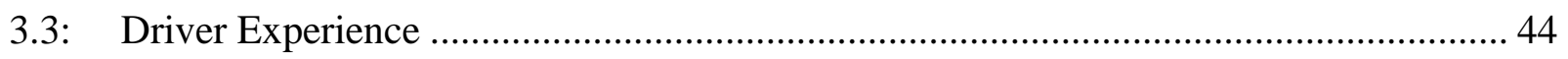




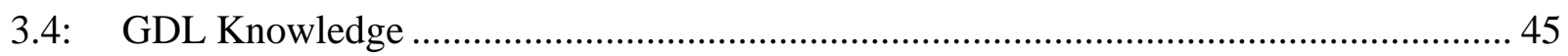

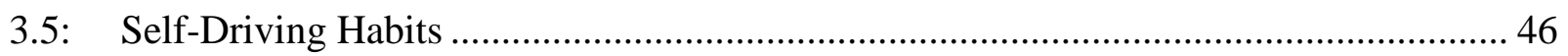

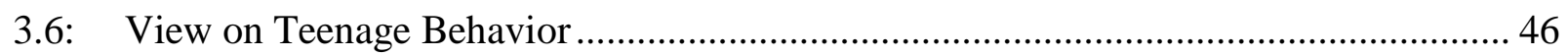

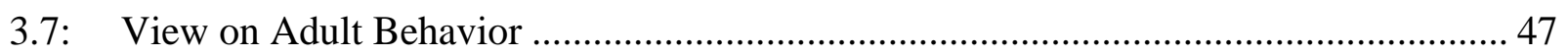

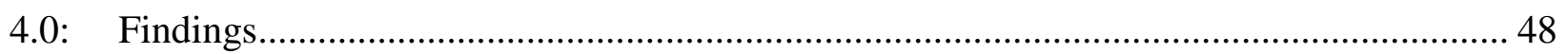

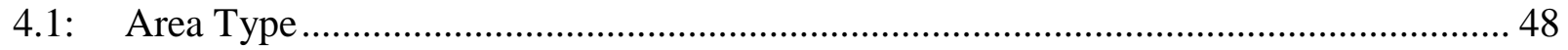

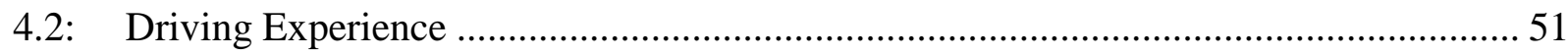

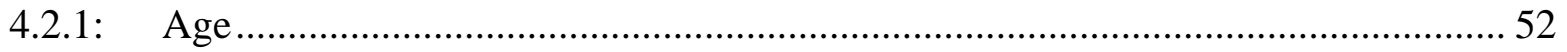

4.2.2: Years since Instructional Permit ......................................................................... 54

4.2.3: Years since Intermediate License ………………………………………….... 55

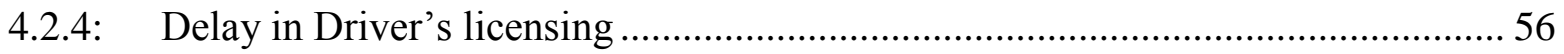

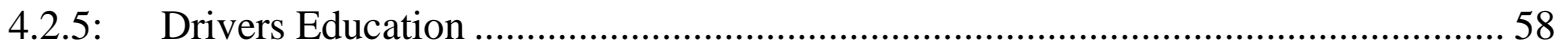

4.2.6: Hours Spend Practicing with Learners Permit....................................................... 60

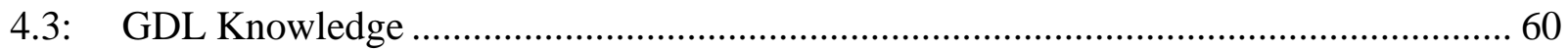

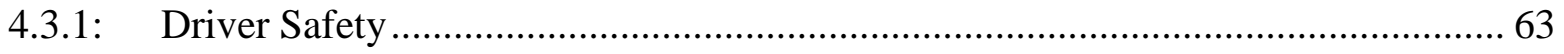

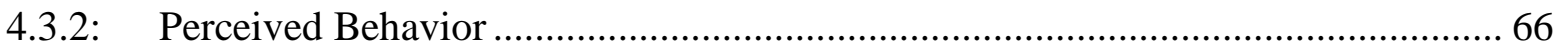

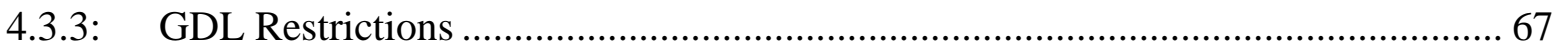

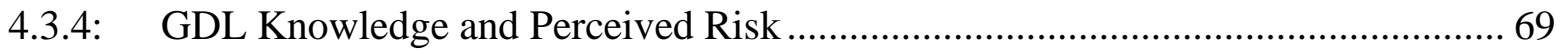

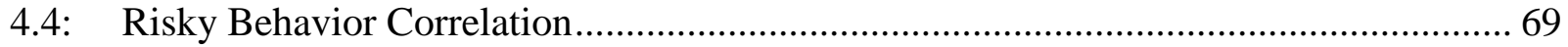

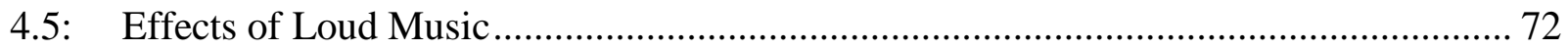

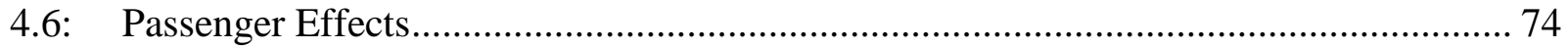

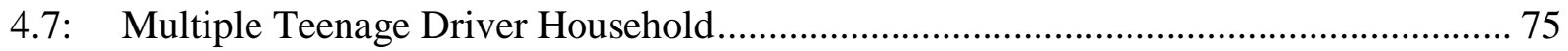

4.8: Driving Trip Purpose

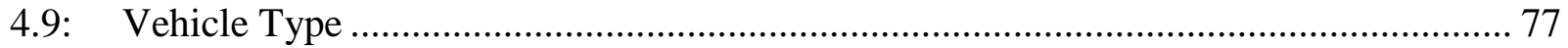

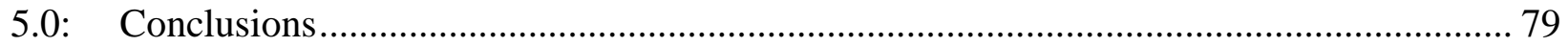

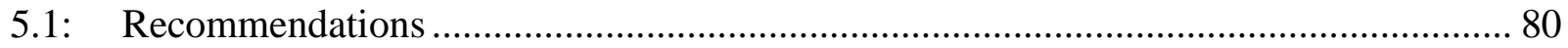

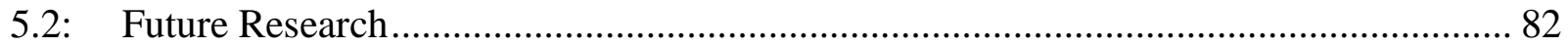

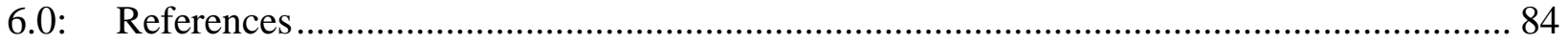

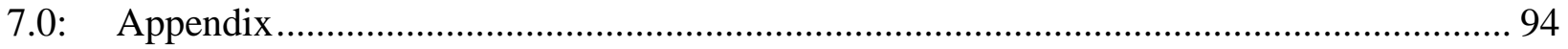

7.1: Complete GDL Survey .......................................................................................... 94

7.2: Graphical Breakdown of Responses by Question .................................................... 103

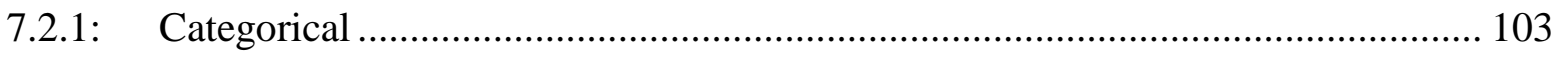

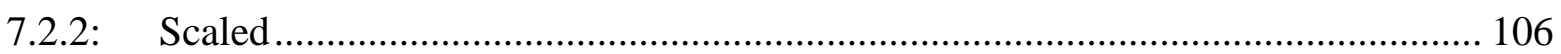

7.3: Detailed Summary of Responses by Question …………….................................... 108 


\section{List of Figures}

Figure 1-1: Crash Fatalities and Fatality Rates, and People Injured and Injury Rates, per 100M VMT, 1990-2014 (NHTSA, 2014 Crash Data Key Findings, 2015).

Figure 1-2: Total Fatality History for Young and Adult Drivers, Data From: (NHTSA's National

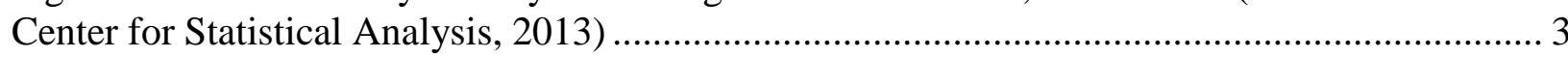

Figure 1-3: Minimum Age for Unsupervised Driving (IIHS, 2016) ........................................... 13

Figure 1-4: Night Restriction Start Times (IIHS, 2016) …………………………………….... 14

Figure 1-5: Restrictions on Passengers (IIHS, 2016)............................................................ 15

Figure 1-6: West Virginia Driver Licenses (WV DOT, 2016) ……………………………..... 15

Figure 1-7: Parents who have heard of the GDL Program (GDL Phase I) ………….................... 17

Figure 1-8: Parent Knowledge Survey Results (GDL Phase I) .................................................. 17

Figure 1-9: Parent Cited Benefits to the GDL program (GDL Phase I) ...................................... 18

Figure 1-10: Parent cited GDL violations (GDL Phase I) …................................................. 19

Figure 1-11: Students who know of the GDL program (GDL Phase I)......................................... 19

Figure 1-12: Student GDL Knowledge Survey Results (GDL Phase I) ………………................. 20

Figure 1-13: Student Cited GDL Violations (GDL Phase I) ………………………………...... 21

Figure 1-14: Law Enforcement officers who know of GDL program (GDL Phase I) .................. 21

Figure 1-15: Law Enforcement Officer Knowledge Survey Results (GDL Phase I) .................... 22

Figure 2-1: List of participating states (Teens in the Driver Seat, 2016) .................................... 31

Figure 2-2: State Driver Education Requirements and Curriculum Control (Chaudhary, Bayer,

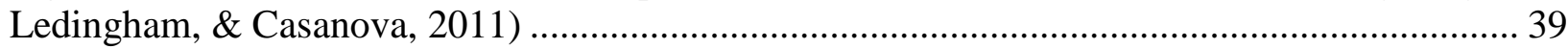

Figure 2-3: Trends in sensation seeking by age in National Annenberg Survey of Youth (Romer

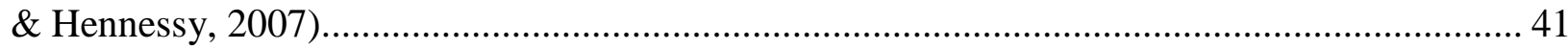

Figure 4-1: West Virginia Population Density Map (Irwin, 2011) ............................................... 49

Figure 4-2: Graph of perceived teenage risk by school region (rural, suburban, and urban) ....... 50

Figure 4-1: Graph of how teenage risk perception compares to age ......................................... 52

Figure 4-2: Likert scale responses of perceived teenage risk by age........................................... 53

Figure 4-3: Graph of how perceived risk of other teenagers change with years since acquiring an

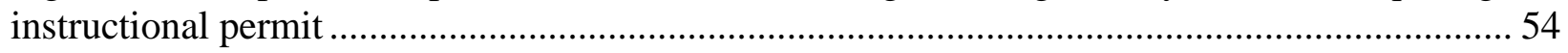

Figure 4-4: Likert scale responses of perceived teenage risk by years since acquiring an

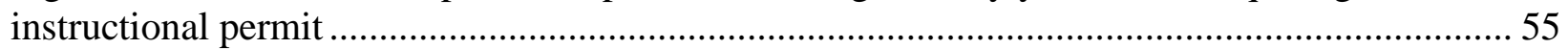

Figure 4-5: Graph of perceived teenage risk by years since acquiring an intermediate license ... 56

Figure 4-6: Likert scale responses of perceived teenage risk by years since acquiring an

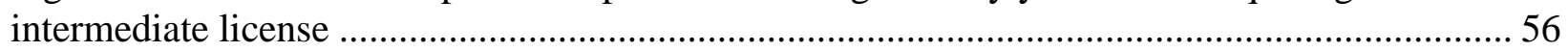

Figure 4-7: Risk perception for drivers who have been licensed for less than one year .............. 57

Figure 4-8: Graph comparing perceived risk of teenagers and adults by time spent driving with instructional permit.

Figure 4-9: Surface map comparing response frequency of teenage knowledge and perceived

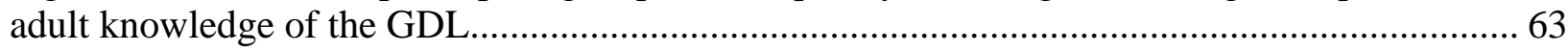

Figure 4-10: Comparing driving risk to whether or not the student believes they know more than

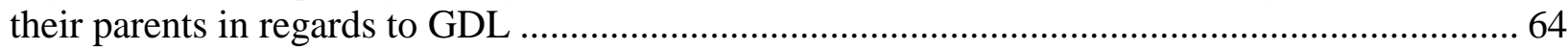

Figure 4-11: Change in driving risk compared to age in regards to who is believed to better

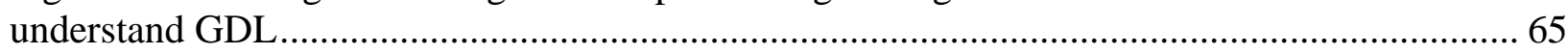

Figure 4-12: Comparison of the change in risk compared to knowledge of GDL and parental enforcement. 
Figure 4-13 Comparison of the perceived risk of other teen compared to knowledge of GDL and

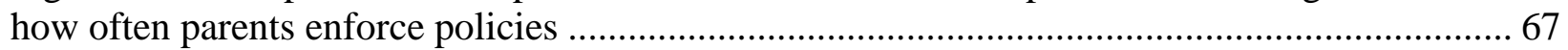

Figure 4-14: Change in the observation of behavior associated with violating GDL and perceived teenage risk 68

Figure 4-15: The correlation between perceived risk of teenage and adult with the self-

assessment of the respondent's GDL knowledge. 69

Figure 4-16: Likelihood of observing certain behaviors in teenagers and adults..... 70 Figure 4-17: Surface map of the correspondence between the perception of teenage and adult drivers 71

Figure 4-18: Likelihood of listening to loud music while in a vehicle by age ......................... 73

Figure 4-19: Likelihood of listening to loud music while in a vehicle by years driving ............. 73

Figure 4-20: Comparison between the frequency one would ride with passengers and combined perceived risk of teens and adults . 75

Figure 4-23: Graph of perceived teenage risk by other household young drivers ..................... 76

Figure 4-24: self-risk factors by driving destination.................................................... 77

Figure 4-25: Graph of perceived teenage risk by vehicle type and condition ........................... 78

\section{List of Tables}

Table 1-1: Fatalities in Crashes Involving a Young Driver, by Person Type and Year, 2004-2013 (NHTSA's National Center for Statistical Analysis, 2013) ..................................................... 3 Table 1-2: Alcohol Involvement among Drivers Age 15 to 20 Involved in Fatal Crashes, by Year and Driver Status, 2004 and 2013 (NHTSA's National Center for Statistical Analysis, 2013)..... 5 Table 1-3: Young Drivers of Passenger Vehicles in Fatal Crashes, by Restraint Use and BAC, 2013 (NHTSA's National Center for Statistical Analysis, 2013) ........................................... 5

Table 1-4: Driver's Involved in Fatal Traffic Crashes, by Age, Speeding Involvement, and BAC (NHTSA's National Center for Statistics and Analysis, 2012)...

Table 1-5: Involvement of 15- to 20-Year Old Drivers in Fatal Crashes, by Gender, 2004 and 2013 (NHTSA's National Center for Statistical Analysis, 2013) ........................................... 7

Table 1-6: Speeding-Related Traffic Fatalities, by State and Roadway Function Class, 2012 (NHTSA's National Center for Statistics and Analysis, 2012) ............................................ 7

Table 1-7: Fatalities in Crashes Involving Young Drivers (Ages 15 to 20), by State and Person type 2013 (NHTSA's National Center for Statistical Analysis, 2013)

Table 1-8: YRBS Results for driving related risk factor in high school students

(West Virginia Department of Education, Office of Research, 2015) (CDC, Division of Adolescent and School Health, 2014).

Table 1-9: WV - Percentage of students who never or rarely wore a seatbelt when riding in a car driven by someone else (West Virginia Department of Education, Office of Research, 2015) ... 10 Table 1-10: Percentage of students who rode one or more times during the past 30 days in a vehicle driven by someone who had been drinking alcohol (West Virginia Department of Education, Office of Research, 2015)

Table 1-11: Percentage of students who drove when they had been drinking in the past 30 days (West Virginia Department of Education, Office of Research, 2015)....

Table 1-12: Percentage of students who texted or e-mailed while driving on or more of the past 30 days (West Virginia Department of Education, Office of Research, 2015) ..... 
Table 1-13: 2013 YRBS Results, West Virginia High School Survey, 10-year Trend Analysis Report (West Virginia Department of Education, Office of Research, 2015) .............................. 12

Table 1-14: West Virginia GDL Requirements (IIHS, 2016)................................................... 16

Table 1-15: Student Reported: Additional restrictions imposed on students by parents (GDL

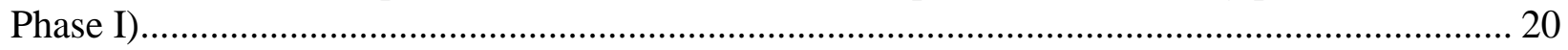

Table 2-1: Summary of Garland High School Risk Awareness Data (Henk \& Fette, 2009) ....... 32

Table 2-2: Teen Belt Use, Post-TDS Garland compared to Mesquite School District, May 2008

(Henk \& Fette, 2009)

Table 4-1: West Virginia Rural and Urban Population (2010 Census) (Alabama State Data

Center, 2015)

Table 4-2: t-Test comparison of the combined average perceived risk perception of both adults

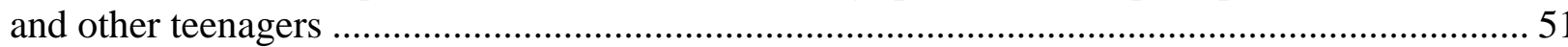

Table 4-1: Correlation of years of experience and perceived teenage risk ................................... 51

Table 4-3: t-Test for the comparison of teenage and adult driving risk perception for newly licensed 18 year olds ....................................................................................................... 58

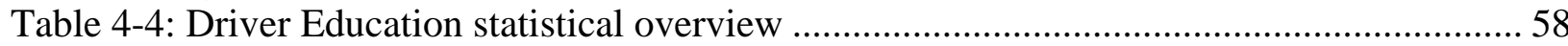

Table 4-5: t-Test comparison of the effects of driver education on groups of young drivers ...... 59 Table 4-6: t-Test determining that teens perceive adults as having a better understanding of GDL

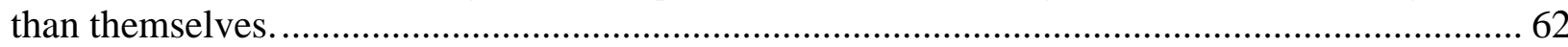

Table 4-7: Correlation matrix for GDL knowledge to perceived safety and behavior ................... 67

Table 4-8: Correlation between behavior in violation of GDL and perceived teenage risk .......... 69

Table 4-9: t-Test on the observed likelihood of partaking in risky behavior (teens and adults) .. 71 Table 4-10: Spearman Correlation between likelihood in observing a combination of different

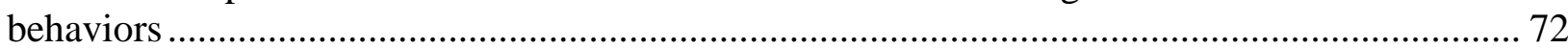

Table 4-11: Correlation between total observed risk and type of passengers............................... 75 


\section{0: Background}

Motor vehicle accidents are responsible for tens of thousands of fatalities each year and millions of injuries. In 2014 alone, 32,675 people were killed in motor vehicle crashes on U.S. roadways and an additional 2.3 million were injured according to the National Highway Traffic Safety Administration (NHTSA, 2014 Crash Data Key Findings, 2015). Of these deaths, 1,678 were young drivers 16 to 20 years of age and 581 passengers age 16 to 20 died while riding with a young driver. Much of this danger stems from these teenage drivers' inexperience on the road.

Additionally, 177,000 young drivers were injured in motor vehicle crashes in 2013 which breaks down to approximately 485 injuries per day (NHTSA, Traffic Safety Facts, Young Drivers, 2015). Even though overall deaths have decreased in past years due to improved safety features and a change in driving habit (Mawson \& Walley, 2014) this still leaves over six teenagers on average dying every day from vehicle related accidents at the hands of either themselves or other teenage drivers. Figure 1-1 shows this decrease from 1990 to 2014.
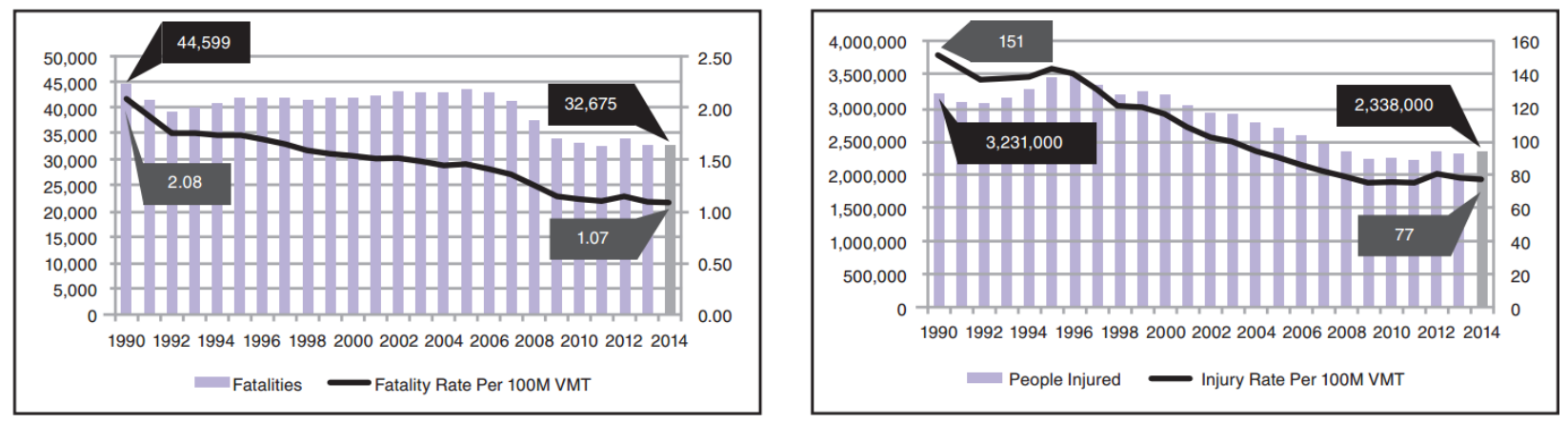

Figure 1-1: Crash Fatalities and Fatality Rates, and People Injured and Injury Rates, per 100M VMT, 1990-2014 (NHTSA, 2014 Crash Data Key Findings, 2015)

Teenage drivers are at high risk partly due to limited driving experience. The graduated driver licensing (GDL) program has been developed to enable young drivers to ease into driving, but other programs could be implemented to increase its effectiveness. Graduated drivers 
licensing typically involves a three phase program which is designed to slowly introduce young drivers to the road by means of placing restrictions on driving such as curfew and passenger limits. Other factors from which this increase in risk deviates include the teenager's likelihood to underestimate dangerous situations, an inability to recognize hazards, low seatbelt usage, higher likelihood of speeding, more aggressive driving patterns, and the costly effects of alcohol (Centers for Disease Control and Prevention, 2015).

\section{1: Purpose of this Research}

New drivers are over three times more susceptible to crashes in their first 1000 miles of on road driving than they are after the 1000 mile mark. What else, in conjunction with the graduated drivers licensing (GDL) program, can be done to improve teenage driver safety? These complementary programs would be implemented in conjunction with current state requirements and would be developed with the safety of the state's youth in mind. Programs targeted at teenage attitudes towards driving are more effective at making significant improvements than relying solely on GDL restrictions including curfew and number of passengers. The following study has been conducted in order to evaluate teenagers' perception of the current GDL program and to identify factors which lead to perceived higher risk driving. This look into the perception teenagers have of their surroundings can be used as an evaluation criteria to establish a course of action aimed at reducing involvement in high-risk activities.

\section{2: National Fatal Crash Statistics Involving Youth}

Overall, the reduction in fatalities on a national scale is a monument to the improved safety standards of the nation's vehicles and roadways. Both young drivers (age 15-20) and adults have shown a decrease in total fatalities over the last decade while the number of miles driven has remained relatively constant between 2.95 and 3.03 vehicle miles travel (VMT). 
Figure 1-2 shows how these fatality rates decreased from 2004 to 3013; young drivers have an average crash reduction rate of $7.4 \%$ per year while adult drivers (age $21+$ ) lag sharply behind at a reduction of $1.9 \%$ per year. This leads to young drivers being less than half as likely to be responsible for on road fatalities as they would have been in 2004 while adults are still around $80 \%$ as likely to be responsible.

Table 1-1: Fatalities in Crashes Involving a Young Driver, by Person Type and Year, 2004-2013 (NHTSA's National Center for Statistical Analysis, 2013)

\begin{tabular}{|c|c|c|c|c|c|c|c|c|}
\hline \multirow[b]{2}{*}{ Year } & \multirow{2}{*}{$\begin{array}{l}\text { Young Driver } \\
(15-20)\end{array}$} & \multicolumn{4}{|c|}{ Passenger of Young Driver } & \multirow{2}{*}{$\begin{array}{c}\text { Occupants of } \\
\text { Other Vehicles }\end{array}$} & \multirow[b]{2}{*}{ Nonoccupants } & \multirow[b]{2}{*}{ Total } \\
\hline & & $<15$ & $15-20$ & $21+$ & Unknown & & & \\
\hline 2004 & 3,634 & 317 & 1,530 & 548 & 7 & 2,113 & 633 & 8,782 \\
\hline 2005 & 3,474 & 229 & 1,429 & 533 & 6 & 1,946 & 624 & 8,241 \\
\hline 2006 & 3,490 & 235 & 1,387 & 550 & 5 & 1,912 & 632 & 8,211 \\
\hline 2007 & 3,190 & 223 & 1,371 & 443 & 7 & 1,829 & 631 & 7,694 \\
\hline 2008 & 2,742 & 170 & 1,067 & 421 & 4 & 1,527 & 521 & 6,452 \\
\hline 2009 & 2,343 & 145 & 958 & 351 & 2 & 1,381 & 469 & 5,649 \\
\hline 2010 & 1,965 & 130 & 845 & 356 & 2 & 1,250 & 493 & 5,041 \\
\hline 2011 & 1,993 & 118 & 777 & 298 & 1 & 1,122 & 473 & 4,782 \\
\hline 2012 & 1,880 & 88 & 682 & 286 & 4 & 1,230 & 502 & 4,672 \\
\hline 2013 & 1,691 & 120 & 623 & 307 & 1 & 1,128 & 463 & 4,333 \\
\hline
\end{tabular}

Fatalities by Driver 2004-2013

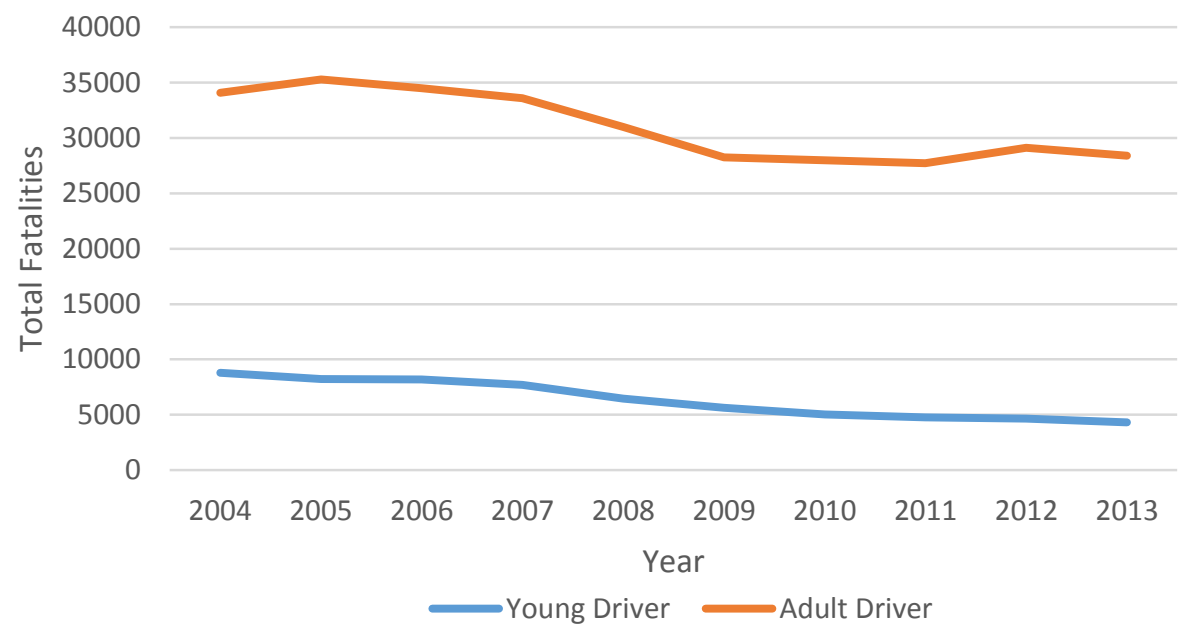

Figure 1-2: Total Fatality History for Young and Adult Drivers, Data From: (NHTSA's National Center for Statistical Analysis, 2013) 


\subsection{1: Alcohol Consumption around Young Drivers}

Drinking and driving is well established as a deadly combination. The impairment associated with the consumption of alcohol can be devastating and leads to an increased risk in motor vehicle crashes. This risk of being in a single vehicle fatal crash can be as much as 80 times higher for an underage drivers ( $<21$ years) with a BAC of $.10 \%$ than a sober driver of the same age group; the risk of involvement in any fatal crash for the same criteria is 30 times as likely (Voas, Torres, Romano, \& Lacey, 2012). This study also highlights the understanding that across all levels of BAC, the risk of motor vehicle crashes is greater in young drivers.

Table 1-2 shows the change in fatalities among young drivers from 2004 to 2013 and their BAC at the time. The overall reduction in young driver fatalities is apparent with the total incident involvement decreasing by about $50 \%$ over the entirely of 10 years period. This overall crash reduction across all BACs is accompanied by a $3 \%$ increase in survival rates. Interestingly enough, this overall trend is not tied to alcohol consumption; changes of less than $1 \%$ can be observed over this decade in regards to distribution of crashes to different BAC classifications. Around $29 \%$ of all crashes involve any alcohol at all while $24 \%$ involve driving with a BAC of what would be over the legal limit for adult drivers. With $80 \%$ of all young driver fatalities involving alcohol being attributed to those with high BACs $(>.08 \%)$, a cultural issue may be present which hasn't been properly addressed in the last decade. 
Table 1-2: Alcohol Involvement among Drivers Age 15 to 20 Involved in Fatal Crashes, by Year and Driver Status, 2004 and 2013 (NHTSA's National Center for Statistical Analysis, 2013)

\begin{tabular}{|c|c|c|c|c|c|c|c|}
\hline \multirow[b]{2}{*}{ Driver Status } & \multirow[b]{2}{*}{ Number of Drivers } & \multicolumn{2}{|c|}{ BAC $.00 \mathrm{~g} / \mathrm{dL}$} & \multicolumn{2}{|c|}{ BAC .01+ g/dL } & \multicolumn{2}{|c|}{ BAC .08+g/dL } \\
\hline & & Number & $\%$ & Number & $\%$ & Number & $\%$ \\
\hline \multicolumn{8}{|c|}{2004} \\
\hline Survived & 4,308 & 3,581 & $83 \%$ & 727 & $17 \%$ & 540 & $13 \%$ \\
\hline Killed & 3,634 & 2,560 & $70 \%$ & 1,074 & $30 \%$ & 881 & $24 \%$ \\
\hline Total & 7,942 & 6,141 & $77 \%$ & 1,801 & $23 \%$ & 1,421 & $18 \%$ \\
\hline \multicolumn{8}{|c|}{2013} \\
\hline Survived & 2,275 & 1,904 & $84 \%$ & 371 & $16 \%$ & 269 & $12 \%$ \\
\hline Killed & 1,691 & 1,199 & $71 \%$ & 492 & $29 \%$ & 405 & $24 \%$ \\
\hline Total & 3,966 & 3,103 & $78 \%$ & 863 & $22 \%$ & 674 & $17 \%$ \\
\hline
\end{tabular}

Alcohol consumption comes with an increase in likelihood of vehicle crashes, but this trend also extends to engagement in risky behaviors such as not using proper seatbelt restraints and speeding. Table 1-3 demonstrates how young drivers who are willing to drink and drive at any BAC level are over twice as likely to also not be wearing a seatbelt in fatal crashes. While this same demographic is 1.5 times as likely to be a victim in these fatal incidents. Both provide a strong and statistically significant correlation.

Table 1-3: Young Drivers of Passenger Vehicles in Fatal Crashes, by Restraint Use and BAC, 2013 (NHTSA's National Center for Statistical Analysis, 2013)

\begin{tabular}{|c|c|c|c|c|}
\hline \multirow[b]{2}{*}{ Restraint Use } & \multicolumn{2}{|c|}{ BAC $.00 \mathrm{~g} / \mathrm{dL}$} & \multicolumn{2}{|c|}{ BAC .01+ g/dL } \\
\hline & Number & $\%$ & Number & $\%$ \\
\hline \multicolumn{5}{|c|}{ Drivers Involved in Fatal Crashes } \\
\hline Restraint Used & 2,003 & $78 \%$ & 364 & $51 \%$ \\
\hline Restraint Not Used & 574 & $22 \%$ & 354 & $49 \%$ \\
\hline \multicolumn{5}{|c|}{ Driver Fatalities } \\
\hline Restraint Used & 487 & $56 \%$ & 143 & $35 \%$ \\
\hline Restraint Not Used & 388 & $44 \%$ & 267 & $65 \%$ \\
\hline
\end{tabular}

Speeding is another common behavior which can be associated with driving under the influence of alcohol. Young drivers' odds of speeding double while they are under the influence of alcohol in fatal crashes, while those who had zero alcohol consumption were $25 \%$ less likely to be speeding. The statistics of young drivers, as well as the remainder of the population can be found in Table 1-4. Another study showed that drivers ages 16-24 perceived less danger in 
different driving situations such as driving impaired and unbuckled in the front seat. This study also demonstrated that young drivers were more likely to engage in risky driving habits such as following too closely or speeding (Jonah \& Dawson, 1987).

Table 1-4: Driver's Involved in Fatal Traffic Crashes, by Age, Speeding Involvement, and BAC (NHTSA's National Center for Statistics and Analysis, 2012)

\begin{tabular}{|c|c|c|c|c|c|c|c|c|c|c|c|c|c|c|c|c|}
\hline \multirow{4}{*}{$\begin{array}{l}\text { Age } \\
\text { Group }\end{array}$} & \multicolumn{16}{|c|}{ Speeding Involvement } \\
\hline & \multicolumn{8}{|c|}{ Speeding } & \multicolumn{8}{|c|}{ Not Speeding } \\
\hline & \multicolumn{2}{|c|}{$B A C=.00$} & \multicolumn{2}{|c|}{$B A C=.01-.07$} & \multicolumn{2}{|c|}{$\mathrm{BAC}=.08+$} & \multicolumn{2}{|c|}{$\mathrm{BAC}=.01+$} & \multicolumn{2}{|c|}{$B A C=.00$} & \multicolumn{2}{|c|}{$B A C=.01-.07$} & \multicolumn{2}{|c|}{$\mathrm{BAC}=.08+$} & \multicolumn{2}{|c|}{$\mathrm{BAC}=.01+$} \\
\hline & Number & $\%$ & Number & $\%$ & Number & $\%$ & Number & $\%$ & Number & $\%$ & Number & $\%$ & Number & $\%$ & Number & $\%$ \\
\hline$<21$ & 958 & 67 & 76 & 5 & 394 & 28 & 470 & 33 & 2,441 & 84 & 89 & 3 & 374 & 13 & 463 & 16 \\
\hline $21-24$ & 650 & 42 & 115 & 7 & 769 & 50 & 884 & 58 & 2,296 & 72 & 138 & 4 & 770 & 24 & 908 & 28 \\
\hline $25+$ & 3,187 & 51 & 349 & 6 & 2,750 & 44 & 3,099 & 49 & 23,857 & 82 & 941 & 3 & 4,421 & 15 & 5,362 & 18 \\
\hline Total & 4,839 & 52 & 543 & 6 & 3,938 & 42 & 4,481 & 48 & 29,083 & 81 & 1,194 & 3 & 5,739 & 16 & 6,934 & 19 \\
\hline
\end{tabular}

\subsection{2: Crash Statistics by Gender}

Insurance companies for years have charged a premium for being a young male driver. Many companies claim this is due to the "number of drivers who died in a fatal car accident was $50 \%$ higher for men than women", men being almost twice as likely to have BACs of over $0.08 \%$, and over 1.5 times as likely to be speeding (Lautieri, 2013). These bold claims by insurance companies have plenty of data backing them up and, if anything, can be underestimates. When focusing particularly on young drivers, males were just under 3 times as likely to be involved in fatal crashes than their female counterparts (Table 1-5). This being said, both male and female young drivers have shown around a 50\% decrease in involvement in fatal crashes since 2004 . This bodes well compared to the $20 \%$ reduction in adult driver related incidents. 
Table 1-5: Involvement of 15- to 20-Year Old Drivers in Fatal Crashes, by Gender, 2004 and 2013

(NHTSA's National Center for Statistical Analysis, 2013)

\begin{tabular}{|c|c|c|c|c|c|c|c|c|}
\hline \multirow[b]{2}{*}{ Gender } & \multicolumn{3}{|c|}{2004} & \multicolumn{3}{|c|}{2013} & \multicolumn{2}{|c|}{ Percentage Change, 2004-2013 } \\
\hline & Total & Ages 15-20 & $\begin{array}{c}\text { Percentage of } \\
\text { Total }\end{array}$ & Total & Ages 15-20 & $\begin{array}{c}\text { Percentage of } \\
\text { Total }\end{array}$ & Total & Ages 15-20 \\
\hline \multicolumn{9}{|c|}{ Drivers Involved in Fatal Crashes } \\
\hline Male & 42,250 & 5,564 & $13.2 \%$ & 32,442 & 2,807 & $8.7 \%$ & -23 & -50 \\
\hline Female & 15,384 & 2,378 & $15.5 \%$ & 11,364 & 1,157 & $10.2 \%$ & -26 & -51 \\
\hline Total & 58,395 & 7,942 & $13.6 \%$ & 44,574 & 3,966 & $8.9 \%$ & -24 & -50 \\
\hline \multicolumn{9}{|c|}{ Driver Fatalities } \\
\hline Male & 20,089 & 2,600 & $12.9 \%$ & 16,039 & 1,252 & $7.8 \%$ & -20 & -52 \\
\hline Female & 6,780 & 1,034 & $15.3 \%$ & 4,829 & 438 & $9.1 \%$ & -29 & -58 \\
\hline Total & 26,871 & 3,634 & $13.5 \%$ & 20,871 & 1,691 & $8.1 \%$ & -22 & -53 \\
\hline
\end{tabular}

\section{3: West Virginia Teenage Crash and Behavioral Statistics.}

West Virginia itself presents its own form of challenges when it comes to driving risks.

Where most of the country has higher fatality rates with urban driving, WV has a larger issue with rural roads (Table 1-6). A recent report ranks West Virginia $6^{\text {th }}$ lowest in the country for condition of rural road (27\% pavement in poor condition) and $7^{\text {th }}$ in the country for rural fatality rate (2.61 fatalities per 100 million VMT) (Moretti \& Kelly, 2015). 42\% of all injuries, 78\% of all deaths and $33 \%$ of all crashes occur in lane departure incidents on West Virginia roads (Mattox \& Smith, 2007). Two issues may arise when honing in on young drivers, the lack of experience and the overestimation of their driving ability. These rural hazards are reinforced by Table 1-6 which shows the percent of West Virginia speeding-related traffic fatalities is twice the national average.

Table 1-6: Speeding-Related Traffic Fatalities, by State and Roadway Function Class, 2012 (NHTSA's National Center for Statistics and Analysis, 2012)

\begin{tabular}{|c|cc|cccccc|}
\cline { 2 - 8 } \multicolumn{1}{c|}{} & \multicolumn{2}{c|}{ Interstate } & \multicolumn{5}{c|}{ Non-Interstate } \\
\hline State & Rural & Urban & Freeway & $\begin{array}{c}\text { Principal } \\
\text { Arterial }\end{array}$ & $\begin{array}{c}\text { Minor } \\
\text { Arterial }\end{array}$ & Collector & Local & Total \\
\hline West Virginia & $10 \%$ & $2 \%$ & $1 \%$ & $23 \%$ & $24 \%$ & $28 \%$ & $12 \%$ & 144 \\
U.S. Total & $5 \%$ & $6 \%$ & $4 \%$ & $19 \%$ & $18 \%$ & $21 \%$ & $24 \%$ & 10219 \\
\hline
\end{tabular}


West Virginia youth is at a greater risk of driving fatalities than the rest of the country, as determined from a 2013 study shown in Table 1-7. The youth in the state, are $28 \%$ more likely to be the driver in a fatal car crash and $42 \%$ more likely to be a passenger in a fatal crash with another young driver.

Table 1-7: Fatalities in Crashes Involving Young Drivers (Ages 15 to 20), by State and Person type 2013 (NHTSA's National Center for Statistical Analysis, 2013)

\begin{tabular}{|c|ccccc|}
\hline State & $\begin{array}{c}\text { Young } \\
\text { Drivers }\end{array}$ & $\begin{array}{c}\text { Passengers in } \\
\text { Young } \\
\text { Drivers' } \\
\text { Vehicles }\end{array}$ & $\begin{array}{c}\text { Occupants of } \\
\text { Other } \\
\text { Vehicles }\end{array}$ & $\begin{array}{c}\text { Non- } \\
\text { occupants }\end{array}$ & Total \\
\hline West Virginia & $50 \%$ & $34 \%$ & $16 \%$ & $0 \%$ & 38 \\
U.S. Total & $39 \%$ & $24 \%$ & $26 \%$ & $11 \%$ & 4333 \\
\hline
\end{tabular}

\subsection{1: Youth Risk Behavior Surveillance System (YRBSS)}

“The YRBSS was developed in 1990 to monitor priority health risk behaviors that contribute markedly to the leading causes of death, disability, and social problems among youth and adults in the United States" (Division of Adolescent and School Health, National Center for HIV/AIDS, Viral Hepatitis, STD, and TB Prevention, 2015). The 2013 YRBSS risk assessment of 148 schools involving 13,583 high school students in grades 9-12 nationally contains four questions key to the evaluation of teenage driving behavior:

- How often do you wear a seat belt when riding in a car driven by someone else?

- During the past 30 days, how many times did you ride in a car or other vehicle driven by someone who had been drinking alcohol?

- During the past 30 days, how many times did you drive a car or other vehicle when you had been drinking alcohol?

- During the past 30 days, on how many days did you text or e-mail while driving a car or other vehicle? 
This study revealed that only $55 \%$ of high school student always wear their seatbelt and only $35 \%$ never text or email while driving. In regards to alcohol, $78 \%$ of respondents reported to have never driven in a vehicle with someone who had been drinking and $92 \%$ of student drivers do not drink and drive. The survey also gave an indication that $35.7 \%$ of high school students, on the national level, do not drive (CDC, Division of Adolescent and School Health, 2014). Table 1-8 shows how the results of 1,793 students in 35 West Virginia public high schools compares to the national average from the same survey. The only question which West Virginia students provided more risky answers was the inquiry into seatbelt usage. According to the survey, West Virginia high school student are 1.5 time as likely to never or rarely wear a seatbelt compared to the national average. All other categories, West Virginia students answered on the conservative side which led to a lower "average risk percentage".

Table 1-8: YRBS Results for driving related risk factor in high school students (West Virginia Department of Education, Office of Research, 2015) (CDC, Division of Adolescent and School Health, 2014)

\begin{tabular}{|c|ccccc|}
\hline State & $\begin{array}{c}\text { Never or } \\
\text { Rarely wore } \\
\text { a Seatbelt }\end{array}$ & $\begin{array}{c}\text { Passenger of } \\
\text { driver who } \\
\text { consumed } \\
\text { alcohol }\end{array}$ & $\begin{array}{c}\text { Drove when } \\
\text { they had } \\
\text { been } \\
\text { drinking }\end{array}$ & $\begin{array}{c}\text { Texted / } \\
\text { E-mailed } \\
\text { while driving }\end{array}$ & $\begin{array}{c}\text { Average Risk } \\
\text { Percentage }\end{array}$ \\
\hline West Virginia & $12 \%$ & $18 \%$ & $8 \%$ & $36 \%$ & $18 \%$ \\
U.S. Total & $8 \%$ & $23 \%$ & $21 \%$ & $46 \%$ & $24 \%$ \\
\hline
\end{tabular}

Table 1-9 though Table 1-12 each show the detailed breakdown of one of the aforementioned questions specifically for West Virginia high schools. The data from these tables were used in the previous national comparison. 
Table 1-9: WV - Percentage of students who never or rarely wore a seatbelt when riding in a car driven by someone else (West Virginia Department of Education, Office of Research, 2015)

\begin{tabular}{|c|c|c|c|c|c|c|c|c|c|}
\hline & \multicolumn{3}{|c|}{ Total } & \multicolumn{3}{|c|}{ Male } & \multicolumn{3}{|c|}{ Female } \\
\hline & Percentage & $\begin{array}{c}95 \% \\
\text { confidence } \\
\text { interval }\end{array}$ & $\mathrm{N}$ & Percentage & $\begin{array}{c}95 \% \\
\text { confidence } \\
\text { interval }\end{array}$ & $\mathrm{N}$ & Percentage & $\begin{array}{c}95 \% \\
\text { confidence } \\
\text { interval }\end{array}$ & $\mathrm{N}$ \\
\hline Total & 11.5 & $(9.1-14.3)$ & 1,791 & 15.8 & $(12.3-20.0)$ & 834 & 6.9 & $(5.1-9.2)$ & 950 \\
\hline \multicolumn{10}{|l|}{ Age } \\
\hline 15 or younger & 11.6 & $(9.1-14.7)$ & 685 & 13.0 & $(8.7-19.0)$ & 306 & 10.2 & $(7.8-13.2)$ & 378 \\
\hline 16 or 17 & 10.5 & $(7.3-14.9)$ & 894 & 16.9 & $(11.7-23.8)$ & 419 & 4.3 & $(2.4-7.6)$ & 473 \\
\hline 18 or older & 13.9 & $(9.1-20.7)$ & 208 & 18.0 & $(11.3-27.4)$ & 109 & - & - & 99 \\
\hline \multicolumn{10}{|l|}{ Grade } \\
\hline 9 th & 11.3 & $(8.4-15.0)$ & 520 & 13.7 & $(9.1-20.2)$ & 241 & 8.7 & $(5.4-13.9)$ & 278 \\
\hline 10th & 14.6 & $(11.7-18.0)$ & 631 & 19.5 & $(15.7-23.9)$ & 301 & 9.5 & $(6.2-14.3)$ & 329 \\
\hline 11th & 8.5 & $(4.6-15.3)$ & 338 & 15.2 & $(8.2-26.6)$ & 156 & 1.6 & $(0.4-6.6)$ & 181 \\
\hline 12 th & 10.7 & $(6.7-16.6)$ & | 291 & 14.6 & $(9.1-22.8)$ & 130 & 6.7 & $(3.2-13.6)$ & 161 \\
\hline \multicolumn{10}{|l|}{ Race/Ethnicity } \\
\hline Black* & - & - & 69 & - & - & 38 & - & - & 30 \\
\hline Hispanic/Latino & - & - & 56 & - & - & 27 & - & - & 29 \\
\hline White* & 11.1 & $(8.6-14.2)$ & 1,504 & 15.2 & $(11.4-19.9)$ & 679 & 7.0 & $(5.0-9.7)$ & 822 \\
\hline All other races & - & - & 43 & - & - & 28 & - & - & 15 \\
\hline Multiple races & - & - & 89 & - & - & 41 & - & - & 48 \\
\hline
\end{tabular}

Table 1-10: Percentage of students who rode one or more times during the past 30 days in a vehicle driven by someone who had been drinking alcohol (West Virginia Department of Education, Office of Research, 2015)

\begin{tabular}{|c|c|c|c|c|c|c|c|c|c|}
\hline & \multicolumn{3}{|c|}{ Total } & \multicolumn{3}{|c|}{ Male } & \multicolumn{3}{|c|}{ Female } \\
\hline & Percentage & $\begin{array}{c}95 \% \\
\text { confidence } \\
\text { interval }\end{array}$ & $\mathrm{N}$ & Percentage & $\begin{array}{c}95 \% \\
\text { confidence } \\
\text { interval }\end{array}$ & $\mathrm{N}$ & Percentage & $\begin{array}{c}95 \% \\
\text { confidence } \\
\text { interval }\end{array}$ & $\mathrm{N}$ \\
\hline Total & 17.8 & $(15.5-20.3)$ & 1,793 & 19.7 & $(16.3-23.5)$ & 836 & 16.0 & $(13.5-18.8)$ & 950 \\
\hline \multicolumn{10}{|l|}{ Age } \\
\hline 15 or younger & 17.4 & $(14.3-21.0)$ & 686 & 13.7 & $(9.9-18.7)$ & 307 & 21.2 & $(16.3-27.1)$ & 378 \\
\hline 16 or 17 & 16.6 & $(13.4-20.4)$ & 895 & 22.3 & $(17.6-27.9)$ & 420 & 11.0 & $(7.8-15.2)$ & 473 \\
\hline 18 or older & 22.6 & $(14.7-33.0)$ & 208 & 23.6 & $(13.7-37.4)$ & 109 & - & - & 99 \\
\hline \multicolumn{10}{|l|}{ Grade } \\
\hline 9th & 16.7 & $(13.6-20.4)$ & 520 & 12.6 & $(8.0-19.2)$ & 241 & 21.2 & $(15.8-27.9)$ & 278 \\
\hline 10th & 15.1 & $(11.3-19.8)$ & 632 & 18.5 & $(12.8-26.1)$ & 302 & 11.4 & $(8.9-14.5)$ & 329 \\
\hline 11 th & 19.3 & $(14.2-25.7)$ & 339 & 27.4 & $(20.7-35.3)$ & 157 & 11.0 & $(6.2-18.8)$ & 181 \\
\hline 12 th & 19.5 & $(13.3-27.7)$ & 291 & 20.0 & $(12.4-30.6)$ & 130 & 19.1 & $(11.9-29.1)$ & 161 \\
\hline \multicolumn{10}{|l|}{ Race/Ethnicity } \\
\hline Black* & - & - & 69 & - & - & 38 & - & - & 30 \\
\hline Hispanic/Latino & - & - & 56 & - & - & 27 & - & - & 29 \\
\hline White* & 17.1 & $(15.3-19.1)$ & 1,506 & 18.4 & $(15.5-21.7)$ & 681 & 15.9 & $(13.6-18.4)$ & 822 \\
\hline All other races & - & - & 43 & - & - & 28 & - & - & 15 \\
\hline Multiple races & - & - & 89 & - & - & 41 & - & - & 48 \\
\hline
\end{tabular}


Table 1-11: Percentage of students who drove when they had been drinking in the past 30 days

(West Virginia Department of Education, Office of Research, 2015)

\begin{tabular}{|c|c|c|c|c|c|c|c|c|c|}
\hline & \multicolumn{3}{|c|}{ Total } & \multicolumn{3}{|c|}{ Male } & \multicolumn{3}{|c|}{ Female } \\
\hline & Percentage & $\begin{array}{c}95 \% \\
\text { confidence } \\
\text { interval }\end{array}$ & $\mathrm{N}$ & Percentage & $\begin{array}{l}95 \% \\
\text { confidence } \\
\text { interval }\end{array}$ & $\mathrm{N}$ & Percentage & $\begin{array}{c}95 \% \\
\text { confidence } \\
\text { interval }\end{array}$ & $\mathrm{N}$ \\
\hline Total & 7.6 & $(6.0-9.5)$ & 1,151 & 10.5 & $(8.1-13.6)$ & 537 & 4.7 & $(2.9-7.4)$ & 609 \\
\hline \multicolumn{10}{|l|}{ Age } \\
\hline 15 or younger & 4.8 & $(2.8-8.2)$ & 333 & 3.1 & $(1.2-7.6)$ & 149 & 6.5 & $(3.8-11.0)$ & 184 \\
\hline 16 or 17 & 8.0 & $(5.6-11.2)$ & 660 & 12.4 & $(8.9-17.0)$ & 309 & 3.7 & $(1.6-8.2)$ & 350 \\
\hline 18 or older & 10.3 & $(5.5-18.3)$ & 154 & - & - & 79 & - & - & 75 \\
\hline \multicolumn{10}{|l|}{ Grade } \\
\hline 9th & 3.7 & $(1.9-7.3)$ & 228 & 1.2 & $(0.3-5.5)$ & 104 & 6.3 & $(3.4-11.5)$ & 124 \\
\hline 10th & 8.8 & $(5.9-13.0)$ & 427 & 12.5 & $(8.0-19.0)$ & 209 & 4.7 & $(2.6-8.2)$ & 218 \\
\hline 11th & 6.9 & $(3.9-12.0)$ & 268 & 10.4 & $(5.4-19.2)$ & 124 & 3.4 & $(1.1-10.4)$ & 143 \\
\hline 12 th & 9.4 & $(5.6-15.4)$ & 220 & - & - & 96 & 4.7 & $(2.0-10.8)$ & 124 \\
\hline \multicolumn{10}{|l|}{ Race/Ethnicity } \\
\hline Black* & - & - & 41 & - & - & 22 & - & - & 19 \\
\hline Hispanic/Latino & - & - & 30 & - & - & 13 & - & - & 17 \\
\hline White* & 7.2 & $(5.7-9.1)$ & 988 & 10.1 & $(7.6-13.2)$ & 451 & 4.4 & $(2.8-7.1)$ & 535 \\
\hline All other races & - & - & 20 & - & - & 14 & - & - & 6 \\
\hline Multiple races & - & - & 55 & - & - & 27 & - & - & 28 \\
\hline
\end{tabular}

Table 1-12: Percentage of students who texted or e-mailed while driving on or more of the past 30 days

(West Virginia Department of Education, Office of Research, 2015)

\begin{tabular}{|c|c|c|c|c|c|c|c|c|c|}
\hline & & Total & & & Male & & & Female & \\
\hline & Percentage & $\begin{array}{c}95 \% \\
\text { confidence } \\
\text { interval }\end{array}$ & $\mathrm{N}$ & Percentage & $\begin{array}{c}95 \% \\
\text { confidence } \\
\text { interval }\end{array}$ & $\mathrm{N}$ & Percentage & $\begin{array}{c}95 \% \\
\text { confidence } \\
\text { interval }\end{array}$ & $\mathrm{N}$ \\
\hline Total & 35.5 & $(31.1-40.3)$ & 1,166 & 38.8 & $(33.3-44.6)$ & 549 & 32.4 & $(27.8-37.3)$ & 612 \\
\hline Age & & & & & & & & & \\
\hline 15 or younger & 13.4 & $(9.9-17.8)$ & 340 & 11.5 & $(7.8-16.8)$ & 153 & 15.2 & $(10.8-21.0)$ & 187 \\
\hline 16 or 17 & 38.7 & $(32.7-45.1)$ & 665 & 43.5 & $(36.4-50.8)$ & 314 & 34.1 & $(28.4-40.4)$ & 350 \\
\hline 18 or older & 55.9 & $(46.9-64.4)$ & 157 & - & - & 82 & - & - & 75 \\
\hline Grade & & & & & & & & & \\
\hline 9th & 10.8 & $(8.1-14.3)$ & 234 & 8.7 & $(5.6-13.2)$ & 108 & 12.9 & $(8.3-19.5)$ & 126 \\
\hline 10th & 24.5 & $(20.9-28.6)$ & 429 & 30.5 & $(25.0-36.6)$ & 211 & 17.8 & $(13.8-22.6)$ & 218 \\
\hline 11th & 43.8 & $(37.7-50.2)$ & 270 & 49.6 & $(41.8-57.5)$ & 126 & 38.1 & $(30.0-46.9)$ & 143 \\
\hline 12th & 54.8 & $(47.2-62.3)$ & 223 & - & - & 99 & 52.3 & $(40.8-63.5)$ & 124 \\
\hline Race/Ethnicity & & & & & & & & & \\
\hline Black* & - & - & 41 & - & - & 22 & - & - & 19 \\
\hline Hispanic/Latino & - & - & 34 & - & - & 16 & - & - & 18 \\
\hline White* & 35.9 & $(31.1-41.1)$ & 998 & 38.5 & $(32.0-45.4)$ & 460 & 33.5 & $(28.6-38.8)$ & 536 \\
\hline All other races & - & - & 21 & - & - & 15 & - & - & 6 \\
\hline Multiple races & - & - & 56 & - & . & 27 & - & - & 29 \\
\hline
\end{tabular}

Additionally, the West Virginia Youth Risk Behavior Survey results reveal certain trend lines over the past decade. Unfortunately, only 2 of the questions for West Virginia have 10 years' worth of survey data with the questions involving texting and driving just being added in 2013. Both the percentage of students who never or rarely wore a seatbelt and who rode one or more times in a vehicle driven by someone who had been drinking alcohol, show slight decreases from 2003-2013 which lends itself to safer decision making in young adults. 
Table 1-13: 2013 YRBS Results, West Virginia High School Survey, 10-year Trend Analysis Report

(West Virginia Department of Education, Office of Research, 2015)

\begin{tabular}{|c|c|c|c|c|c|c|c|c|}
\hline \multicolumn{9}{|c|}{$\begin{array}{l}\text { Total } \\
\text { Injury and Violence }\end{array}$} \\
\hline 2003 & 2005 & 2007 & 2009 & 2011 & 2013 & Linear Change ${ }^{*}$ & Quadratic Change* $^{*}$ & $\begin{array}{r}\text { Change from } \\
2011-2013\end{array}$ \\
\hline \multicolumn{9}{|c|}{$\begin{array}{l}\text { QN8: Among students who rode a bicycle during the past } 12 \text { months, the percentage who never or rarely } \\
\text { wore a bicycle helmet }\end{array}$} \\
\hline 84.9 & 84.0 & 85.3 & 86.1 & 85.8 & 88.7 & No linear change & No quadratic change & No change \\
\hline \multicolumn{9}{|c|}{$\begin{array}{l}\text { QN9: Percentage of students who never or rarely wore a seat belt when riding in a car driven by } \\
\text { someone else }\end{array}$} \\
\hline 15.2 & 15.2 & 16.6 & 14.0 & 13.8 & 11.5 & Decreased, 2003-2013 & No quadratic change & No change \\
\hline \multicolumn{9}{|c|}{$\begin{array}{l}\text { QN10: Percentage of students who rode one or more times during the past } 30 \text { days in a car or other } \\
\text { vehicle driven by someone who had been drinking alcohol }\end{array}$} \\
\hline 24.3 & 24.8 & 23.8 & 25.6 & 18.7 & 17.8 & Decreased, 2003-2013 & $\begin{array}{l}\text { No change, 2003-2009 } \\
\text { Decreased, 2009-2013 }\end{array}$ & No change \\
\hline
\end{tabular}

\section{4: Graduated Drivers Licensing}

Ever since the introduction of the first instance of the graduated drivers licensing (GDL) program in 1921, states have been working towards providing a means to ease young drivers onto the road. It began with Connecticut implementing a law that allow drivers as young as 16 to drive with a licensed adult (National Museum of American History, n.d.) and later with New York in 1925 setting this instructional period to three months (Corasaniti \& Williams, 2013). Today, every state has some form of the GDL program which began to see most of its restrictions placed in the 1990s (Gruffyydd, 2014).

All states and the District of Columbia have adopted a three-stage GDL system. There is no federal law dictating the requirements for teenage drivers and it is up to the state lawmakers to decide which provisions they wish to adopt. Three of the main restrictions which vary state to state are a minimum age to drive unsupervised, a curfew, and a restriction of the number of passengers in the vehicle. These restrictions are typically place on the intermediate license (Level II) which exists between the instructional permit and before full licensure. 


\subsection{1: Driving Age}

The intermediate license is primarily used to place restrictions on young drivers, limiting unsupervised driving during high-risk situations. Often, this is determined by the combination of a minimum age of the learner's permit and associate minimum requirements (i.e., practice hours and minimum time with learners permit). The most common age to adopt a level II license is 16 years with 33 states setting this as their minimum. The remaining states and the District of Columbia fall somewhere within the range of 14 years and 3 months to 17 years (IIHS, 2016).

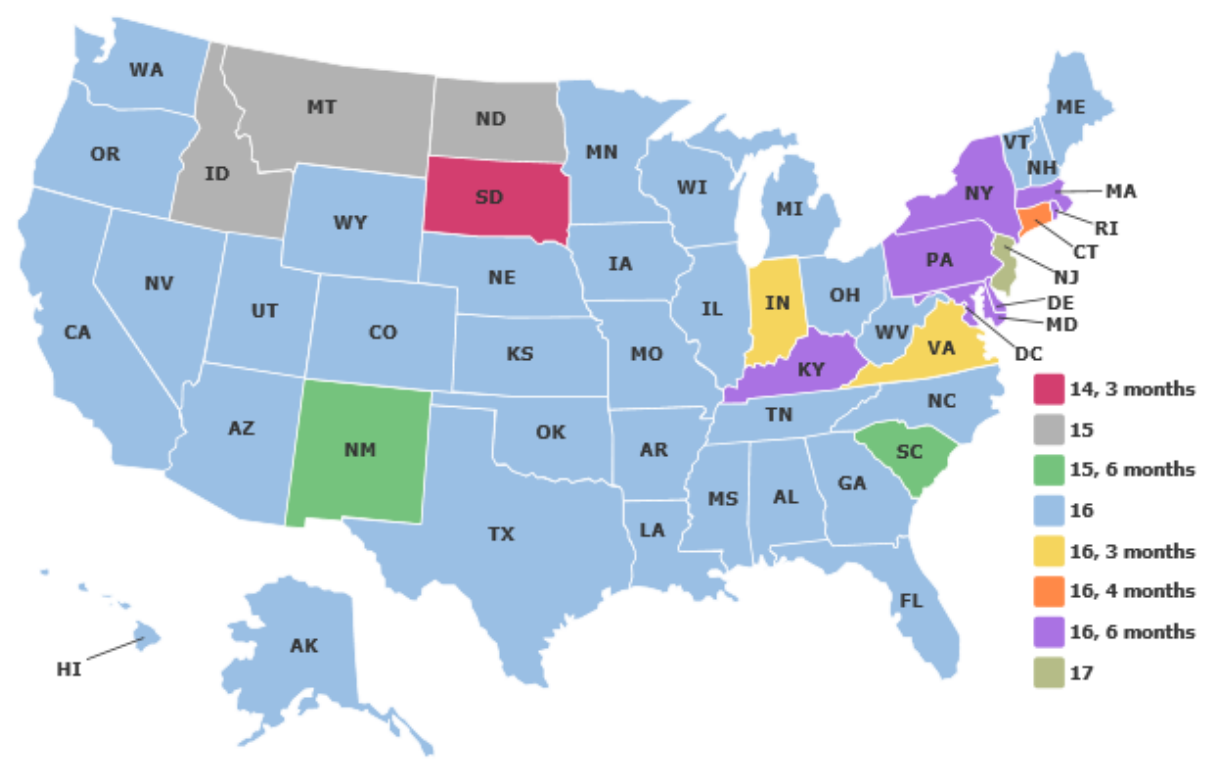

Figure 1-3: Minimum Age for Unsupervised Driving (IIHS, 2016)

\subsection{2: Night Restriction}

All but one state place some form of curfew on drivers holding an intermediate license with most states have their curfews set to after 11:00 p.m. This curfew is intended to limit the high-risk situation of driving at night due to visibility and drowsiness. "Drowsy Driving" has been reported to cause as many as 7,500 fatalities annually and is something that should be avoided at all levels of driving (Wheaton, Shults, Chapman, Ford, \& Croft, 2014). 


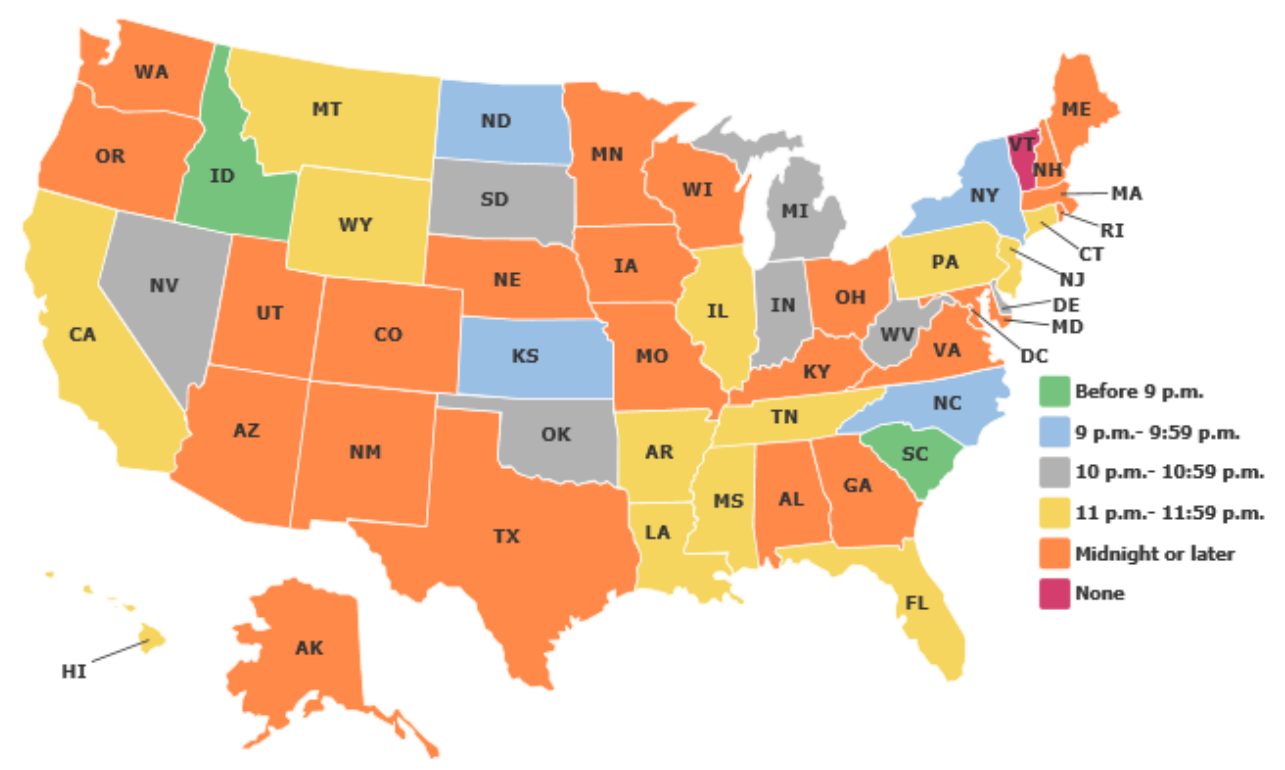

Figure 1-4: Night Restriction Start Times (IIHS, 2016)

\subsection{3: Passenger Restrictions}

Most states impose some sort of limit to the number of passengers drivers with an intermediate license are allowed to carry. Having two or more peer passengers can triple the risk of a fatal crash with a teenage driver (Winston, Kallan, Senserrick, \& Elliott, 2008). One study shows that $71 \%$ of males and $47 \%$ of females who crashed while carrying passengers were directly distracted by the actions and movements of their passenger (Curry, Mirrman, Kallan, Winston, \& Durbin, 2012). 


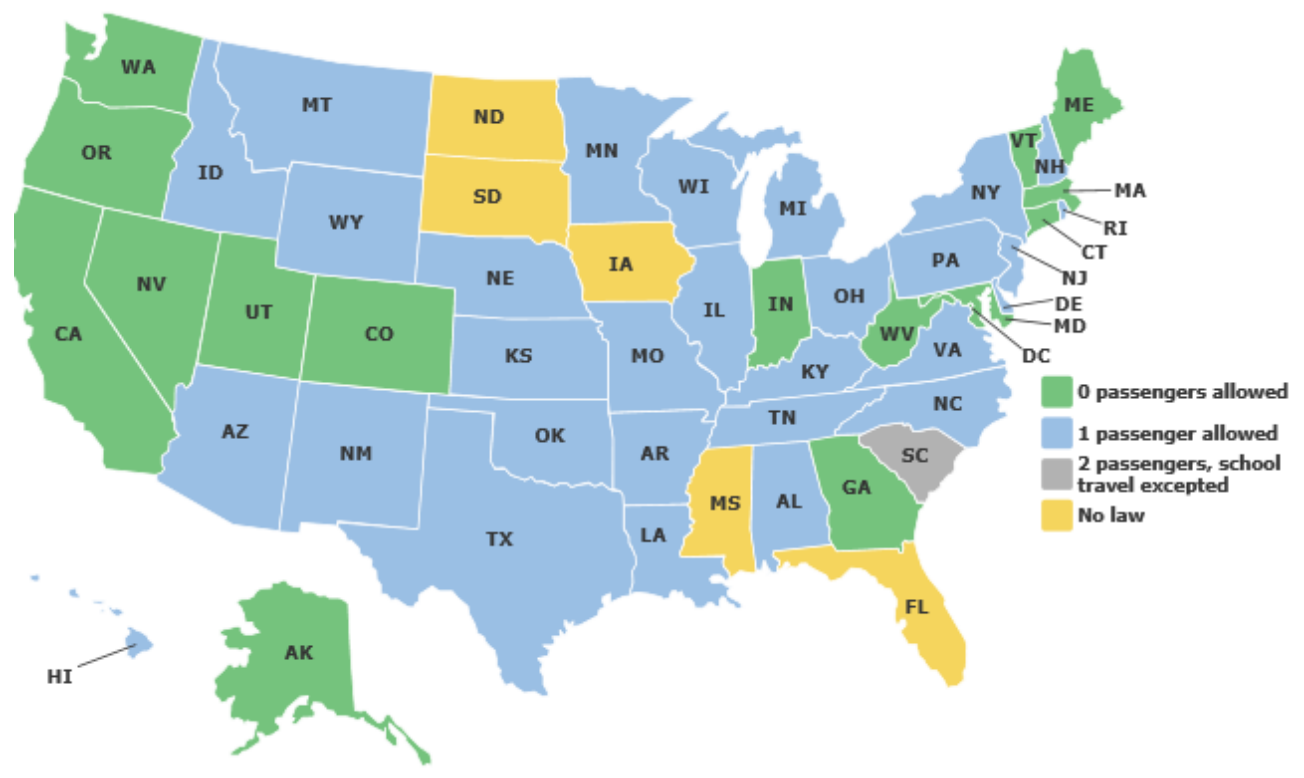

Figure 1-5: Restrictions on Passengers (IIHS, 2016)

\subsection{4: West Virginia GDL}

Table 1-14 shows the basic regulation behind the state of West Virginia's graduated driver licensing program. West Virginia's restrictions place it among the more conservative of states for introducing teenage drivers to the road. This creates a safer environment for teenage divers to learn to drive than in other states in the country, though West Virginia is not the most restrictive. Each level has a unique identification card for ease in the identification process for law enforcement and other agencies (Figure 1-6).
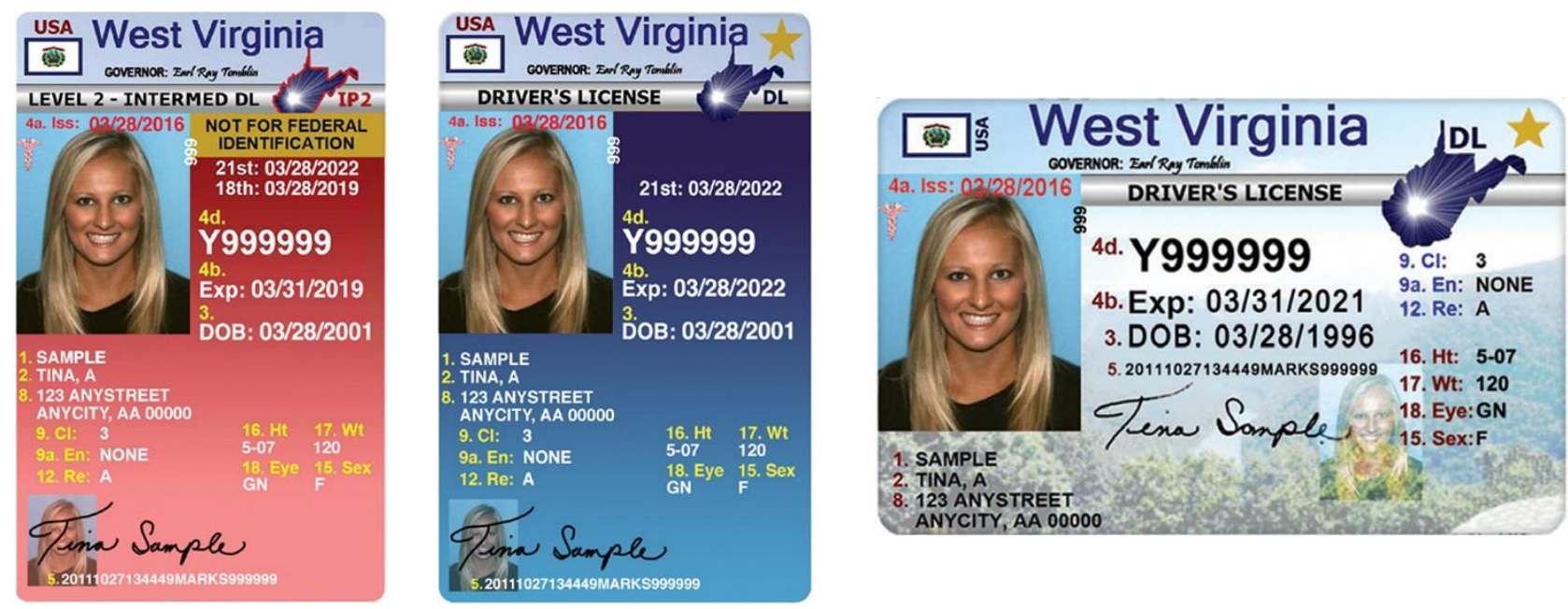

Figure 1-6: West Virginia Driver Licenses (WV DOT, 2016) 
TO GET A LEARNERS PERMIT YOU MUST

\begin{tabular}{l|l} 
Have a minimum age of & 15
\end{tabular}

BEFORE GETTING AN INTERMEDIATE OR RESTRICTED LICENSE YOU MUST

\begin{tabular}{l|l}
\hline Have your permit for & 6 months $^{1}$ \\
\hline Complete minimum supervised driving of & 50 hours, 10 of which must be at night (none with driver education) \\
\hline Have a minimum age of & 16
\end{tabular}

RESTRICTIONS DURING INTERMEDIATE OR RESTRICTED LICENSE STAGE

\begin{tabular}{l|l}
\hline Nighttime restriction & 10 p.m. - 5 a.m. \\
\hline $\begin{array}{l}\text { Passenger limit (family members excepted } \\
\text { unless otherwise noted) }\end{array}$ & $\begin{array}{l}\text { first } 6 \text { months-no passengers younger than 20; second } 6 \text { months-no more } \\
\text { than } 1 \text { passenger younger than } 20\end{array}$ \\
\hline
\end{tabular}

MINIMUM AGE AT WHICH RESTRICTIONS MAY BE LIFTED

\begin{tabular}{l|l} 
Nighttime restriction & 12 months and age 17 or until age 18 , whichever occurs first (min. age: 17)
\end{tabular}

\begin{tabular}{l|l}
\hline Passenger restriction & 12 months and age 17 or until age 18, whichever occurs first (min. age: 17)
\end{tabular}

\section{5: Previous Analysis of West Virginia's Graduated Driver Licensing Program}

The following (Section 1.5:) contains data from Phase I of the GDL analysis and set out to evaluate the perspective, knowledge, and opinion of GDL policy in West Virginia (Noble, Martinelli, Unnikrishnan, \& Martinelli, 2012).

\subsection{1: Parental Findings}

The study showed that $54 \%$ of parents had never heard of the GDL program or were unsure if they had. Of the $43 \%$ that had heard of GDL, $29 \%$ heard of it through DMV literature, $19 \%$ heard of it through their son or daughter, and the rest were unsure where they had heard about GDL (Figure 1-7). 


\section{Do parents know of the GDL program}

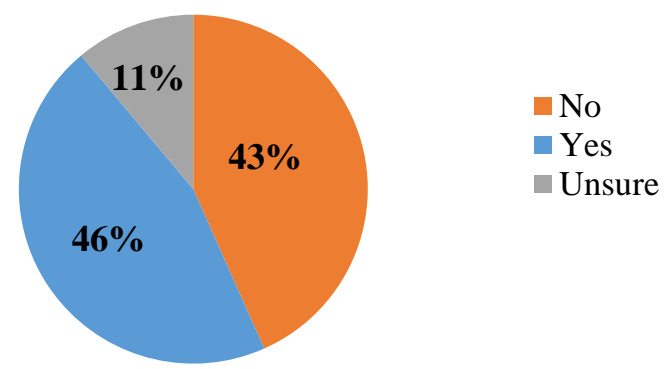

Figure 1-7: Parents who have heard of the GDL Program (GDL Phase I)

Figure 1-8 shows a 5 question survey that was administered to the parents of high school juniors and seniors. Where most parents knew what the minimum age for obtaining an instructional permit was, relatively few knew how many stages were in the GDL program and even fewer know the minimum age of full licensure. Just over half of parental respondents were able to correctly identify the correct curfew and passenger restrictions. GDL is a system that relies heavily on parents to help enforce policies, this is difficult when they do not know the system themselves.

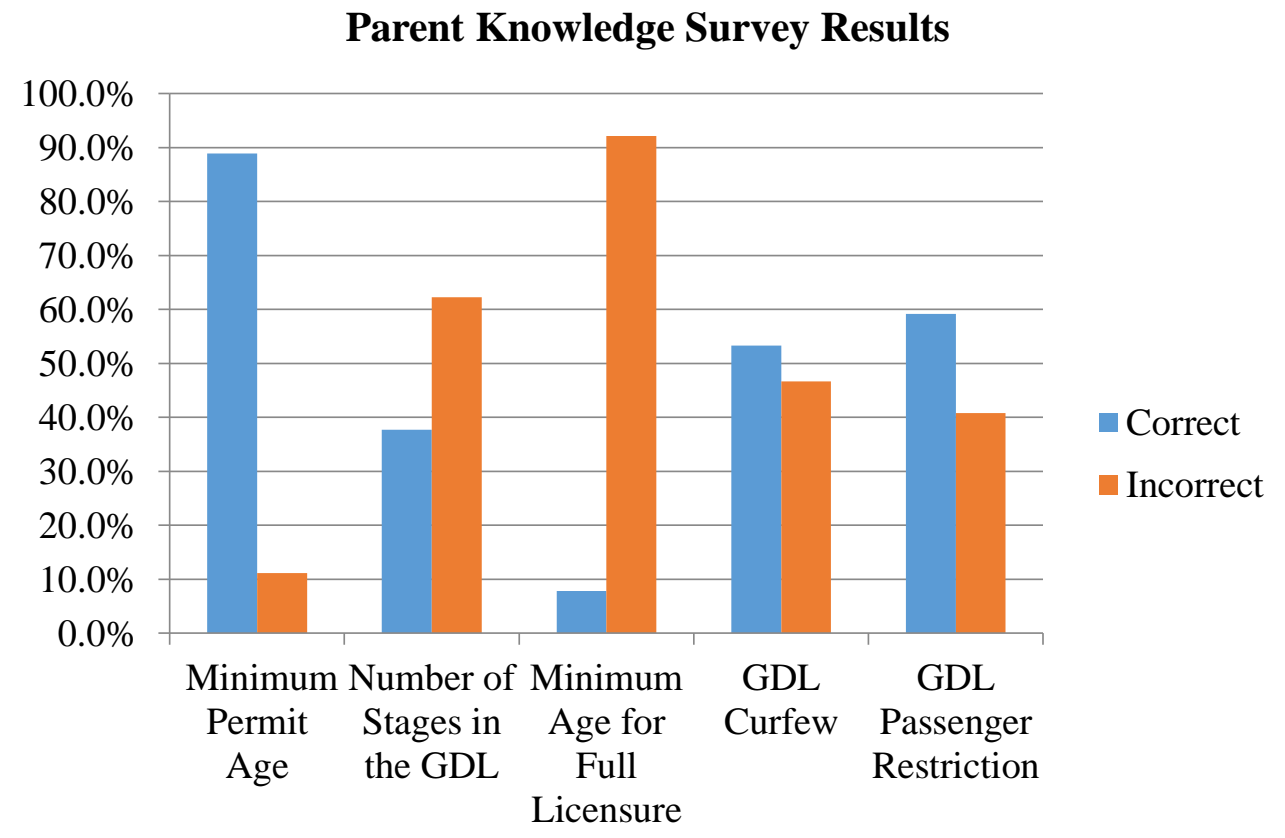

Figure 1-8: Parent Knowledge Survey Results (GDL Phase I) 
Most parents felt that the greatest benefit of the GDL was the added confidence it gave teenage drivers and an increase in public safety. Only 4\% saw no benefit and 5\% were unsure what benefits there could be (Figure 1-9).

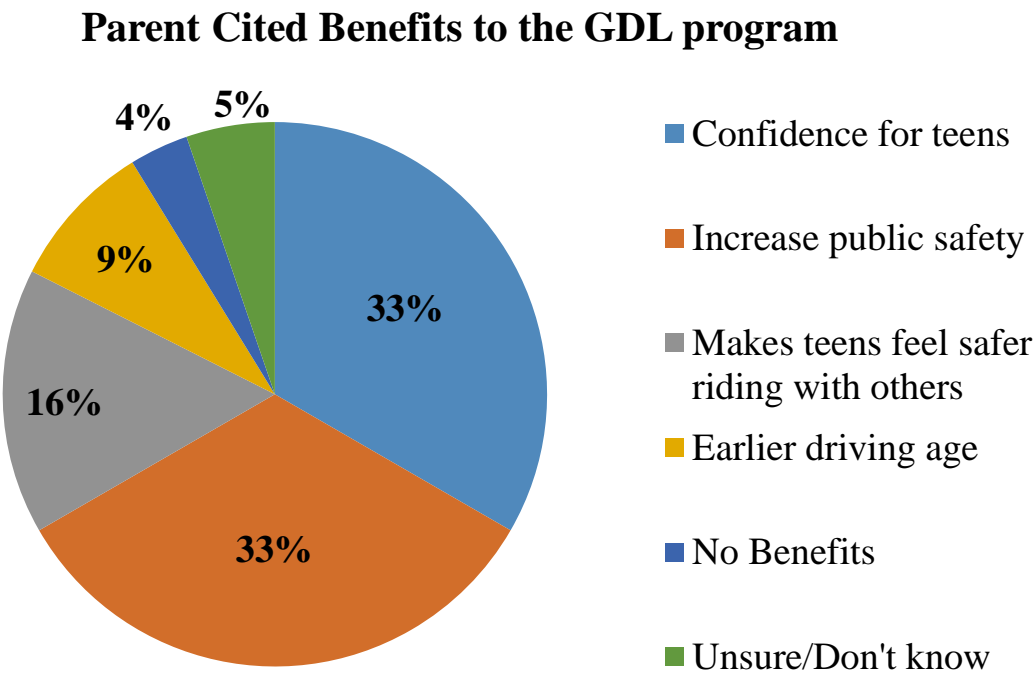

Figure 1-9: Parent Cited Benefits to the GDL program (GDL Phase I)

The two most common GDL violations, as cited by parents, were passenger and mobile phone use, with curfew falling closely in third. In addition, $71 \%$ of parents say that they actively use GDL policy to restrict their son/daughter's driving. Most parents also reporting imposing additional restriction on their child's driving such as destination and weather conditions. 


\section{Most often violated GDL restriction as cited by parents}

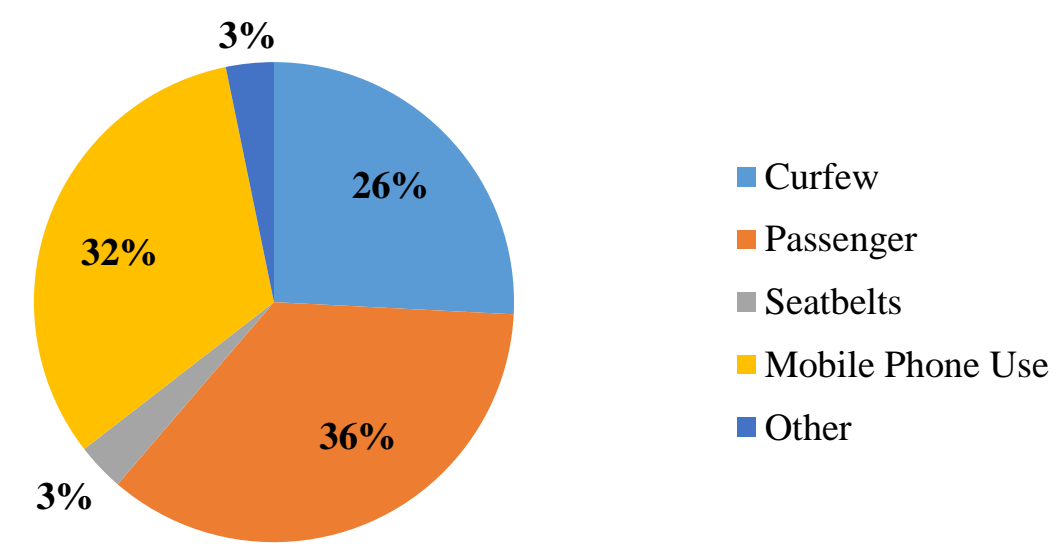

Figure 1-10: Parent cited GDL violations (GDL Phase I)

\subsection{2: Student Findings}

Of the over 400 high school students surveyed, only a little over half knew of the GDL program. This number was lower than expected.

\section{Do students know of the GDL}

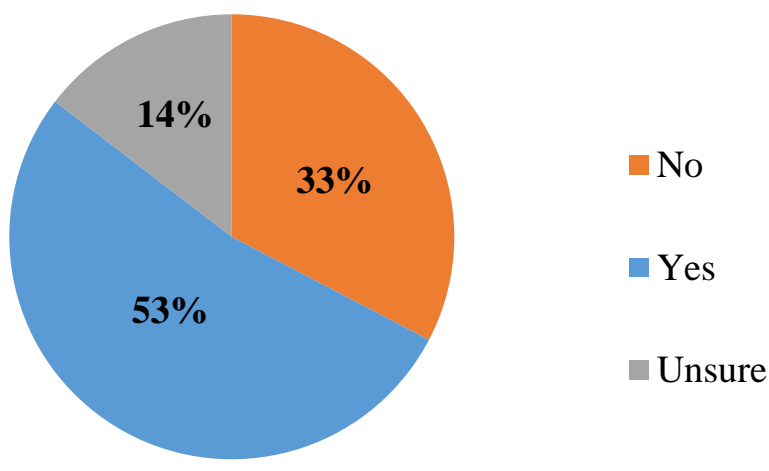

Figure 1-11: Students who know of the GDL program (GDL Phase I)

Students showed a fair understanding of the minimum age to acquire an instructional permit and what the limits for curfew and passenger restrictions were. 


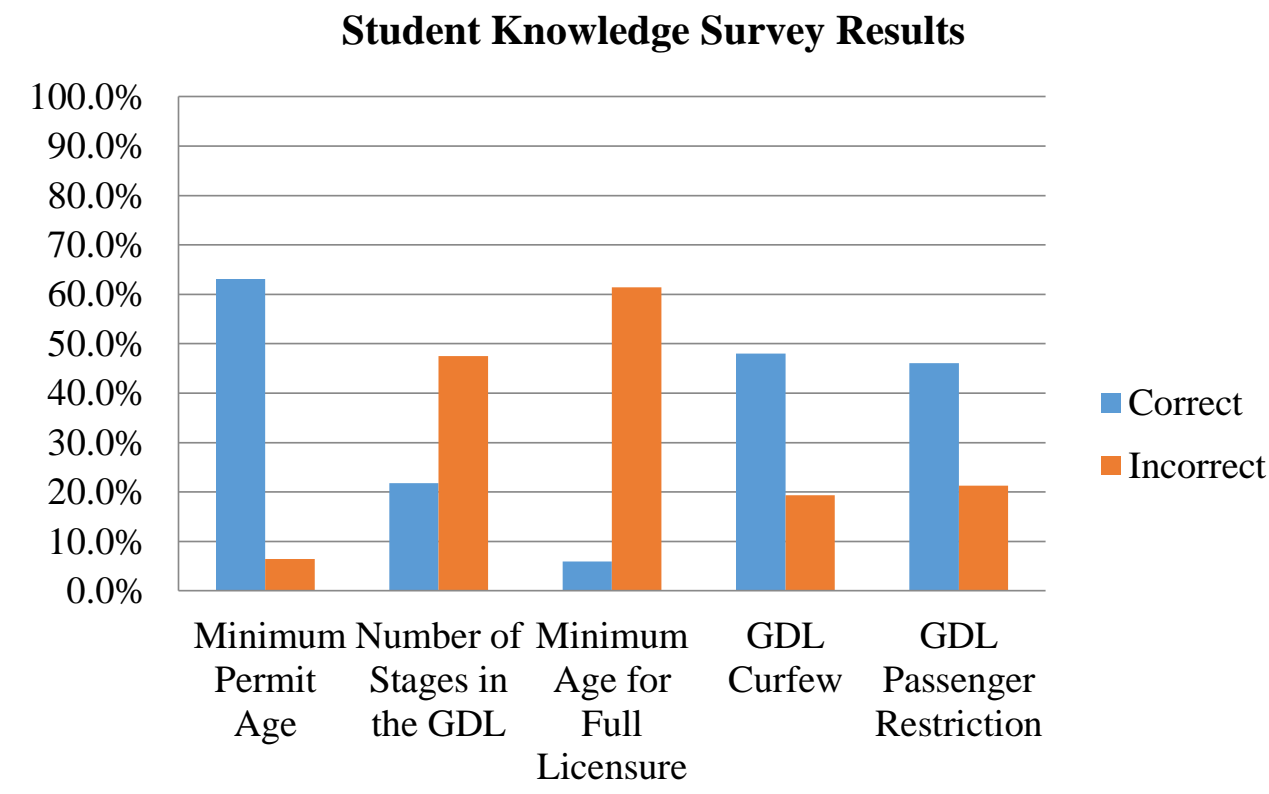

Figure 1-12: Student GDL Knowledge Survey Results (GDL Phase I)

Just under half of all surveyed students had to report their destination to their parents and/or obtain permission before driving. Only $18 \%$ said that their parents impose no additional restrictions.

Table 1-15: Student Reported: Additional restrictions imposed on students by parents (GDL Phase I)

\begin{tabular}{|l|c|}
\hline Restrictions & Student \\
\hline Must report destination & $42 \%$ \\
\hline Permission before driving & $39 \%$ \\
\hline Limits on travel during severe weather & $37 \%$ \\
\hline Must report expected time of return & $30 \%$ \\
\hline Must report passengers & $28 \%$ \\
\hline Limits on time of day & $22 \%$ \\
\hline No restrictions & $18 \%$ \\
\hline Limits on distance traveled & $14 \%$ \\
\hline Limits on roads traveled & $11 \%$ \\
\hline Other & $2 \%$ \\
\hline
\end{tabular}


Unlike parents, the most common citation by students is mobile phone use followed by exceeding passenger limitations.

\section{Most often violated GDL restriction cited by students}

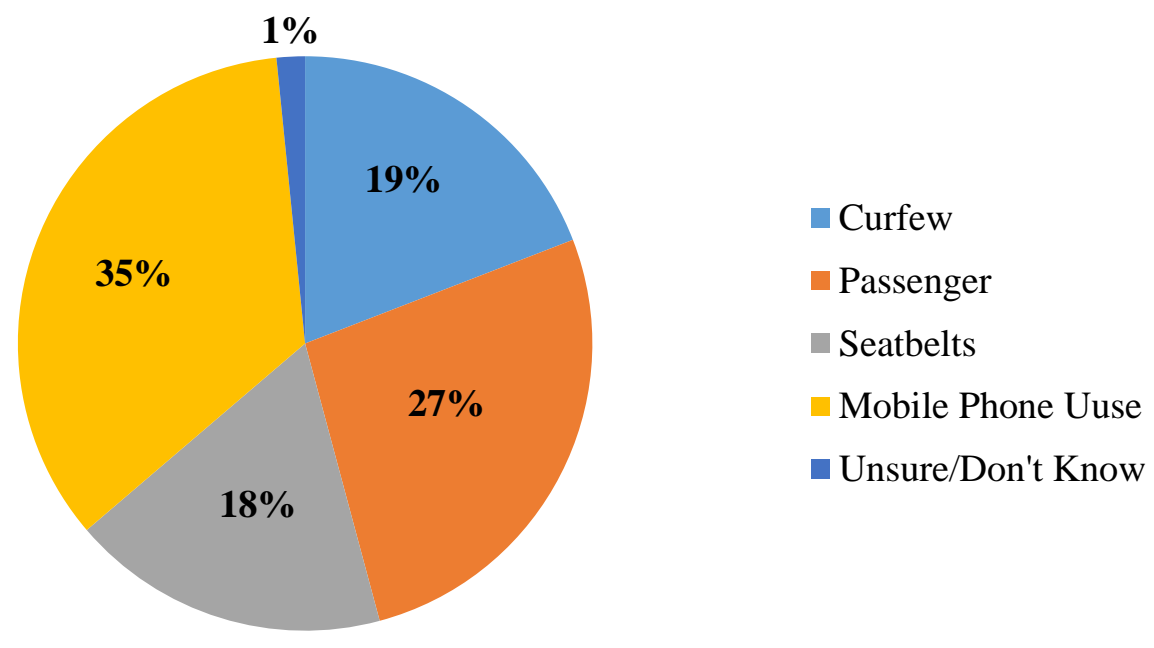

Figure 1-13: Student Cited GDL Violations (GDL Phase I)

\subsection{3: Law Enforcement Findings}

Of the over 100 West Virginia law enforcement officers surveyed, most knew of the GDL program, while a surprising $12 \%$ did not.

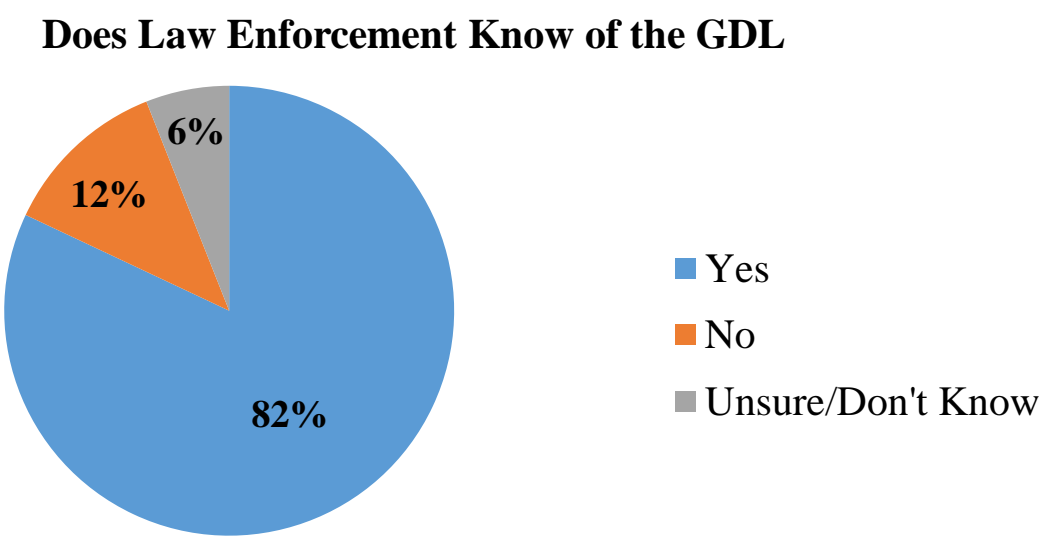

Figure 1-14: Law Enforcement officers who know of GDL program (GDL Phase I) 
Almost all of the officers know the current minimum age for licensure while the majority were able to identify the number of stages in the GDL. Less than $65 \%$ knew the parameters for the curfew and less than $45 \%$ for passenger restrictions while less than $15 \%$ know the minimum age for licensure.

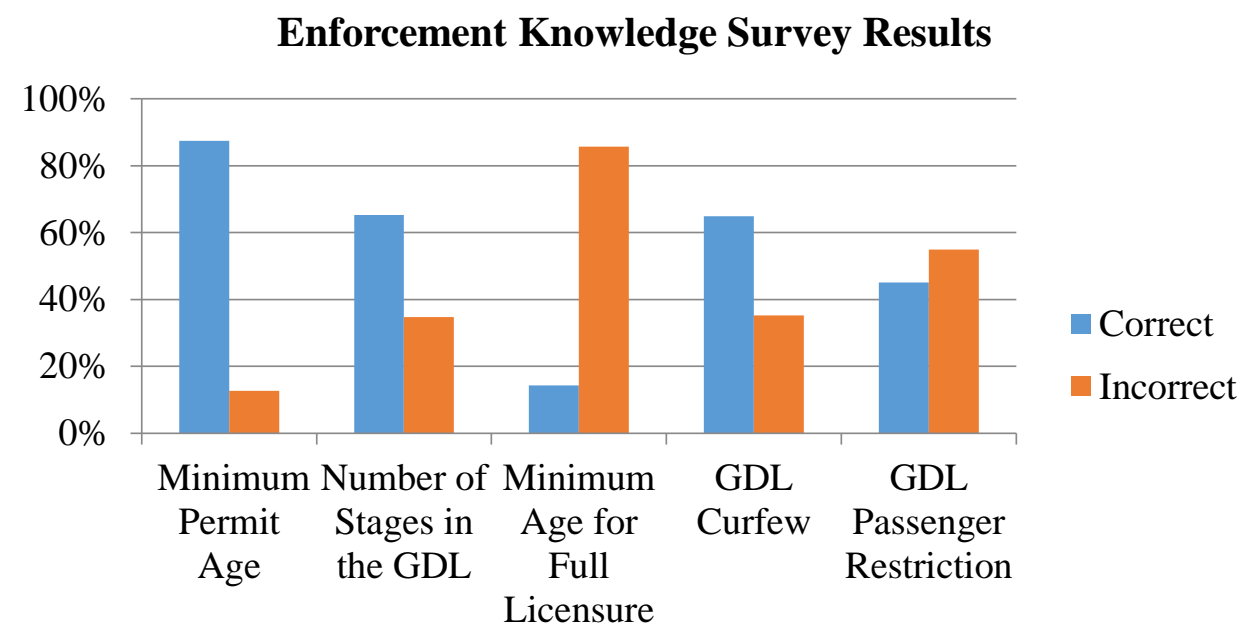

Figure 1-15: Law Enforcement Officer Knowledge Survey Results (GDL Phase I)

\subsection{4: GDL Phase I Summary}

While parents may be the first line of enforcement of the GDL program, incredibly few parents were knowledgeable about the rules and restrictions behind GDL. Parents need to become more involved, informed, and aware of the process through which their sons and daughters are going. Despite several parents and students reporting use of GDL to limit driving capabilities, the system is not being optimized due to lack of knowledge.

Increasing student and parent education is a crucial step in gaining full benefit from GDL and allowing it to become a helpful tool in the protection of young drivers. According to police officers, GDL regulations are difficult to enforce due to limited staff and the inability to identify the vehicles of drivers currently under GDL restriction. It is crucial for the success of the program that all parties work together to provide the most beneficial experience. 


\section{0: Literature Review}

The following literature review is separated into an overview risk identification methods for young drivers, existing programs targets towards teenage driving safety, and research associated with some initial project assumption.

\section{1: Risks Associated with Teenage Driving}

Becoming accustomed to new things can be a difficult, this has proven itself to be true time and time again with man taking the wheel of a vehicle for the first time. Driving a personal vehicle has become a rite of passage in today's fast-paced society as the vehicles per household reaches approximately 1.8 (Governing, 2014) and the vehicles per population has grown at an average rate of 1.6\% (Dargay, Gately, \& Sommer, 2007) a year with just short of 260 million (US DOT FHA, 2014) vehicles being on the road in the United States of America. With new drivers hitting the road each year, special attention needs to be paid towards these young and novice drivers. Although not all young adults choose to get behind the wheel in their mid to late teens, research shows that this is the period of time where drivers are at the highest risk, as discussed later.

\subsection{1: Analysis Methods for Evaluating Teenage Driving Statistics}

The idea that new drivers are at higher risk for crashing is not a new concept. This limited exposure to driving combined with more aggressive driving behavior, the addition of teenage passengers, time of day, and some alcohol use has help push states into establishing some sort of graduated drivers licensing (GDL) program (McCartt, Shabanova, \& Leaf, 2001). These programs may vary from state to state but all set out to accomplish the same task of slowly introducing drivers to the road. Several different analytical approaches have been taken in the 
determination of what contributes to the increase in crash rates for these drivers. Some studies have used age at the time of the incident (McKnight \& McKnight, 2000) while others took into consideration time elapsed since licensure (Gregersen, et al., 2000) which show a steep decline in accidents after the first few months. Both of these analysis methods have merit and both ideas of experience have factored into the development of many state's GDL programs in the form of minimum age restrictions and minimum time with learners permit. For example, West Virginia's GDL program requires drivers to be at least 15 years of age to obtain a Level I Instruction Permit, 16 years of age to obtain a Level II Intermediate Driver's License, and 17 years of age for a Level III Full Class E License; the latter two have the requirement of having the previous level for 6 and 12 months, respectively (West Virginia Graduated Driver Licensing, 2011).

The aforementioned measurements of driving experience work well but both leave large variability in how much experience the young driver actually has. A driver could easily begin driving at the age of 18 and simply skip the level I and II licensing steps whereas another driver could have been driving since the age of 15 and have gone through each of the appropriate steps; this brings an issue to having a drivers age dictate experience. Another case would be two drivers, both of which began driving as early as possible, however only one drives a vehicle on a semi-daily basis while the other only drove once or twice a month through their teenage years; in this context, time since licensure is not a fair judge of experience either.

A more thorough method is the compare crash statistics with miles driven since licensure. A study using this method surveyed 2859 high school freshman across multiple states and kept track of their driving habits through self-reported data until their senior year (McCartt, Shabanova, \& Leaf, 2001). Of the original number of participants, 911 completed the study which tracked miles driven, time of acquiring license, crash incidents, parental restrictions, 
academic grades, and several additional attributes. Crashes were found to be 3 to 3.5 times more likely to occur during the first 250 miles of driving and continues to decrease until the 1000 mile mark. On the other hand, when evaluating the crash data compared to months driving after licensure, the data are more normalized with crashes only being 2 to 2.5 times as likely in the first month compared to the rest of the first year. The average miles driven per month increases from 200 miles at the beginning of the licensure, leveling off at around 500 miles a year. This study helped highlight the critical nature of teenage drivers in the first 1000 miles of driving.

Crash rates may be higher in the early months of driving and this is an issue which the GDL set out to correct when it was first implemented. A 2010 study showed a 21 percent reduction in crash rate when drivers age 15 to 17 were prohibited from driving with any passengers in the vehicle (McCartt, A. T.; Teoh, E. R.; Fields, M.; Braitman, K. A.; Hellinga, L. A., 2010). When comparing crash rates of drivers age 18 to 20 , a nine percent reduction in driver fatalities was found in states that had an extensive GDL program (Zhu, Cummings, Chu, Coben, $\& \mathrm{Li}, 2012)$. With several other studies supporting similar claims, there is little doubt that the GDL is a beneficial program, however, more can still be done to reduce fatalities.

\subsection{2: Behavioral Analysis of Young Drivers}

A lack of driving experience is only one part of the issue that pertains to high crash rates among teenage drivers; teenage behavior also plays a fundamental role. Aimed to gradually increase the driving experience of beginner drivers by restricting their privileges, state GDL programs have shown initial success. Unfortunately, the GDL program does not adequately address the larger issue - a teenager's driving mentality. No level of driver skill can undermine the importance of correcting risky attitudes that define teenage driving. Over time, teens can 
revert back to their original risk-taking behaviors of driving resulting in many ill-advised actions with unintended consequences.

The high-risk behavior most commonly found in teens, texting and driving, is a growing issue in traffic safety and resonates across all populations. Young adults are much more involved with sending text messages in general, sending and receiving an average of 109.5 messages daily (Smith, 2011). According to a study done by Erie Insurance (Paris, 2008), a Pennsylvanian insurance provider, $57 \%$ of the 2127 licensed teenage drivers admitted to sometimes or often reading or sending texts when driving. The temptation for young drivers to want to immediately respond to each and every incoming text message, no matter the situation, is a negative behavior that will continue to put many drivers at risk.

Another significant characteristic of young drivers is listening to loud music. While loud music coming from a car stereo or headset (which are still legal in most states according to AAA) may seem meaningless, it's actually another risky behavior most juveniles often enjoy. In fact, an astounding 93\% of teen drivers play loud music while driving (Paris, 2008). Loud music has been found to significantly affect the response time to peripheral stimuli making it more difficult to safely avoid oncoming vehicles or pedestrians. Loud music forces the brain to process more than it would normally which can impair one's driving performance in critical situations (Brodsky, 2002). Even more interesting, the tempo of a song can affect the speed at which one actually drives or perceives him or herself to drive, meaning faster paced tunes can cause motorists to excessively speed (North \& Hargreaves, 1999).

Certain individuals or peer groups can also influence adolescent drivers to behave erratically. It's human nature for youth to try to prove themselves in the eyes of their peers; the same applies to drivers when one takes the wheel. When a teen presses down on the gas pedal for 
the first time, he or she has a tendency to want to quickly prove him or herself as a skilled driver. This is why peer influence is possibly the most constant risk factor that contributes to unsafe teenage driving (Hatfield \& Fernandes, 2009). There are numerous studies that conclude just the presence of a single teenage passenger increases risky driving, most notably speeding. Furthermore, it has been witnessed that male teenage passengers heighten the risk of unsafe driving more than female teenage passengers. From a study observing students heading home from high school, it was found that the presence of a male teenage passenger results in shorter headways between vehicles and an increased average speed of $5 \mathrm{mph}$. Although it is uncertain why male passengers negatively influence other drivers more than female passengers, one notion is clear, males and females both have unique effects on the driving behaviors of fellow teenage drivers. (Simons-Morton, Lerner, \& Singer, 2005).

Whenever teenagers are not out impressing their peers, they're most likely in the presence of their parents. A majority of teens may learn risky driving behaviors from friends, school, social media, etc., but all unsafe driving habits can potentially be reversed with constructive parental guidance. Parents have the greatest influence on reshaping their child's behavior (Brown \& Ogden, 2002). They are in a key position to demonstrate the fundamentals of safe driving and moderate good driving techniques, if the parents so choose. From a three-month study examining the relations between risky driving and parenting, it was discovered that highrisk teenagers are three times more likely to report low parental monitoring and two times more likely to report low parental restrictions than low-risk driving teens (Hartos, Eitel, \& SimonsMorton, 2002). This shows that when parents are not involved in the learning process, teenagers take full advantage of the freedom to do what they want; in many cases they observe and quickly mimic the risky driving habits of other unsafe drivers around them. Without the oversight of 
responsible parents, teenagers are free to develop their own assumptions of what is considered typical driving behavior.

On the other hand, parents can pass on the same risky driving behaviors they demonstrate on a daily basis. Children are keen to pick up on subtle behaviors exhibited by parents. From the early stage of infancy to adulthood, children continuously monitor and process their parent's lifestyle, including driving habits. This is why higher levels of sensation seeking, anxiety and aggression displayed by the parents - more so in the father- contribute to a higher chance of risky driving in their offspring (Taubman, Ari, Kaplan, Lotan, \& Prato, 2015). Even if the parents are present, they are not necessarily a good influence.

\section{2: Existing Programs Targeted Towards Driver Safety}

\subsection{1: Early Education and Education Strategies}

Since one of the main dilemmas with young drivers is the increased likelihood to engage in risky behavior, it is important to focus on what solutions may currently exist to this abstract problem. Since there are certain groups of teenage drivers willing to ignore the GDL or increase in risky behavior on their own, some programs have been put in place to educate students before they are of driving age. Another approach is to focus on and intervene with teenage drivers who have had prior offense in order to reduce the number of reoccurrences.

One such plan follows the model of early education that begins with an introduction in middle school to the potential dangers and risks in driving and can follow students into high school with more practical lessons leading into a more formal driver's education course (ClarkKevan, Hamilton, \& Shults, 2010). The report list a series of lesson plans ranging from evaluation surveys to full involved activities ranging from 10 minutes to over 2 hours. One such 
activity is an "Anticipatory Set Activity" which involves middle school students sprinting and catching balls. Students must time their runs to catch the ball off the second bounce and run one trial under normal circumstances and a second trial with the introduction of distractions. The data are measured and compared using graphs created by the students. This program serves to both educate students about the dangers of distractions on the road as well as in the vehicle and to educate them in a fun and engaging manner. Priming pre-teens at this early age to be aware of dangers on the road will better prepare them for the transition to becoming full time drivers and will allow them to feel more comfortable when first getting behind the wheel. Currently, there has not been research done into the long-term effects of this program, but its premises can easily be applied to middle and high school student on a state-wide level by integrating with particular classes. With programs such as these, students will at least be exposed to concepts such as distracted driving and delayed reactions well before they would ever consider taking a driver's education course.

The University of Iowa evaluated the effectiveness of a program called Steering Teens Safe. The program in question focuses on parental involvement and is intended to be an instructional-based system broken up into 22 lessons ranging from "basic safety principles" to “setting guidelines for your child to drive." For parents, completion of the program involves (University of Iowa College of Public Health, 2014):

- Completing a 1-hour lunch time training on communication

- Answering three questionnaires over the next 6 months

- Attending two additional lunch meeting where you can talk with other parent's about your experiences

- Completion of Self-guided tutorial on teen driving 
The initial study, which involved 1-, 2-, and 3-month follow-up assessments, focused on 83 parents participating in Steering Teens Safe. Overall, the parents' reports spending around 101.5 minutes on average discussing driving goals with their teenage drivers and 30 minutes practicing safe driving. Among issues raised, one concern was that barriers such as time commitment and teenage attitude towards the program affected involvement, however this was not the case. Currently, the research shows positive reactions from parents with a high acceptability and shows "promise for real-world delivery", however "future studies are needed to assess intervention impact.” (Ramirez, et al., 2013)

Teens in the Driver Seat (TDS) is another program targeted towards the betterment of young drivers, but this program highlights the importance of peer influence. There are two primary focuses of this program established in 2003 in the state of Texas. The first is raising attention to the five risk factors most common in teenage driving (nighttime driving, speeding, distractions such as cell phones and other teen passengers, low seat belt use, and alcohol). The second focus is on involving teenagers directly in safety campaigns targeted towards their peers (Henk \& Fette, 2009). Other organizations throughout the country offer programs targeted towards better understanding of the risks of driving, with most solely emphasizing the dangers of drinking and driving. Few states offer programs covering all the aforementioned categories; most of these are covered in the GDL program of each state, however short of placing restriction on what the young driver is legally allowed to do, not much attention is paid to actually educating them on why the danger exists. Even fewer states actually involve students in their safety campaigns.

The TDS program follows four main steps which can be modified depending on the respective school. Firstly, a select group of students are identified and are formed into leadership 
team with the assistance of dedicated faculty members. Secondly, the selected student are evaluated to determine their current level of understanding associated with driving risks via a per-program assessment survey. Thirdly, the team is placed in charge of items such as "studentled press conferences, school showcase pages on the TDS web site, skits, assemblies, observational surveys of student driving behavior, activities at athletic events and community fairs." One critical path for these programs is to ensure that the student participants are “exclusively responsible for both the development and delivery of all messages." Lastly, the leadership team is given a post-program assessment to evaluate changes and to seek ways to further better the program. Figure 2-1 shows a list of states participating in the program with Texas and Georgia leading the effort. (Henk \& Fette, 2009)

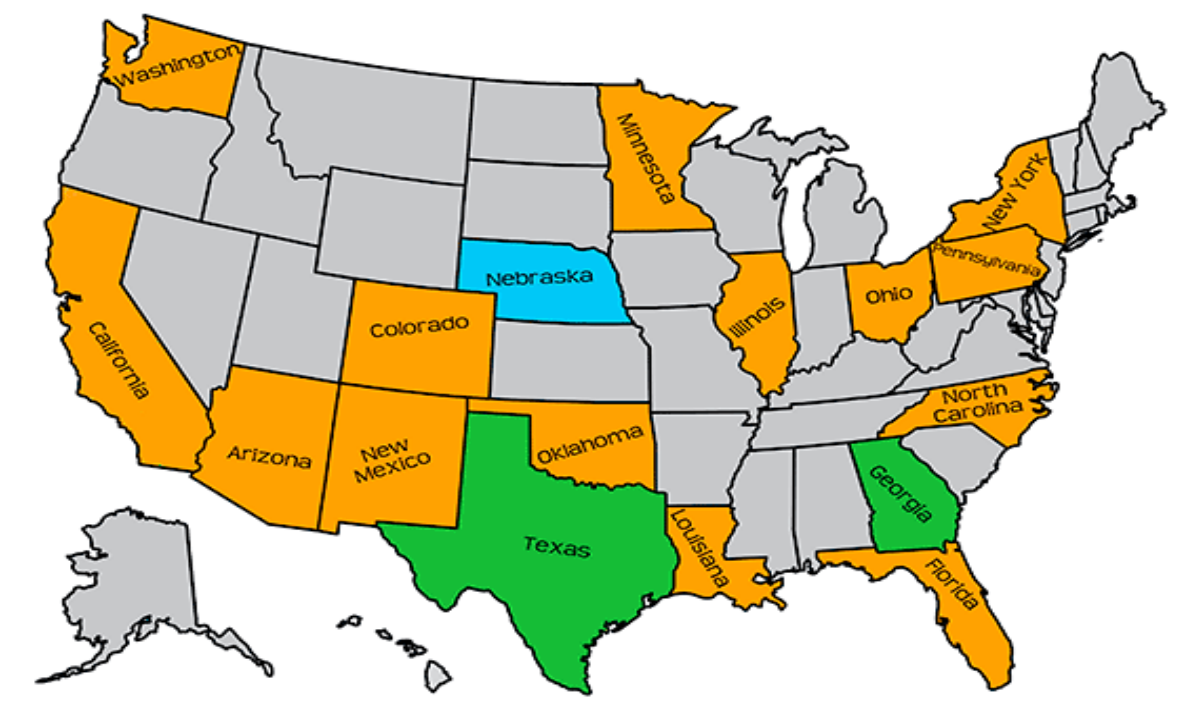

Figure 2-1: List of participating states (Teens in the Driver Seat, 2016)

Garland, Texas was the focus of one case study around the effectiveness of TDS. All seven high schools within the Garland school district participated beginning spring 2016 and the results were compared to the neighboring district of Mesquite which was not participating in the program. Field observations showed a $30 \%$ drop in cell phone usage and a $14 \%$ increase in seatbelt usage. After the first 3 years of implementation, teenage crash involvement dropped for 
$28 \%$ of all crash to around $16 \%$. Most critically, in the four years prior to the program, 3 teen traffic fatalities were experienced per year on average while after the program this fell to .3 fatalities per year on average. The results from the pre and post assessment can be found in Table 2-1 and shows the largest increase the dangers of driving at night.

Table 2-1: Summary of Garland High School Risk Awareness Data (Henk \& Fette, 2009)

\begin{tabular}{|l|c|c|c|c|}
\hline Teen Driving Risk & $\begin{array}{c}\text { Pre-TDS \% } \\
\text { Aware } \\
(\mathrm{n}=1,105)\end{array}$ & $\begin{array}{c}\text { Post-TDS \% } \\
\text { Aware } \\
(\mathrm{n}=617)\end{array}$ & Net Change & Percent Change \\
\hline Driving at night & 1 & 14 & +13 & $+1,300 \%$ \\
\hline Teen passengers & 31 & 43 & +12 & $+39 \%$ \\
\hline Cell phone/"texting" & 60 & 83 & +23 & $+38 \%$ \\
\hline Seat belt use & 13 & 16 & +3 & $+23 \%$ \\
\hline Speeding & 48 & 47 & -1 & $-2 \%$ \\
\hline Drinking \& driving & 84 & 77 & -7 & $-8 \%$ \\
\hline
\end{tabular}

Table 2-2 represents data obtained through the observation of seatbelt usage for both school districts. Garland maintains a higher seatbelt use percentage throughout all categories. When compared to the 2007 observations of $85.7 \%$ overall for Garland and $77.4 \%$ overall for Mesquite, Garland is the only one that exhibited an increase while Mesquite actually declined over the year. A more recent study of 20 Texas counties showed a $14.6 \%$ reduction in injury and fatal crashes where the program had been in place for at least 3 years (Teens in the Driver Seat, 2016). The website also claims that the program is in almost 1,000 school across 37 states outside of Texas. Figure 2-2 shows fewer states because it only highlights the areas which the program is prominent and where schools can easily request support. 
Table 2-2: Teen Belt Use, Post-TDS Garland compared to Mesquite School District, May 2008 (Henk \& Fette, 2009)

\begin{tabular}{|c|c|c|}
\hline Category & $\begin{array}{c}\text { Garland, with TDS Program } \\
(\mathbf{n}=\mathbf{1 , 5 6 6 )}\end{array}$ & $\begin{array}{c}\text { Mesquite, no TDS Program } \\
(\mathbf{n}=\mathbf{1 , 4 9 1 )}\end{array}$ \\
\hline Driver & 93.5 & 80.7 \\
\hline Front Passengers & 89.1 & 66.8 \\
\hline Back Passengers & 40.6 & 33.3 \\
\hline Overall & 90.2 & 75.3 \\
\hline
\end{tabular}

\subsection{2: Post-Incident Intervention}

On the other hand, there are programs marketed as intervention strategies. One such study focused on the development and effects of Teen RIDE (Reality Intensive Driver Education), a course developed between the collaborative efforts of the Worcester Juvenile Center in Massachusetts and various health care providers (Manno, Maranda, Rook, Hirschfeld, \& Hirsh, 2012). The program is designed to be a "day-long interactive multimodality intervention aimed at modifying high-risk driving behaviors among adolescents who are firsttime driving offenders" with hopes that the experience will "modify high-risk driving behaviors and reduce driving offense recidivism among participants, compared with peers who did not receive this intervention". First time offenders can be required to attend this program as part of their judicial sentence where they will be sent to a partnered hospital (University of Massachusetts Memorial Medical Center) from 8:00 AM until the end of the day. Within the course, these teen drivers and parents are exposed to a variety of effects that simulate the surreal conditions of traffic accidents, from minor to fatal. Driver's begin the day with a large group lecture and then split into smaller groups; meanwhile, parents are shown a realistic video depicting the aftermath of a fatal crash involving three teenagers which the younger group will be shown later. The groups progress through the day participating in real-life scenarios design to 
imitate the aftermath of such accidents. The scenarios range from a simulated trauma bay experience with staff to a mock physical therapy session where young driver are shown what it would be like to "live with" the injury by adhering to the limitation of that assigned injury for the rest of the day.

The study involving the previous program continued from 2005-2008, during which 268 students attended one of 13 Teen RIDE courses offered. This group of teenage drivers was compared to a group with similar violations in a neighboring district which did not receive the rehabilitation course. The study concluded that drivers who had completed the course had a recidivism rate of $6 \%$ for the first 6 months after the program with $0 \%$ offending more than once. Meanwhile, the control group had a 56\% recidivism rate within 6 months of the arrest with $14 \%$ offending more than once (Manno, Maranda, Rook, Hirschfeld, \& Hirsh, 2012). The results of this study show how much attitude towards driving can have an impact on driving behavior. The teenagers in the program were not considered more skilled drivers than the control group, but there was a clear shift in precaution on the road.

\section{3: Initial Project Assumptions}

There are several concepts that are being explored with this report. The first is that young drivers going through GDL do not experience the same level of instruction from each of their parents during the instruction phase of their licensing cycle. Another concern is that GDL itself does not address the behavioral tendencies of these teenage drivers. Next, drive's education often is both limited in its implementation within West Virginia and often comes too late in a student's schooling to have a noticeable effect. Lastly, teenagers are incredibly susceptible to peer pressure and the actions of their social circle. 


\subsection{1: Inconsistent and Inadequate Training}

Young drivers are not all receiving adequate training by the time they start driving on their own. In an ideal world, novice drivers would be able to smoothly transition into this new stage of their lives, unfortunately this is not the case for all drivers. The requirements to begin licensed operation of a motor vehicle in the state of West Virginia require that the potential driver "must be at least 15 years old, pass a vision screening, pass a knowledge test, have a valid School Driver Eligibility Certificate from your county school board, and the consent ... of your parent or legal guardian indicating permission for issuance of the Level 1 GDL instruction permit" (West Virgina DMV, 2016). All these requirements are ones that the state deems necessary to be eligible for a Level 1 GDL Instruction Permit, however only one of these has a direct correlation with the teenager's ability to perform on the road assuming that they are able to acquire proper corrective vision if necessary; this factor is the knowledge test. This knowledge test consist of 25 questions, 19 of which must be answered correctly in order to pass and obtain the permit, and is designed to test the applicant's understanding of general driving knowledge, traffic rules and regulations, and road signs and pavement markings (DMV Practice Tests in West Virginia, 2016).

One limiting factor with the knowledge test is that being knowledgeable about a subject matter doesn't necessarily translate to being a more skilled driver. A comparison can be made between skills and habits. While many habits take 21-30 days to fully acquire depending on the individual, skills can follow the same logic as they are not acquired overnight. This leads to the question asked by (safedriver, 2013): "how does one day of training give you a skill?" Taking this logical approach, one can assume that even the most knowledgeable of new drivers, have little to no skill when they get behind the wheel for the first time. Graduated drivers licensing 
addressed this dilemma with experienced drivers effectively becoming driving instructors to youth going through the system as it is associated with a 30\% reduction in fatal crash among 15 to 17 year olds (McCartt, Shabanova, \& Leaf, 2001).

However, it is impossible to ensure that each new driver completes their instructional permit with the same level of experience under the current system. Much of the education process is placed on the parents of the young driver or other adult influences in their life and, therefore, can vary greatly case by case. The main benchmarks of the Level 2 GDL Intermediate Driver's License are having 180 days consecutive conviction free driving, passing a road skills test, and completing the 50 required practice hours with at least 10 hours of night driving (West Virgina DMV, 2016). These requirements are placed upon all youth age 18 and under and, for the most part, is a good evaluation of skill. A shortcoming of this system is the quality control on practice hours, students and parents could easily lie on their forms about the actual number of practice hours they completed. Even if this wasn't the case, several young drivers enter their skills test under prepared and must take multiple attempts to pass. One study showed that only $46 \%$ of examinees passed on their first attempts with $47 \%$ of those who failed passing on their second attempt (Sexton \& Grayson, 2009). This means that roughly 29\% of people do not pass on their first two attempts, but may continue to take the test until they do.

\subsection{2: Limitation of GDL on Behavioral Influence}

Current graduated drivers licensing programs do not significantly affect teenagers' likelihood to engage in high risk behavior. This isn't to say that GDL is ineffective, when analyzing the data, the opposite is true. Prior to widespread implementation of GDL legislation, the fatal crash involvement rate was 37 per 100,000 population for drivers age 16-17 in 1995 (FARS, 2012). In 2010, this statistic showed a 57\% decrease from its 1995 counterpart which is 
largely attributed to the implementation of GDL programs (Shults \& Ali, 2010). Several other groups have confirmed the benefits of GDL over the past 15 years: (Hedlund, Shults, \& Compton, 2006) who have also conducted research in 2003-2005 and (William, Shults, \& Ali, 2012) in more recent years.

Shortcomings behind the behavior influence of GDL became apparent in a 2002 study in the State of North and South Carolina. These states were in a situation where cell phone usage was prohibited for teenagers going through the GDL system in North Carolina but not its southern neighbor. At first there was no decline in cellphone usage in North Carolina, but a slight decrease was found after 2 years. Surprisingly enough, South Carolina experienced a similar decline despite there being no laws surrounding the matter. The study determined that this behavior restriction had no long-term effect (Goodwin, O'Brien, \& Foss, 2012).

Some would say another dilemma with GDL is the difficultly in enforce policies at the law enforcement level. Most age-related restrictions are seen as secondary offenses as law enforcement has little ways of identifying the age of the driver prior to being stopped. New Jersey is one of the few states that have deployed a countermeasure to this issue by requiring all drivers under the age of 21 to display a red, reflective decal on their license plate (State of New Jersey Motor Vehicle Commission, 2015). This law change, which was effective May 1, 2010, proved to have some negative feedback from both parents and teenagers who viewed the law as discriminating against minors (St. Martin, 2010). Some stated that they felt they would become unfairly targeted by police officers while others were concerned that criminals would be able to easily target minors and their vehicles based on this requirement. This law made it all the way to the New Jersey Supreme Court where it was deemed lawful. 
"The most pressing challenge is to clarify the effects of GDL at ages 18 and 19, where there is conflicting evidence" (Williams, Tefft, \& Grabowski, 2012). The AAA study mentions how few states have developed in-depth studies on the before and after effects of implementing GDL programs that are based on more than just crash statistics. Some suggest that it is possible this reduction in teenage crashes can stem from other reasons and is only partially due to GDL and not nearly as much as some proponents would claim. The study concludes that further research needs to be done for "filling important knowledge gaps" for flushing out the true benefits of GDL and enhancing the program for the future.

\subsection{3: Drivers Education}

More educated drivers are better prepared for hazards they may encounter on the road. Unfortunately, driver's education courses often become available after students have already been driving for multiple years and miss the crucial development period. This is partially due to West Virginia being one of the states that does not require driver education prior to licensure. This leaves many new drivers without the benefit of these courses and the course transitions more into an insurance break rather than an instructional course for some students. West Virginia isn't the only state without this requirement (Figure 2-2), but this requirement does increase education and exposure to teenage drivers (Chaudhary, Bayer, Ledingham, \& Casanova, 2011). 


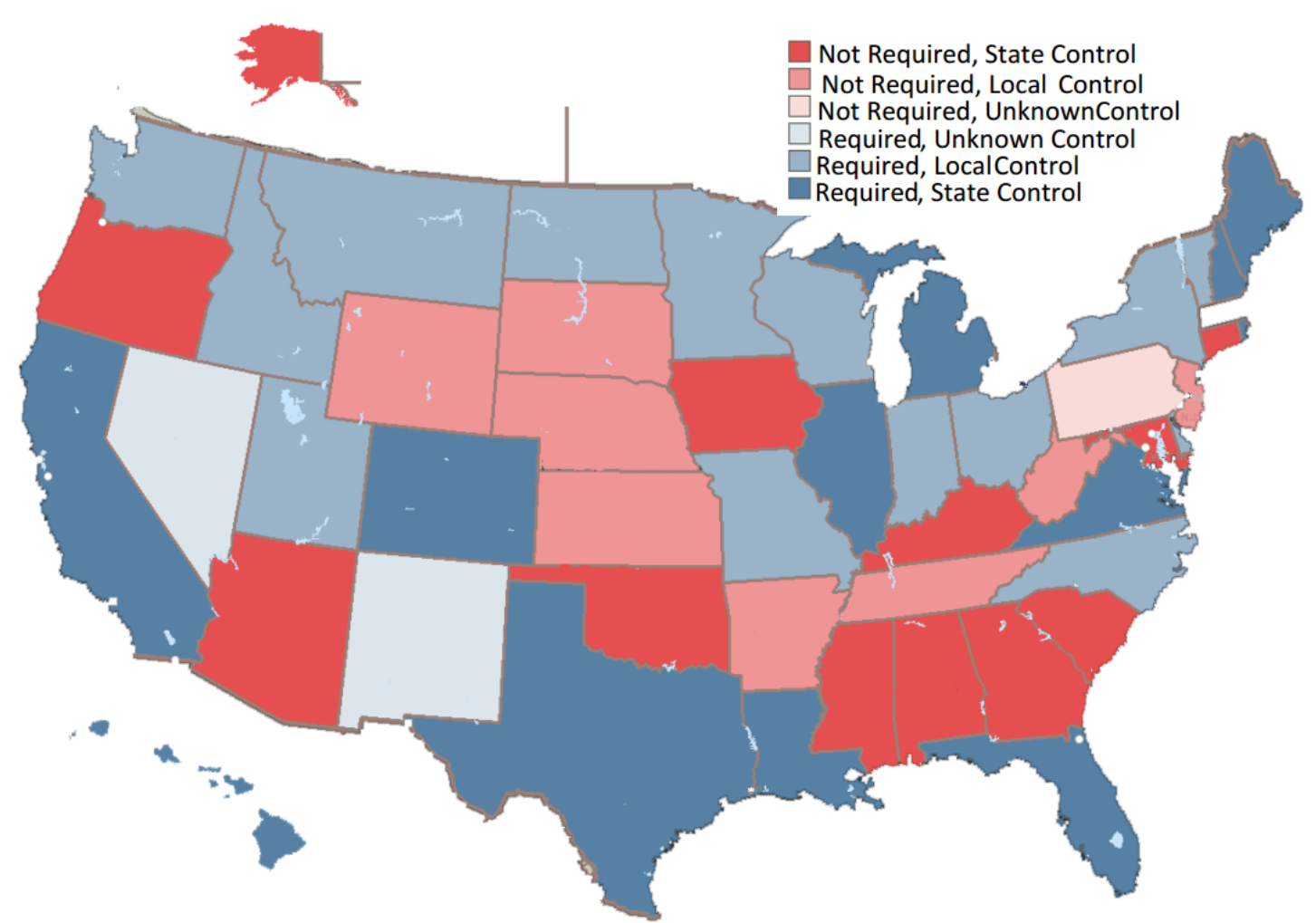

Figure 2-2: State Driver Education Requirements and Curriculum Control (Chaudhary, Bayer, Ledingham, \& Casanova, 2011)

Another dilemma is the inconsistency from school to school; where West Virginia has recently implemented a statewide curriculum (Education, WV Board of, 2011) since the publication of Figure 2-2, variance can occur in vehicle type and quality/frequency of instruction. This becomes an issue when some students receive more time behind the wheel than others, while a student in a separate school may find themselves having car models that are outdated or not up to standards of other states in terms of safety control features. Students in the aforementioned study also reported receiving a varied degree of hours behind the wheel.

\subsection{4: Social Influence}

The social circle of a teenage driver greatly affects their driving habits. One of the most common examples of this is the impact passengers have on crash statistics which has been previously stated. Delving deeper into the research, teenagers who are exposed to risky driving 
practices are more accepting of risky driving behaviors (Sarkar \& Andreas, 2004). Furthermore, male drivers (age 16-18) are more likely to engage in high-risk behaviors such as speeding or performing illegal maneuvers while other passengers are present before a crash than if they were driving alone. Females of the same demographic do not show the same trend (Curry, Mirrman, Kallan, Winston, \& Durbin, 2012).

Many view driving as a form of social prestige and are thus influenced by the opinions of their friends and peers. The degree at which young drivers value this social status has a strong, positive correlation with their increase the tendency of taking risks (Sela-Shayovitz, 2008). Not all peer influence is negative, however. A psychology study showed that "positive experiences with peers will decrease, or moderate, the negative effects that typically result from nonoptimal experiences in other domains" (Bukowski \& Adams, 2005). An example of this has been used in the past with peer-assisted components of community-based prevention programs. These programs have the potential to be integrated with the school system and have been used in the past with public health issues to great success. The theory behind this is that "Trained peer educators are a more credible source of information and could serve also as positive role models who could dispel misconceptions that all adolescents engage in high-risk behaviors" (DiClemente, 1993).

Among the largest sources of adolescent trajectories or behaviors that carry through to young adulthood is a rise in sensation seeking (Chambers, Taylor, \& Potenza, 2003). This increase can be linked to the release of dopamine which is common especially in young adults. Among youth ages of 14 to 22 , males were found to have a prolonged period of change in their overall level of sensation seeking (Romer \& Hennessy, 2007). It was also found that females peaked early at age 16 while males peaked later at age 19 and had less dramatic of a drop off 
afterwards (Figure 2-3). Even though most would consider sensation seeking behavior as a negative trait it can actually help reduce risk taking because the experience gained from excessive risk taking enables high sensation seekers to develop greater patience. "Despite ... greater risk taking, high-sensation seeking youth can learn from the consequences of their behavior and ultimately become less impatient than their less risky peers" (Romer D., 2010). This reduction in impatience can be expanded upon through programs that would provide adequate experience that can be used in the transition to adulthood and also protect them for engaging in behaviors that have adverse consequences.

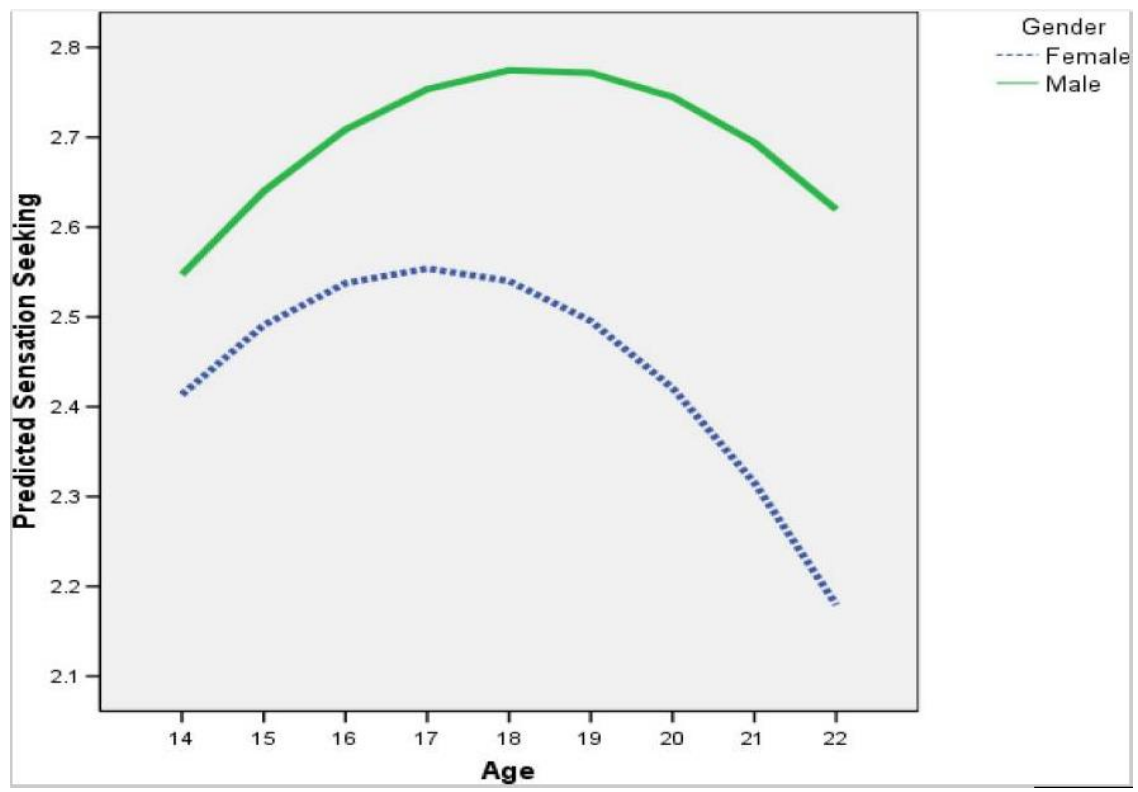

Figure 2-3: Trends in sensation seeking by age in National Annenberg Survey of Youth (Romer \& Hennessy, 2007)

Another social impact on teenager drivers and what is usually the largest is that of one's parents. One study using in-vehicle data recorders (IVDR) in vehicles driven by students within a GDL program found a positive correlation between the risk indices of parents and their children (Lotan, Toledo, Prato, Yarok, \& Hasharon, 2010). This study concluded that there would be a benefit for increasing the time required that young drivers must driver under parental supervision. 


\section{0: Research Approach}

The heightened crash risk of teenage drivers has been well-established for several years through research and the observation of crash statistics. Furthermore, studies have shown that the risk is highest in the first 1000 miles of driving (McCartt, Shabanova, \& Leaf, 2001). An aspect which is less understood is what, beyond inexperience, contributes to these higher crash rates. Likely candidates are having teenage passengers in the vehicle, lack of education about the risks involved with driving, negative peer or parental influence, and perception of those around them. The focus of this study is to hone in on certain patterns or similarities linking teenagers in high school to their perception of the driving habits of their peers and the adults in their lives. In order to obtain this information, a survey will be used to gauge the perception of high school students towards risky driving behaviors.

\section{1: Survey Format}

Past research has been conducted with goals of identifying self-risk and crash rates, however little has been done in the area of perception. One key factor that can be attribute to decision-making is the standing of one's peers and parental entities. If a young driver perceives that it is the "norm" to engage in high-risk behaviors such as speed and texting, that driver is more likely to engage in such activities themselves.

In order to better understand the behavior of teenage drivers and what influences their engagement in high-risk activities, a survey was administered to three different high schools. Each high school represented a separate demographic of West Virginia, urban (Morgantown High), suburban (University High), and rural (Clay-Battelle Middle/High). Morgantown High was chosen for its location in the downtown Morgantown, WV with higher population densities 
and a location closer to businesses. Clay-Battel Middle/High, on the other hand, was selected because of its location in low population density areas around rural roads. University High falls somewhere between the two schools in one of the outlying areas of Morgantown, WV. The survey targets several categories of interest including: driver demographic, driver experience, knowledge of the graduated drivers licensing program, habits of the driver, perception of the behavior of other teens, and perception of the behavior of adults.

All surveys were completed in the month of December with either paper or electronic surveys. Prior to the administration of the surveys, all three high schools received passive consent forms to be distributed to the students where parents could opt to have their children not participate in the survey. The schools were also given a set of talking points for each survey administrator which described the purpose of the survey and what it entailed. Students were informed that they could chose not to answer any question which they did not feel comfortable answering and that they could stop at any time. Morgantown High School took an online version of survey that spanned from December 1 to 2. Clay-Battelle Middle/High only surveyed grades 9-12 and completed a paper version on December 7 while University High School also completed the paper version later that same week.

The administered survey consisted of 44 questions, 12 of which were questions polled in conjunction with a separate study on school zone safety. Of the remaining 32 questions, 17 were asked using a 7 point Likert scale, 12 were single option categorical, 1 was multiple options categorical, and 2 were free response. The purpose of the scaled questions was to evaluate the perceived exposure to high-risk activities from themselves and their surroundings. These scaled values are represented as averages throughout the report and used to compare risk factors of different demographics of teenagers. Of the 2,339 total students surveyed, 1,261 were from 
Morgantown High, 890 were from University High, and 188 were from Clay-Battelle; these numbers roughly correspond with each school's total enrollment. The complete survey as well as a breakdown of the responses from all the school can be found in the Appendix.

\section{2: Driver Demographic}

Several questions were asked with the goal being to better understand the background of the students completing the survey. Due to limitations placed by the institutional review board, the questions were broad and kept related to the student rather than family situation. Because the main goal of this study is to develop programing for all West Virginia high school students, questions on gender and academic standing were excluded. This was with the purpose of creating a survey which would follow a passive consent formatting with parents and students able to opt out of the survey rather than opt in and, in the process, increase the number of responses.

One of the main focuses of the demographic questions was to create a baseline that measures the effects of an increase in age and driver experience has on the teenager's perception of driving amongst their peers and the adults in their life. Another category of interest is whether or not the student drives a new or used vehicle and what type of vehicle that may be. These questions are targeted at whether or not certain vehicle types play a role in the likely of engaging in high risk behavior. The last demographic factor the study is concerned with is whether or not there are other teenage drivers in the household which would indicate the potential benefit of going through this learning process with other drivers.

\section{3: Driver Experience}

From these questions, the study is able to determine the age of the students and how many years each has had their instructional permit or driver's license. This time period can be 
used to estimate the subject's driving experience in place of a more accurate and much more difficult to obtain benchmark of miles driven. The issues surrounding using "miles driven" stems from the need to obtain accurate mileages from each student in the scope of a 15 minute survey. The accuracy of each high school student knowing their exact mileage would be questionable.

Driver's Education courses are frequently offered in high schools throughout the state and are included in the curriculum for all three schools in question. One concern is that this course is primarily taken by upperclassmen and is not taken by students until after the stage in time where they are at the highest risk; this is one of the major focal points of the survey. An additional parameter being considered is the time spent driving under their leaners permit; this is not being used as a metric to evaluate adherence to GDL requirements, but rather to identify the significance driving more hours than required has on the student.

\section{4: GDL Knowledge}

The GDL program has proven itself over the years to reduce the crash rates for teenage drivers; however adherence to the regulations has never been at adequate levels. Short of sheer disobedience of these drivers to the policies in place, some of this can be attributed to the lack of knowledge of both students and parents. Teenagers that have a limited understanding of what regulations are in place may be at high risk due to this fact. This is exemplified when the parents or guardian of the student do not reinforce these policies. The goal of these questions is to pull out the impact the GDL has on teenage drivers from an understanding standpoint.

The study also aims at receiving feedback from students in regards to their opinion on the GDL program. Key comments from the surveyed students will be highlighted later in the report. A combination of these comments and seeking the frequency of certain GDL violations are some 
of the questions asked to further the understanding of the effectiveness of the GDL on teenage behavior.

\section{5: Self-Driving Habits}

One of the key attributes which affects driving ability, as indicated by previous research (McKnight \& McKnight, 2000), is driving with passengers in the vehicle. The assumption that the state of West Virginia makes is that teenage passengers are more distracting than adult passengers. The law in place prohibits passengers under the age of 20 during the first six months of an intermediate license then allows at most one passenger under 20 for the second six months. A rough estimate of the percent of teenage passengers was taken by combining a frequency analysis of likelihood of driving with teenage passengers and comparing it to all passengers in general. The survey also sought to obtain the frequency which the student was a passenger in other vehicles driven by other teenager drivers. Another driving habit being examined is the frequency which loud music is played in the vehicle which will be factored into the risk analysis as it is considered a high-risk activity even though it's not explicitly restricted by the GDL.

\section{6: View on Teenage Behavior}

In order to compile a fair assessment of the perception teenagers have on their own demographic, a series of questions was asked targeting established risky behaviors. Since the goal of this portion of research is to focus on how different groupings of students perceive risky behavior, questions were asked on 7 point Likert scales of "Never" to "Always" in relation to how often they observed their "friends or classmates" engage in the activities of speeding, texting, talking on the phone, and eating while driving. These same questions were also asked in terms of how often observe adults in their life engaging in these same behaviors. A benefit of 
performing this type of analysis is the elimination of any error obtained by students not wanting to reveal condemning information about their driving habits.

Two additional questions were asked specifically focusing on how frequently teens observe friends and classmates violating GDL curfew and passenger restrictions. Since these topics do not apply to their adult counterparts, they were limited to just the perception of teenage drivers. For most analyses, these two grouping are combined into one teen risk factor; these latter two will only be omitted when directly comparing perceptions of teen drivers against the perception of adults.

\section{7: View on Adult Behavior}

As mentioned earlier, the main components that make up the view on adult driving behaviors will be their likelihood of being seen exceeding the speed limit, texting, talking on the phone, and eating while driving. An interest point of this survey is to see how teenagers view their own driving abilities against the adults in their lives. A correlation between the two could suggest a critical focus moving forward on the roles parents and guardians play in the development of the driving abilities of the youth. 


\section{0: Findings}

The aforementioned survey results were analyzed and relevant information was extracted. Apart from addressing the initial project assumptions, other interesting trends were brought forth by the study. Many graphs utilize the Likert scale responses to demonstrate concepts and are all on a "1-7" scale with and central value of "4", despite the ranges of these graphs being manipulated to better show differences in values. Throughout the remainder of the report, several concepts will be repeated which are classified by:

- Teen Risk or Perceived Teen Risk - the combined average of Likert scale responses inquiring about the observation of peers partaking in speeding, texting, talking on the phone, and eating while driving.

- Adult Risk or Perceived Adult Risk - the combined average of Likert scale responses inquiring about the observation of adults partaking in speeding, texting, talking on the phone, and eating while driving.

- Driver Safety/Risk - the combined average of Likert scale responses inquiring about the rate at which the surveyed student drives with teenage passengers and all passengers in general, is a passenger of teenage driver, and the likelihood that they listen to loud music while driving. (This category only applicable to those with licenses.)

\section{1: Area Type}

West Virginia is a diverse state with areas of dense population scattered throughout parts of the state (Figure 4-1). Table 4-1 shows the population breakdown of the state based of the 2010 census. Despite of $97 \%$ of the state being rural land, just under half of the state lives in these areas. In order to better understand the driving behaviors in the different population 
densities defined by urban and rural, different high school were survey that represented each of these location types. Clay-Battelle Middle/High is located off of state route 7 in what is considered rural West Virginia and is significantly smaller than the other two schools in the county. Morgantown High is an urban school located in downtown Morgantown off of Wilson Ave. and has the largest student body which serves most of the students living in town. University High is located outside of town and services students in the outlying areas, for the sake of this study, this area will be considered suburban due to its location.
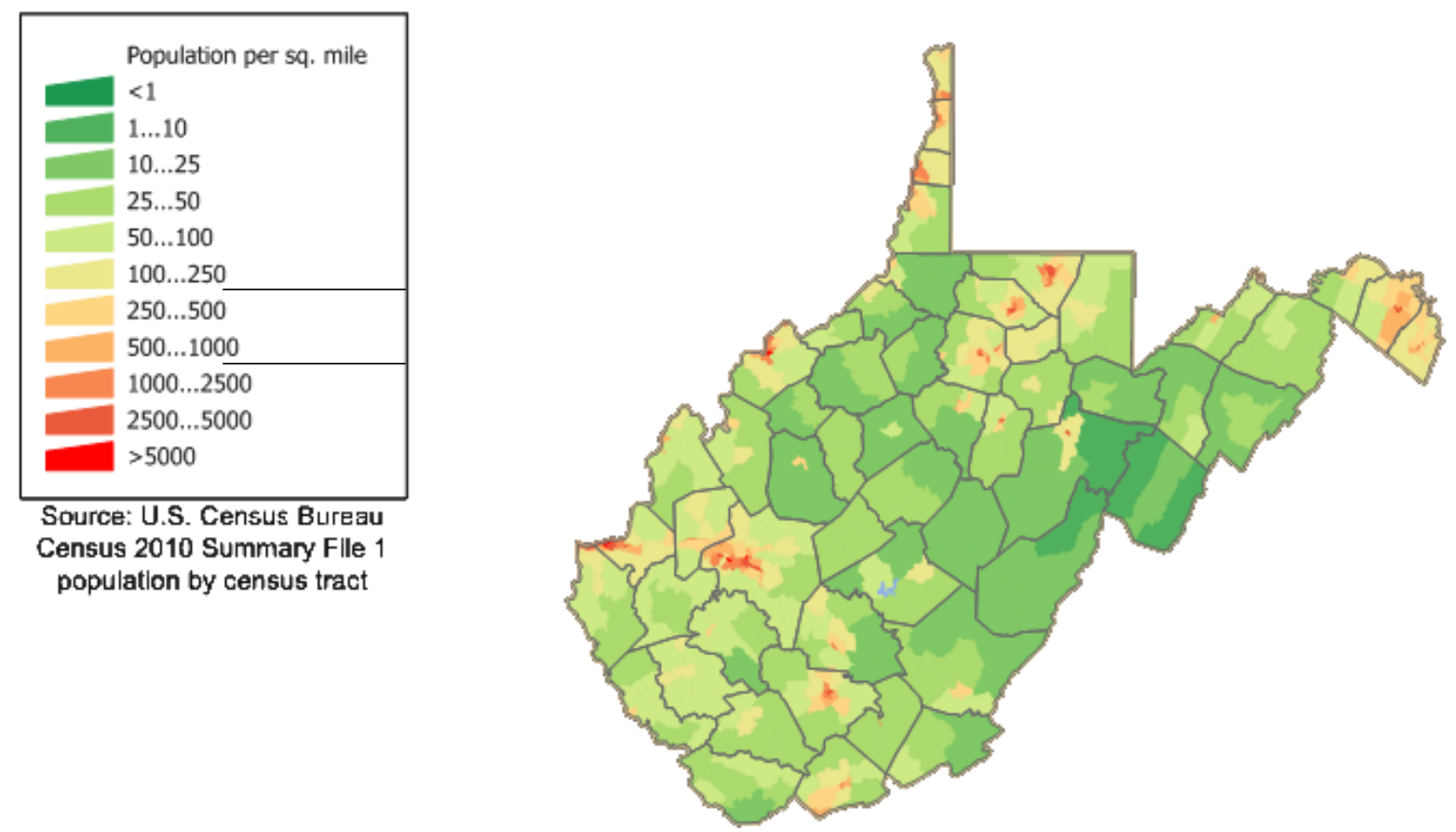

Figure 4-1: West Virginia Population Density Map (Irwin, 2011)

Table 4-1: West Virginia Rural and Urban Population (2010 Census) (Alabama State Data Center, 2015)

\begin{tabular}{|cc|cccc|cccc|}
\hline \multicolumn{2}{|c|}{ Total } & \multicolumn{4}{c|}{ Rural } & \multicolumn{4}{c|}{ Urban } \\
$\begin{array}{c}\text { Total } \\
\text { Population }\end{array}$ & $\begin{array}{c}\text { Area } \\
\text { in Sq } \\
\text { Miles }\end{array}$ & $\begin{array}{c}\text { Rural } \\
\text { Population }\end{array}$ & $\begin{array}{c}\text { Percent } \\
\text { Rural } \\
\text { Population }\end{array}$ & $\begin{array}{c}\text { Rural } \\
\text { Area in } \\
\text { Sq Miles }\end{array}$ & $\begin{array}{c}\text { Percent } \\
\text { of Total } \\
\text { Area }\end{array}$ & $\begin{array}{c}\text { Urban } \\
\text { Population }\end{array}$ & $\begin{array}{c}\text { Percent } \\
\text { Urban } \\
\text { Population }\end{array}$ & $\begin{array}{c}\text { Urban } \\
\text { Area in } \\
\text { Sq Miles }\end{array}$ & $\begin{array}{c}\text { Percent } \\
\text { of Total } \\
\text { Area }\end{array}$ \\
\hline $1,852,994$ & 0.7 & 950,184 & 51.28 & $23,397.9$ & 97.34 & 902,810 & 48.72 & 640.3 & 2.66 \\
\hline
\end{tabular}


The same trend of adults being perceived as being more likely to engage in risky driving behaviors is observed in the by region breakdown. Across all three categories of rural, suburban, and urban, respondents viewed other teenage drivers as having a below average chance of engaging in risky behavior while adults remained about average (Figure 4-2). What is interesting about the responses though is that students attending the rural school are more likely to have a higher perception of risk in their surroundings than those in urban and suburban schools.

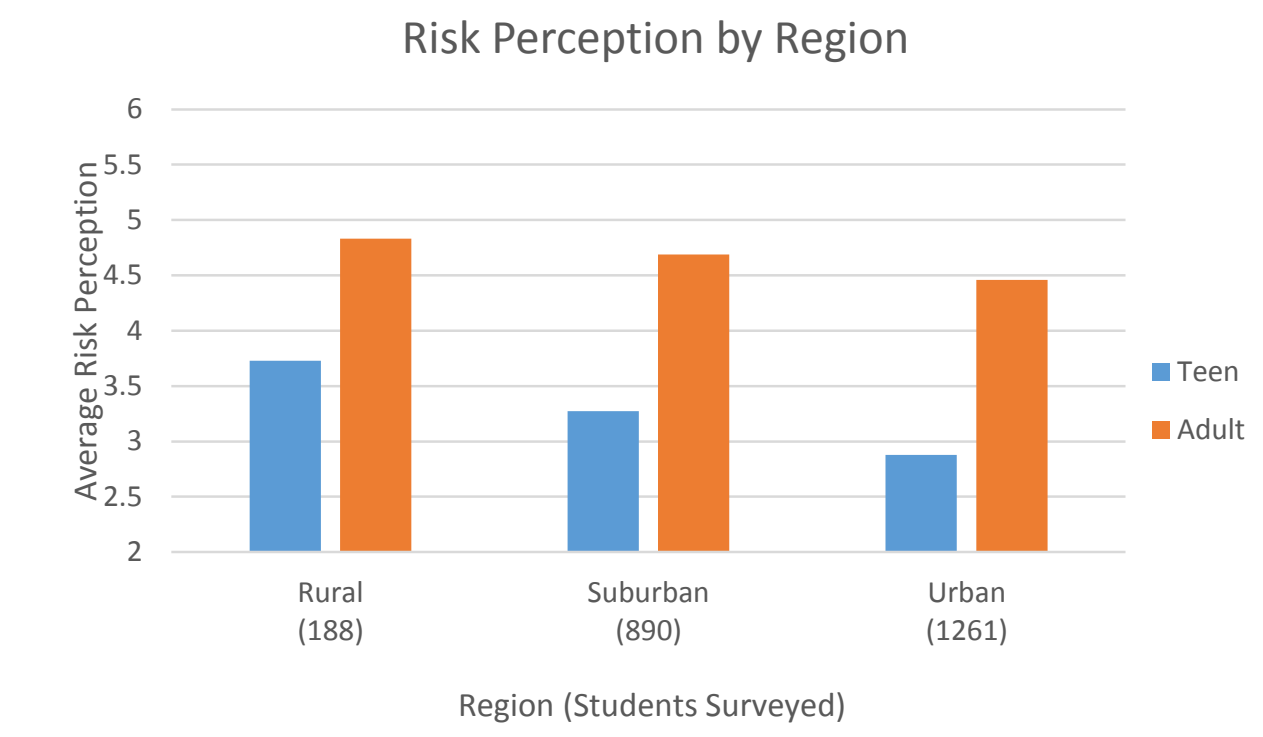

Figure 4-2: Graph of perceived teenage risk by school region (rural, suburban, and urban)

When computing the t-Test in Table 4-2, survey respondents that did not complete all applicable questions were ignored; this is the reason the observation count is lower than in Figure 4-4. Running a chi squared test also showed a correspondence between region and perceived risk and was completed by treating each Likert response as its own category. The students attending the suburban school seemed to fall logically between their rural and urban counterparts. This suggests that as students are selected further from populated areas and more towards less inhabited regions, they are more likely to have higher risk observation rates. 
Table 4-2: t-Test comparison of the combined average perceived risk perception of both adults and other teenagers

\begin{tabular}{lrr}
\hline \multicolumn{1}{r}{ Region t-Test } & Urban & Rural \\
\hline Mean & 4.05 & 4.53 \\
Variance & 1.93 & 1.73 \\
Observations & 1249 & 181 \\
Hypothesized Mean & & \\
Difference & 0 & \\
df & 242 & \\
t Stat & -4.542 & \\
& $4.393 \mathrm{E}-$ & \\
$\mathrm{P}(\mathrm{T}<=\mathrm{t})$ one-tail & 06 & \\
t Critical one-tail & 1.651 & \\
& $8.785 \mathrm{E}-$ & \\
$\mathrm{P}(\mathrm{T}<=\mathrm{t})$ two-tail & 06 & \\
$\mathrm{t}$ Critical two-tail & 1.970 & \\
\hline
\end{tabular}

\section{2: Driving Experience}

More driving experience leads to safer driving habits. This is a standard assumption that many would make and, as many studies have shown, crash rates decrease with number of years of driving experience (Gregersen, et al., 2000). However, the same does not hold true when it comes to teenage exposure to high-risk driving. Risk exposure from other teenagers actually increased with age and years of driving experience on average of $11 \%$ each year. A correlation was determined for each of the following sections using the spearman correlation teen risk against their age and years since obtaining their instructional permit and intermediate license. Age was found to have the strongest influence on perceived teen risk (Table 4-3).

Table 4-3: Correlation of years of experience and perceived teenage risk

\begin{tabular}{|lr|}
\hline \multicolumn{2}{|c|}{ Spearman Correlation } \\
\hline \multirow{2}{*}{ Age } & Teen Risk \\
Instructional & $33.2 \%$ \\
Intermediate & $29.7 \%$ \\
& $13.8 \%$ \\
\hline
\end{tabular}




\subsection{1: Age}

When comparing average perceived risk to the age of student, it was found that the students are $26 \%$ more likely to observe risky driving behavior from age 14 to 18 ; this percentage rises to $59 \%$ when just evaluating the perception of other teenagers. This leads to a total increase of $6 \%$ per year and $12 \%$ per year due to teenager. Figure 4-3 and Figure 4-4 both demonstrate how the likelihood of observing high risk situation increases dramatically with age. It can also be seen that, as student get older, their views of their peers become more akin to that of other adults.

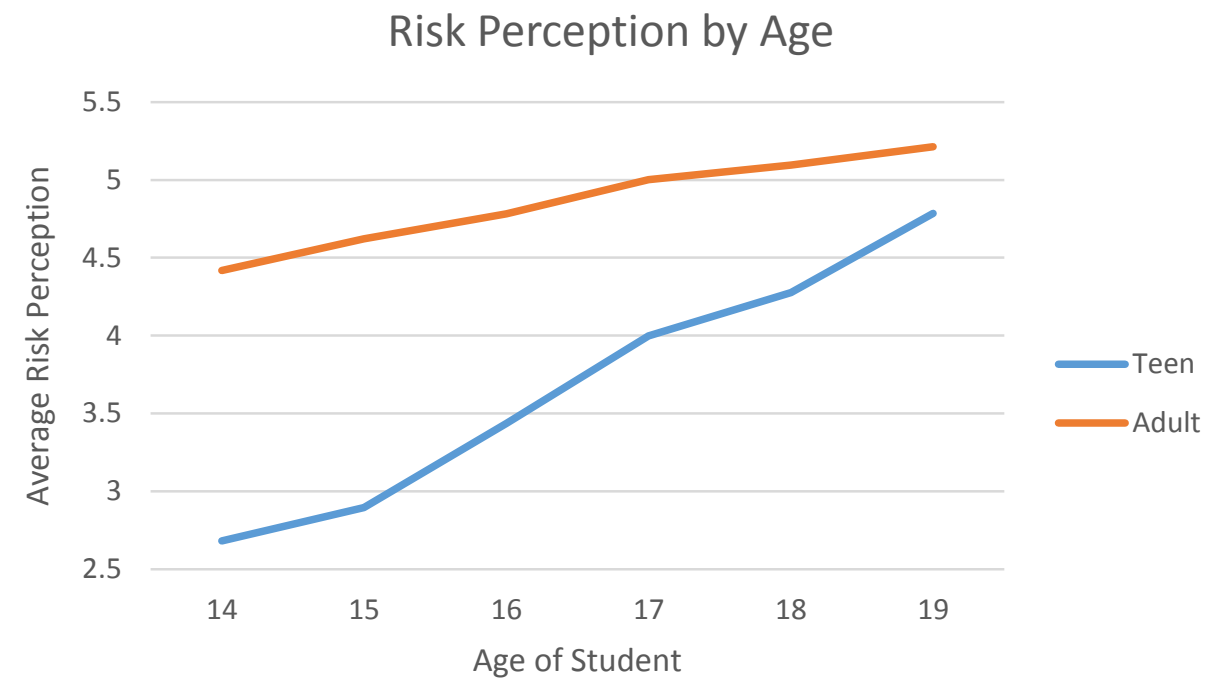

Figure 4-3: Graph of how teenage risk perception compares to age 


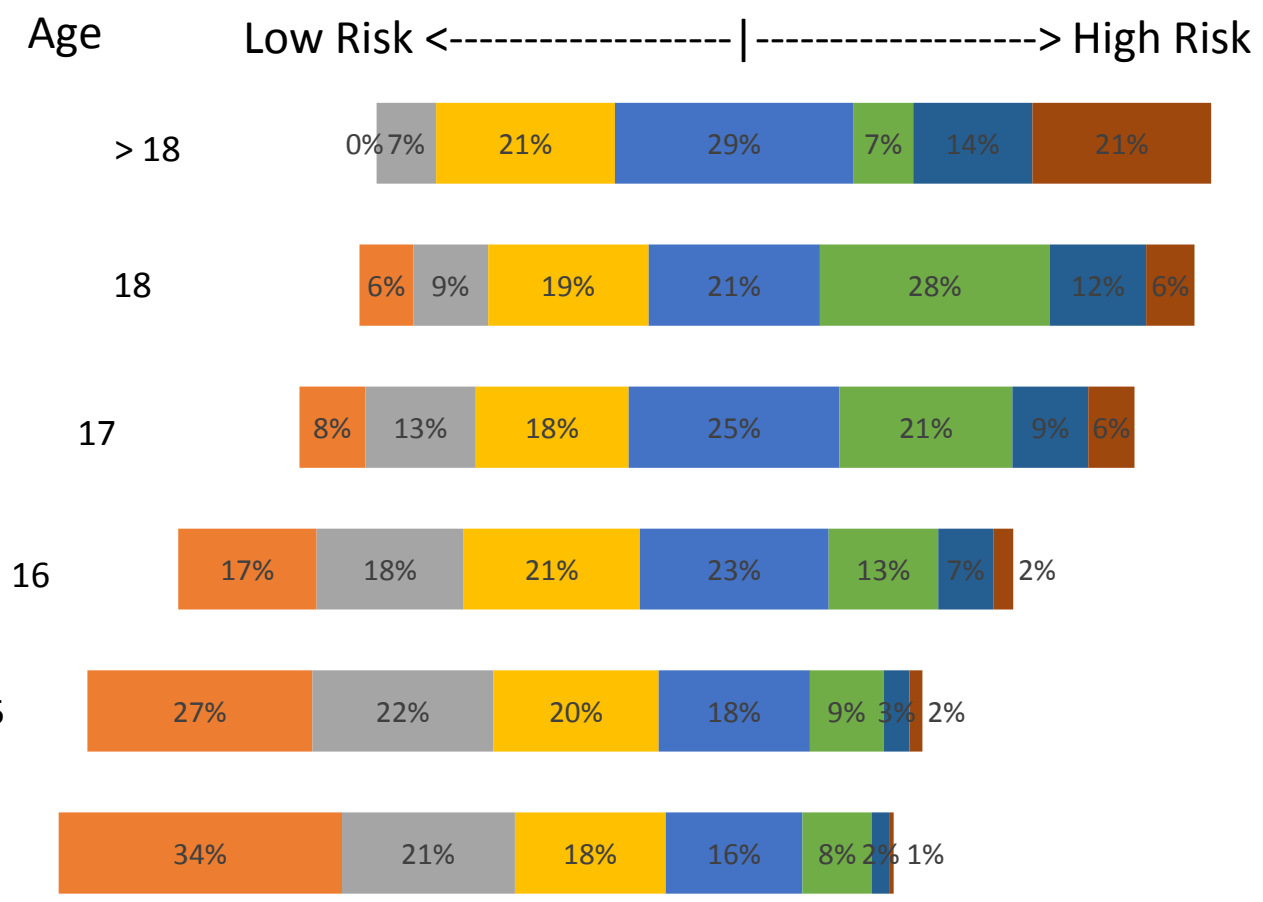

Figure 4-4: Likert scale responses of perceived teenage risk by age 


\subsection{2: Years since Instructional Permit}

A similar analysis was performed evaluating the years of driving experience since the student acquired a learner's permit. Of the 1138 students who have had a learner's permit at one point in life, the perception of risky behavior was found to increase by $42 \%$ from the time of acquisition to over three years later. This contributes to just under an $11 \%$ increase per year of driving experience. Figure 4-5 and Figure 4-6 both demonstrate how perceived risk increases with number of years since the student obtained their learners permit.

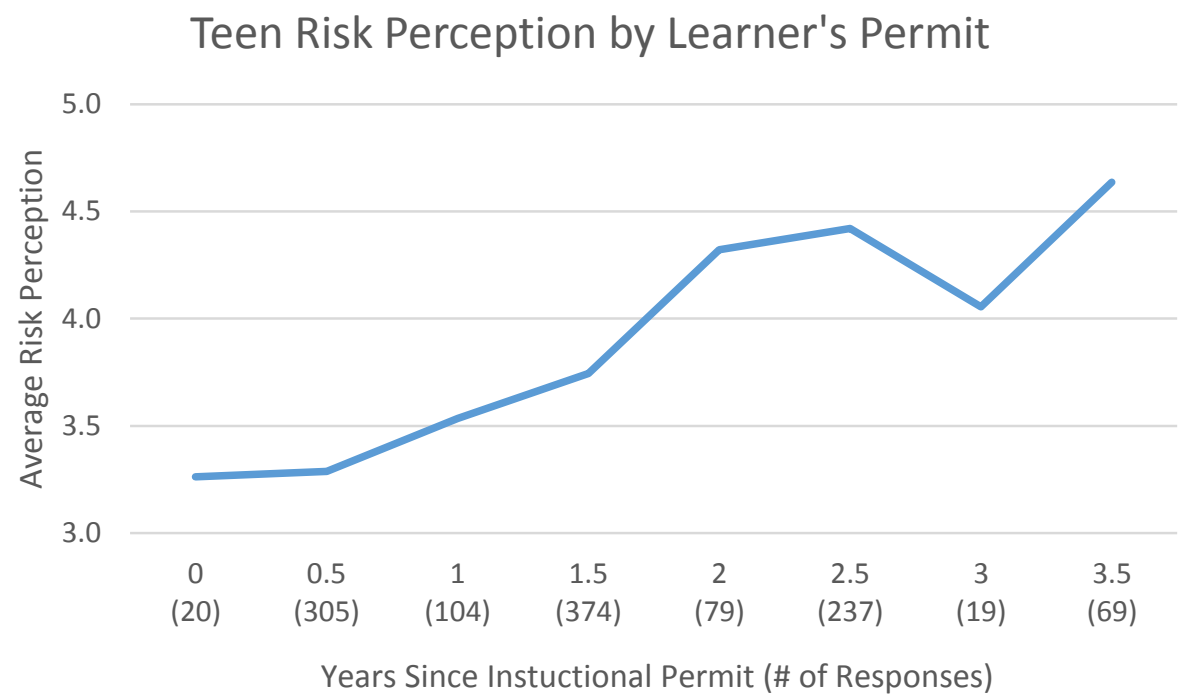

Figure 4-5: Graph of how perceived risk of other teenagers change with years since acquiring an instructional permit 


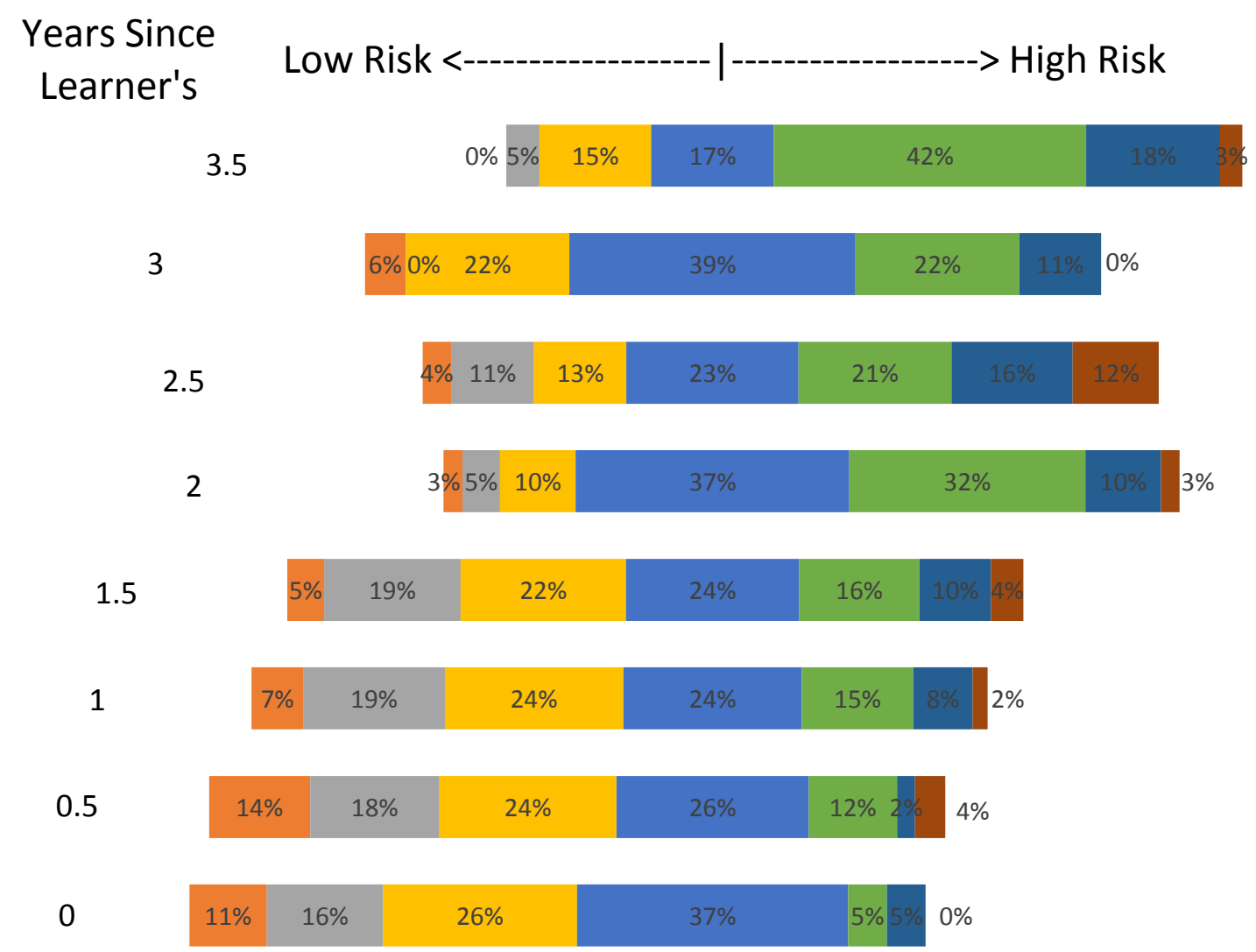

Figure 4-6: Likert scale responses of perceived teenage risk by years since acquiring an instructional permit

\subsection{3: Years since Intermediate License}

Comparable to the risk increase observed with the instructional permit, observed risk increases on average of $10 \%$ per year in respect to time since the acquisition of an intermediate license. Due to the smaller range of this category (2.5 years), there is less variety in the responses. These 653 responses stay within 1 point of each other on average. Figure 4-7 and Figure 4-8 show the change in this perceived risk as the amount of time the student has their intermediate license increases. 


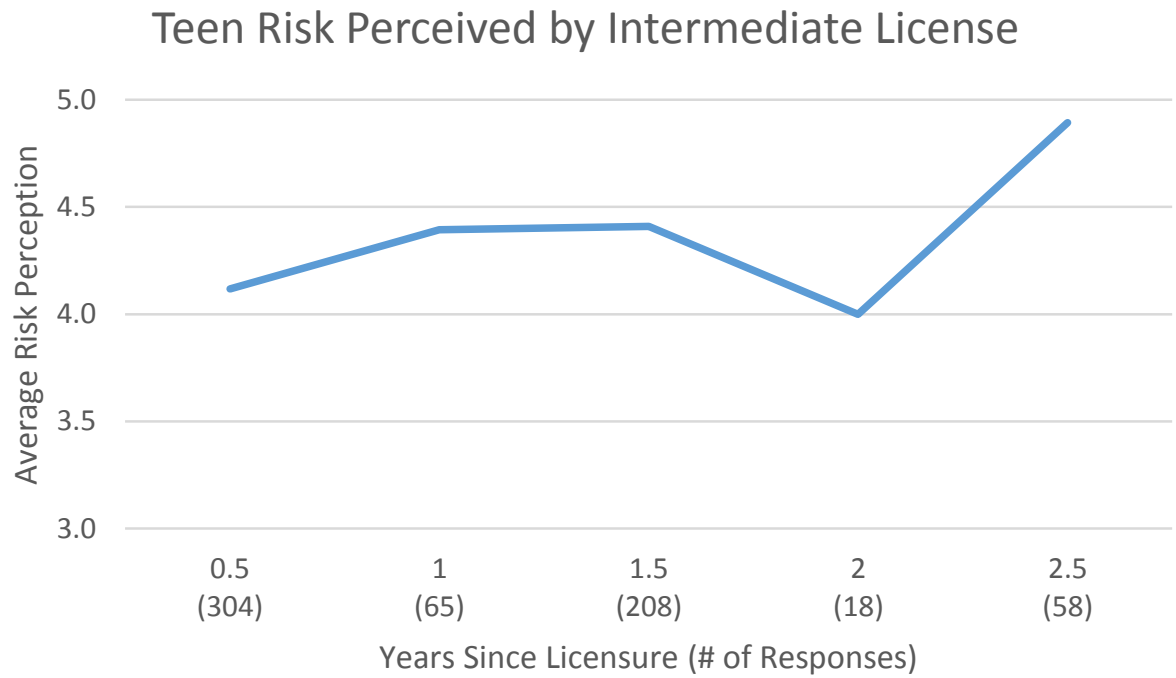

Figure 4-7: Graph of perceived teenage risk by years since acquiring an intermediate license

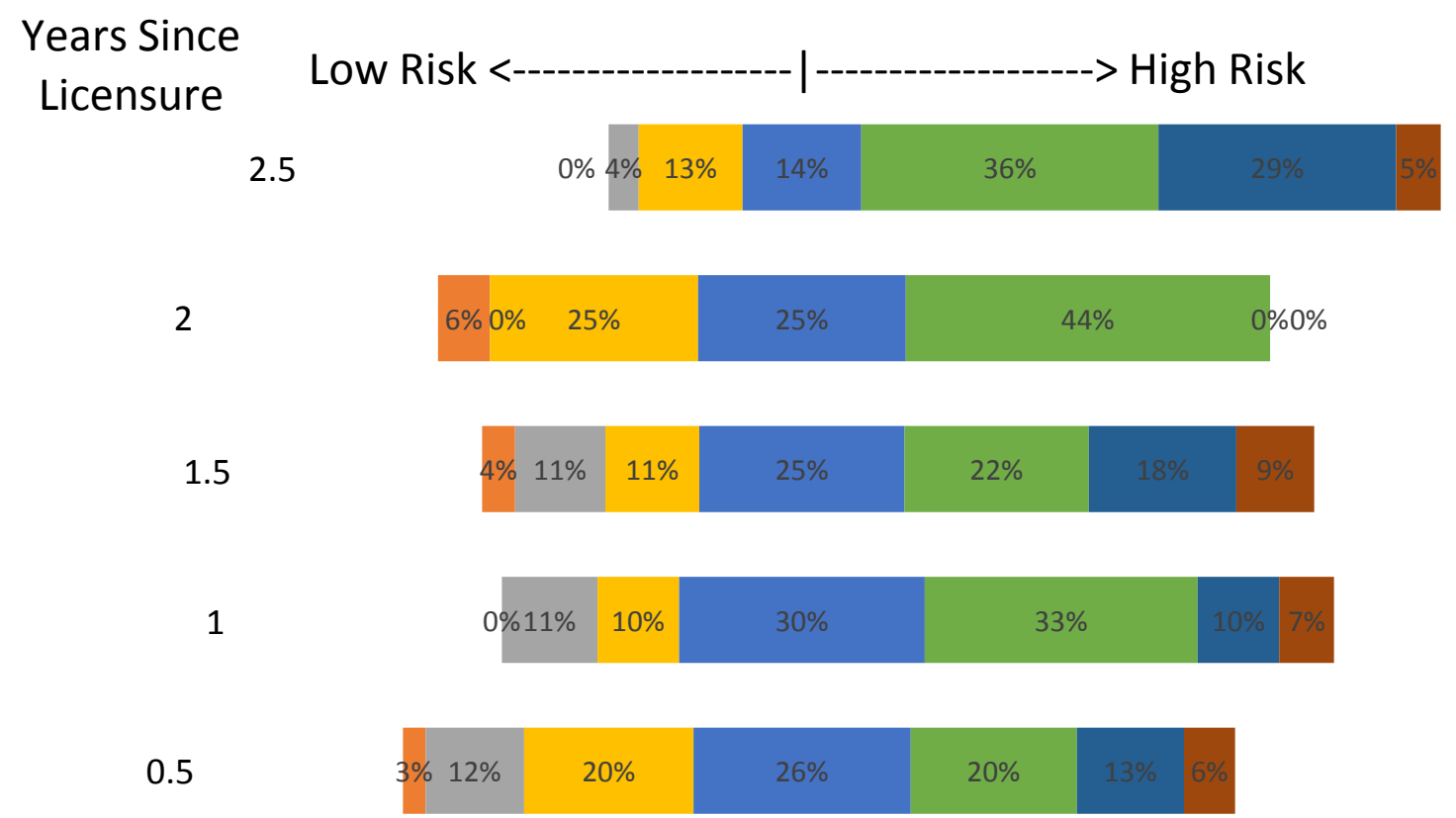

Figure 4-8: Likert scale responses of perceived teenage risk by years since acquiring an intermediate license

\subsection{4: Delay in Driver's licensing}

Waiting to get a driver's license leads to more responsible behavior involving themselves and other teenage drivers. In the scope of this study, safer driving behavior is defined as the average likelihood of the student riding with other passengers, driving with other passengers in 
their vehicle (both teen and adult), and frequency of listening to loud music; these factors combine to form a measure of level of distraction for which the young driver is accustomed. Figure 4-9 shows that if students are more likely to wait until later in life to begin driving on their own, they are slightly less likely to observe adult risk-taking behavior and slightly more likely to observe teenage risk-taking behavior. These students are also less likely to drive with other passengers and listen to loud music.

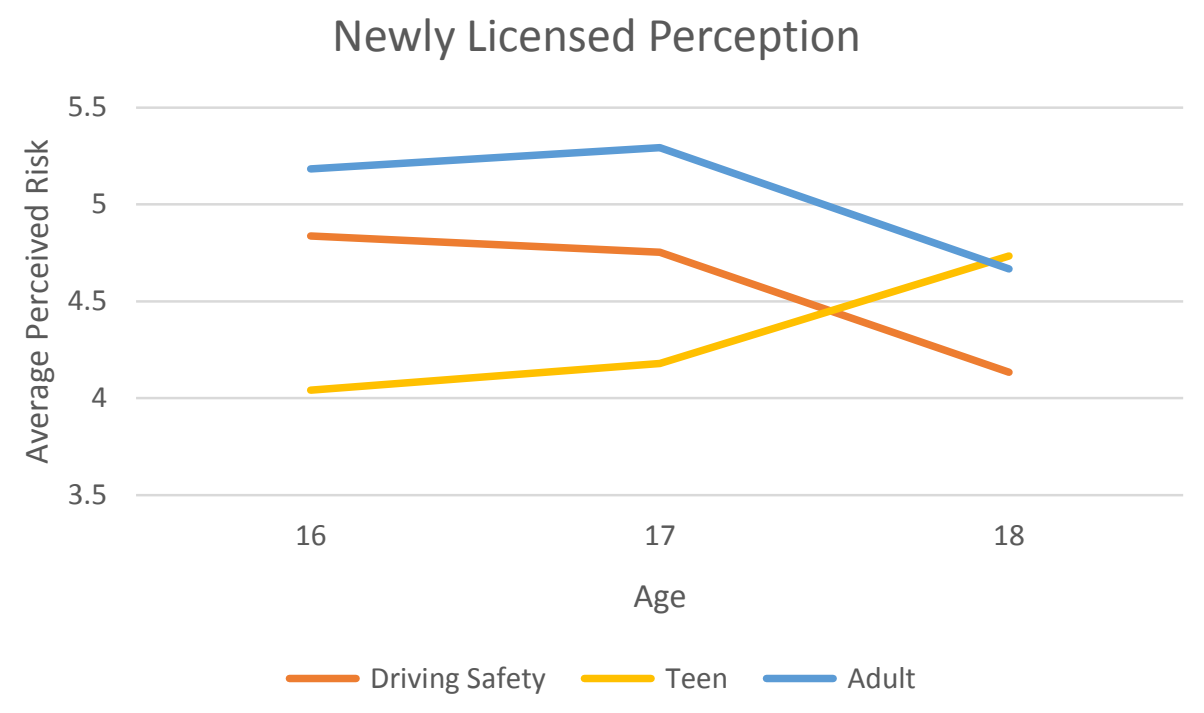

Figure 4-9: Risk perception for drivers who have been licensed for less than one year

An interesting observation is that if students obtain their license at the age of 18 , the perceptions of adult and teenage risk taking are similar enough to each other that there is no significant difference (Table 4-4). This gap in perception which was observed in younger drivers is no longer present, this could be due to the feeling of maturity that allows the student to have a better understanding of the road before he/she begins driving on their own and as they approach adulthood. This matches other trends found in the study where the view of peers falls more in line with adults as the student becomes older. 
Table 4-4: t-Test for the comparison of teenage and adult driving risk perception for newly licensed 18 year olds

\begin{tabular}{lcc}
\hline \multicolumn{1}{c}{$t$-Test 18 Year New Driver } & Teen & Adult \\
\hline Mean & 4.31 & 4.44 \\
Variance & 1.71 & 2.45 \\
Observations & 32 & 32 \\
Hypothesized Mean & 0 & \\
Difference & & \\
df & 60 & \\
t Stat & -0.347 & \\
P(T<=t) one-tail & 0.365 & \\
t Critical one-tail & 1.671 & \\
P(T<=t) two-tail & 0.730 & \\
t Critical two-tail & 2.000 & \\
\hline
\end{tabular}

\subsection{5: Drivers Education}

Taking a driver's education course is typically synonymous with a better understanding of the rules of the road and insurance discounts. One interesting finding from the research shows is the perceived risk and change of risky driving behavior slightly increases after taking one of these courses (Table 4-5). This is apparent with students 15 years of age who show a 0.5 point increase in perception of teenage risk. The perception rise could be attributed to the increase of awareness towards which behaviors can lead to accidents while the more hazardous driving could be attributed to greater confidence on the road (McCartt, A. T.; Teoh, E. R.; Fields, M.; Braitman, K. A.; Hellinga, L. A., 2010). However this does not prove significant when narrowing down the range to only those 17 years of age and old. The fact that driver's education courses are typically offered to upper classmen does slightly skew the data. Only $17 \%$ of high school students surveyed have enrolled in a driver education course.

Table 4-5: Driver Education statistical overview

\begin{tabular}{|c|cccccc|}
\hline $\begin{array}{c}\text { Driver's } \\
\text { Education }\end{array}$ & $\begin{array}{c}\text { Average } \\
\text { Age }\end{array}$ & $\begin{array}{c}\text { Years Since } \\
\text { Learners }\end{array}$ & $\begin{array}{c}\text { Years Since } \\
\text { License }\end{array}$ & Average Risk & $\begin{array}{c}\text { Risk } \\
15\end{array}$ & $\begin{array}{c}\text { Risk } \\
17+\end{array}$ \\
\hline No & 16.1 & 1.5 & 1.1 & 3.7 & 2.8 & 4.0 \\
Yes & 16.6 & 1.8 & 1.1 & 4.2 & 4.3 & 4.1 \\
\hline
\end{tabular}


Table 4-6 shows a series of t-Test executed to determine if driver education plays a significant role in teenage perception. When analyzing students 15 years of age, only 60 of the 623 students (less than 10\%) have taken drivers education. The students that have taken driver education do show a statistically significant change in perception of teenage driving. This is not the same for those students 17 years of age and older who do not show a significant change in perception. 208 of the 700 students (around 42\%) in this older age group have taken a driver education course at some point in their high school career. Where most everyone in driver education courses drive vehicles, 65 respondents did not yet have their learners. The data suggests that, in terms of the likelihood of recognizing dangers of other drivers, students show a greater benefit when taking driver education at an earlier age.

Table 4-6: t-Test comparison of the effects of driver education on groups of young drivers

\begin{tabular}{|c|c|c|c|c|}
\hline \multirow{2}{*}{$\begin{array}{c}\text { Driver Education Teen Risk } \\
\text { t-Test }\end{array}$} & \multicolumn{2}{|c|}{15} & \multicolumn{2}{|c|}{$17+$} \\
\hline & No & Yes & No & Yes \\
\hline Mean & 2.83 & 3.45 & 4.04 & 4.13 \\
\hline Variance & 2.33 & 2.58 & 2.44 & 2.61 \\
\hline Observations & 517 & 56 & 477 & 203 \\
\hline $\begin{array}{l}\text { Hypothesized Mean } \\
\text { Difference }\end{array}$ & 0 & & 0 & \\
\hline$d f$ & 66 & & 370 & \\
\hline t Stat & -2.7598 & & -0.6584 & \\
\hline $\mathrm{P}(\mathrm{T}<=\mathrm{t})$ one-tail & 0.0037 & & 0.2553 & \\
\hline t Critical one-tail & 1.6683 & & 1.6490 & \\
\hline $\mathrm{P}(\mathrm{T}<=\mathrm{t})$ two-tail & 0.0075 & & 0.5107 & \\
\hline t Critical two-tail & 1.9966 & & 1.9664 & \\
\hline
\end{tabular}




\subsection{6: Hours Spend Practicing with Learners Permit}

Little correlation exists between number of practice hours and the perceived risk of adults and teenagers. The graph in Figure 4-10 does show how those who do not drive are less likely to observe risky driving behavior in their peers and adults than their driving counterparts.

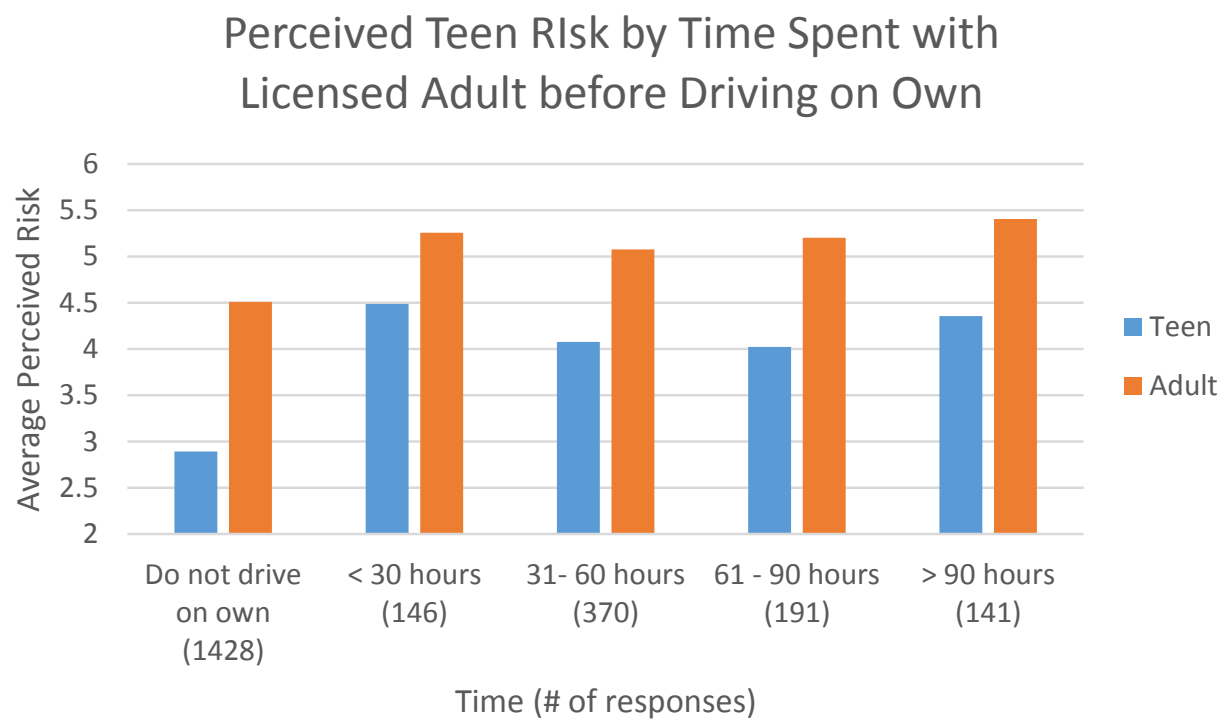

Figure 4-10: Graph comparing perceived risk of teenagers and adults by time spent driving with instructional permit

\section{3: GDL Knowledge}

Upon examining the survey responses relating to perceived GDL knowledge of the adults in the respondent's life and of the respondent's knowledge, it was found that teenage students perceive their parents or guardians to have greater knowledge about the GDL program ( 
Table 4-7). This finding supports to the notion that parents are seen as valuable resources and are expected to know more about driving than the students themselves. A greater variance exists with the knowledge teens possess which can be attributed to the range of age and experience of the student drivers compared to the more seasoned adult drivers in their lives. However, the spearman correlation between these two values is low at $38.5 \%$. 
Table 4-7: t-Test determining that teens perceive adults as having a better understanding of GDL than themselves.

\begin{tabular}{lll}
\hline GDL Knowledge t-Test & Teen & Adult \\
\hline Mean & 3.36 & 4.80 \\
Variance & 3.88 & 3.44 \\
Observations & 2169 & 2169 \\
Hypothesized Mean Difference & 0 & \\
df & 4320 & \\
t Stat & -24.796 & \\
& $2.59 \mathrm{E}-$ & \\
$\mathrm{P}(\mathrm{T}<=\mathrm{t})$ one-tail & 127 & \\
t Critical one-tail & 1.645 & \\
& $5.18 \mathrm{E}-$ & \\
$\mathrm{P}(\mathrm{T}<=\mathrm{t})$ two-tail & 127 & \\
t Critical two-tail & 1.961 & \\
\hline
\end{tabular}

Below in Figure 4-11 is a surface map that indicates the relation between teen and adult knowledge of the GDL. Most of the overlap occurs at the average of each values, with the second peak being at the lowest rating of each category and third being at highest in each. This graph also shows that adults, for the most part, are seen to have a much better understanding of the process. It is noted that the perception of adult GDL knowledge does not align with the actual knowledge from GDL Phase I study (Noble, Martinelli, Unnikrishnan, \& Martinelli, 2012). 


\section{Corresponding GDL Knowledge}

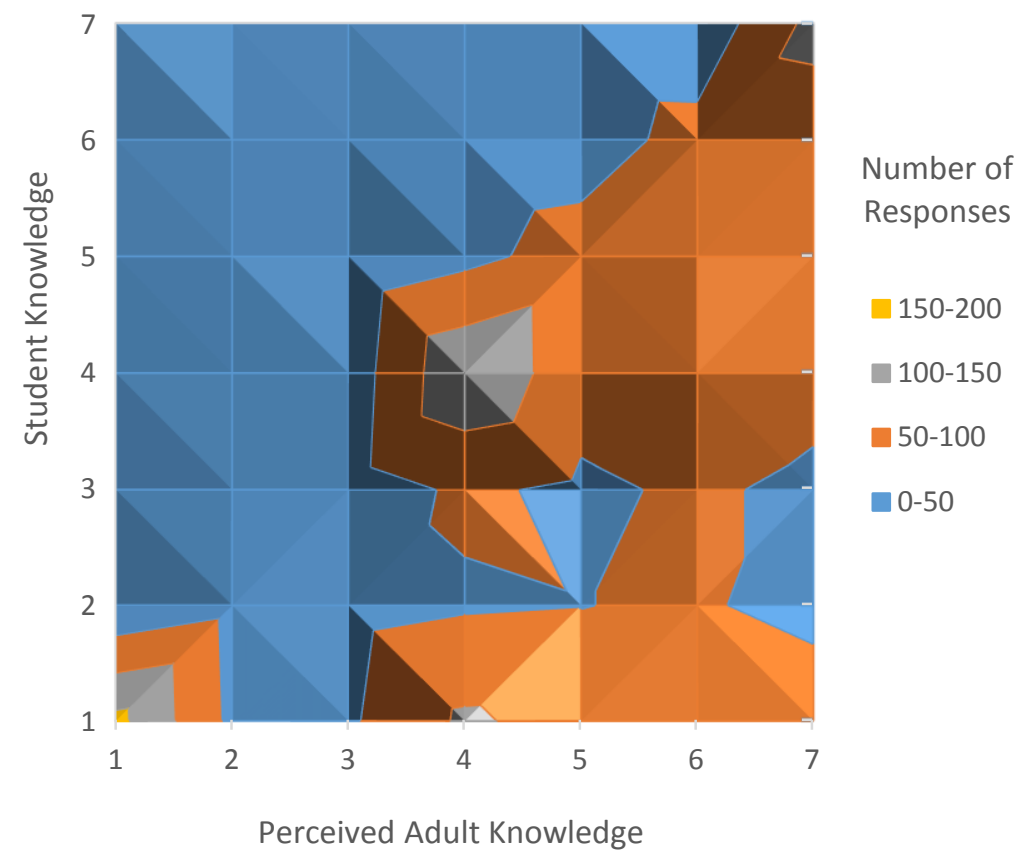

Figure 4-11: Surface map comparing response frequency of teenage knowledge and perceived adult knowledge of the GDL

\subsection{1: Driver Safety}

Knowledge can be the foundation for safer driving experience. This is a statement seems to be a backing force behind the State of West Virginia Driver's Licensing Handbook (West Virgina DMV, 2016) as it aims to educate new drivers and those responsible for their teaching (parents or guardians). However, more knowledge leads to more confidence on the road and could potentially lead to over confidence. Of the 2169 students that responded to both questions regarding perceived adult and self-knowledge of the GDL, $11.2 \%$ thought that they had a better understanding of the GDL program than their guardians; when just looking at those students that drive, this percentage slightly increase to $16.6 \%$ (Figure 4-12). The students who believe they are more knowledgeable could also believe they are experienced enough to take greater risks on the road. 


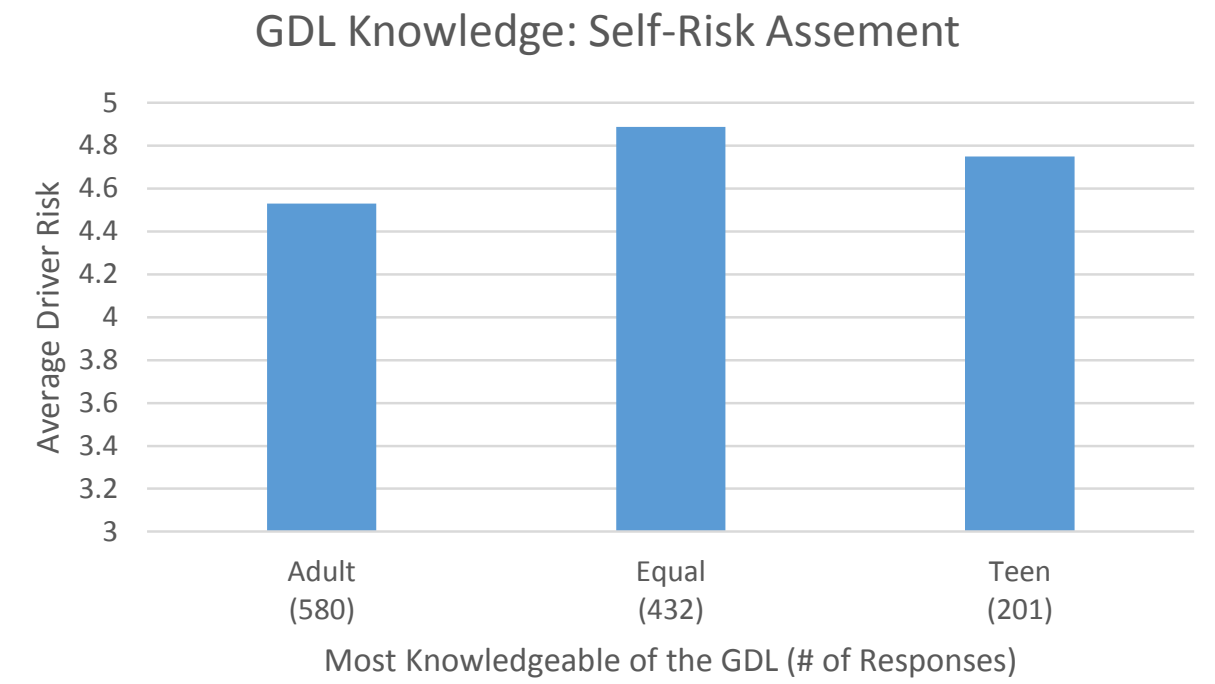

Figure 4-12: Comparing driving risk to whether or not the student believes they know more than their parents in regards to $G D L$

When further breaking down risk perception by age, it becomes apparent that these different groupings of students behave differently as they progress in age. Whether students thought they had more knowledge of the GDL, their parents did, or thought both were about equal, all show an increase in driver risk with each year on the road. Those who viewed both as equal showed the slightest average increase on driver risk as they progressed in age. For those who believed that adults had a better grasp on the GDL program, they showed a more significant increase in driver risk than the group who said they had equal understanding. The "Adult" group, falls between the two other categories at age 16 and consistently rises to approximately meet the "Equal" group at age 18.

At 16 years of age, students who responded that they believe they knew more about the GDL than their parents were less likely to engage in risky behaviors such as driving with other teen passengers and listening to loud music. This is partly due to the limitation placed on them via the GDL process. However at age 17, this trend inverts and this demographic is at the highest risk for participating in these activities which does not appear to fluctuate until 18 years of age. 
Two things that could cause this sudden increase are eagerness to obtain a level III license or over confidence in their abilities. When young drivers turn 17, some are eligible for their level III driver's license. This allows for all restrictions to be lifted except for zero alcohol tolerance. Young drivers in the "Teen" group may have a greater sense that they are ready for this added responsibility and could potentially take on greater responsibilities. Figure 4-13 demonstrates some of these theories.

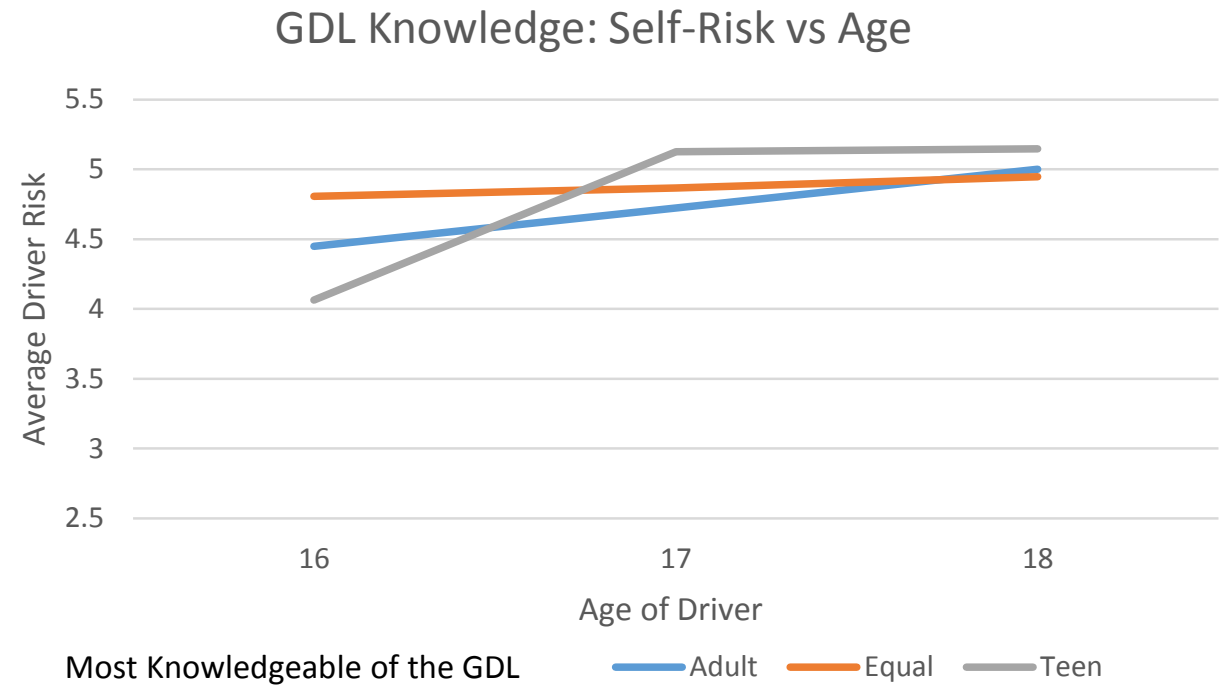

Figure 4-13: Change in driving risk compared to age in regards to who is believed to better understand GDL

Figure 4-14 indicates how self-reported knowledge stacks up against each individual student's likely to engage in high risk behaviors. Young drivers who engage in more risky behavior have an increased likelihood of having greater GDL knowledge, the same could also be said about parental knowledge; however it is on a more gradual increase. There also seems to be no linear correspondence between how frequently parental guardians use the GDL to enforce rules of their own and driver risk across both adults and teenagers. The trend does seem to suggest that low frequency enforcement, based on responses to the survey question relating to how frequently parents enforce GDL policy, leads to lower risk but higher GDL enforcement 
only equating to an average risk factor. From there, parental GDL enforcement slowly trails off as the risk factor increases.

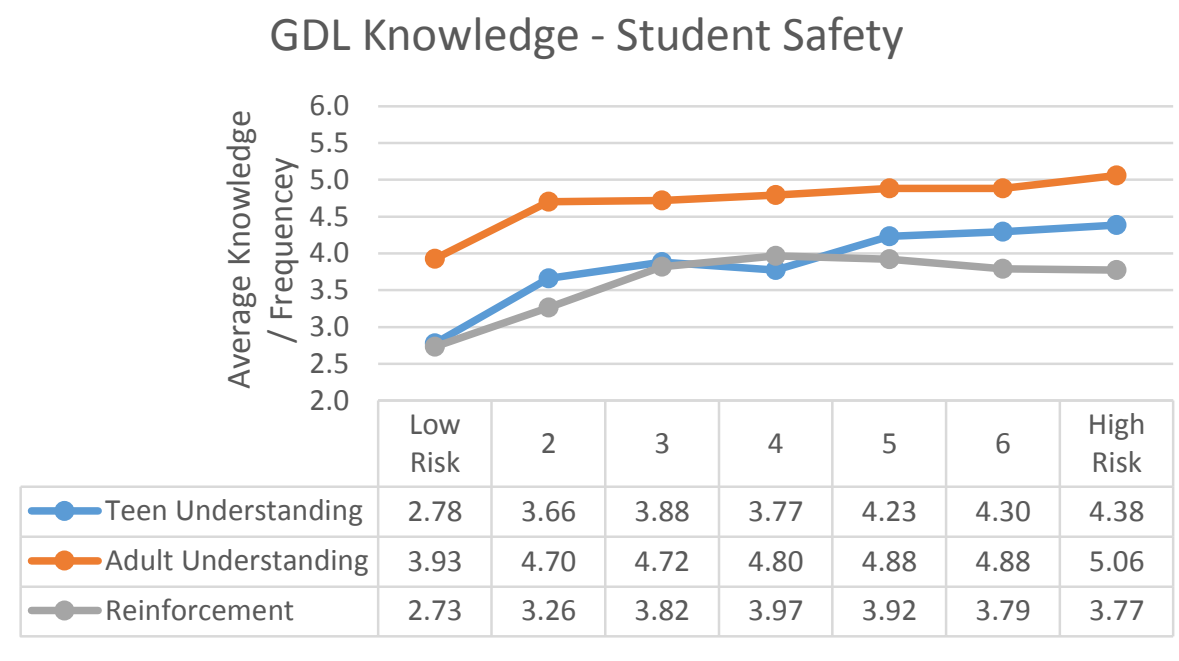

Average Driver Risk

Figure 4-14: Comparison of the change in risk compared to knowledge of GDL and parental enforcement

\subsection{2: Perceived Behavior}

The more knowledge one or one's parents have of the GDL, the more responsive the student is to the risky behaviors of others. The data suggested that there is little to no correlation between perceived knowledge and the frequency of GDL policy enforcement, though there is a small, positive correlation between teenage GDL knowledge and perceived teenage risk shown in Figure 4-15. 


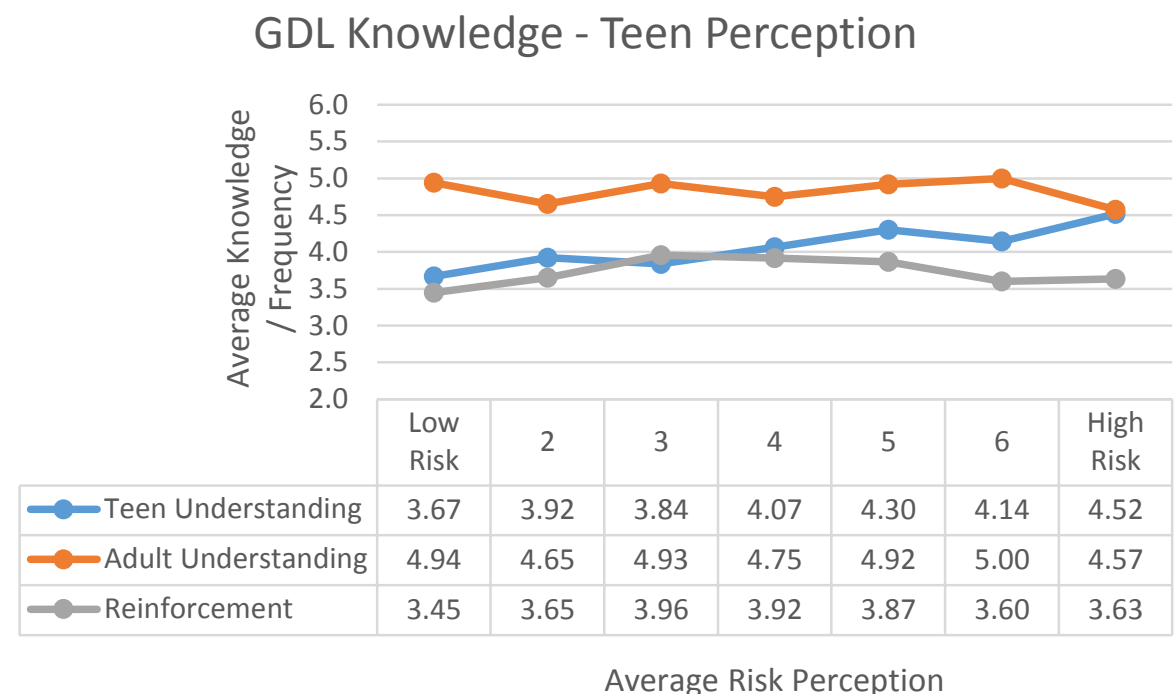

Figure 4-15 Comparison of the perceived risk of other teen compared to knowledge of GDL and how often parents enforce policies

When seeking correlation between knowledge of GDL and perceived risk, little is found. The largest correlation can be found with how much individual students believe they know about GDL and their perception on behavior of other teens (Table 4-8). This suggests the idea that the more aware of the law students are, the greater chance they have at noticing risky behavior from their peers.

Table 4-8: Correlation matrix for GDL knowledge to perceived safety and behavior

\begin{tabular}{|ccc|}
\hline \multicolumn{3}{|c|}{ Spearman Correlation } \\
\hline & Safety & Behavior \\
Teen & $26.3 \%$ & $27.3 \%$ \\
Adult & $10.5 \%$ & $5.2 \%$ \\
Reinforce & $16.6 \%$ & $5.2 \%$ \\
\hline
\end{tabular}

\subsection{3: GDL Restrictions}

Based on the data, students who observed high occurrences of others ignoring one type of GDL restriction are likely to see those ignoring others, however this tendencies do not necessarily translate to a correspondence to observed risk factors such as speeding and texting 
while driving. The likelihood for each observed violation does increase as the student approaches the age of 18 (Figure 4-16). Curfew and passenger restrictions can be lifted as early as 17 years of age which could partially effect the outcome. Students may not be aware at what age the law allows for passenger and curfew extensions, thus slightly inflating the value for these higher ages since some of their peers may be driving more friends around legally. Table 4-9 shows that both GDL violations have below a 7\% correlation with the perception of teenage risk taking behaviors (speeding, texting, talking on the phone, and eating while driving). However, ignoring curfew and passenger limit restriction has a spearman correlation of $80 \%$ which indicated that the students believe that these two happen at about the same rate of increase with age. The average of these values are also consistently within .2 points of each other across all ages. It can be concluded that the perception is that if students are going to ignore one GDL restriction, they are almost equally as likely to ignore others placed on them.

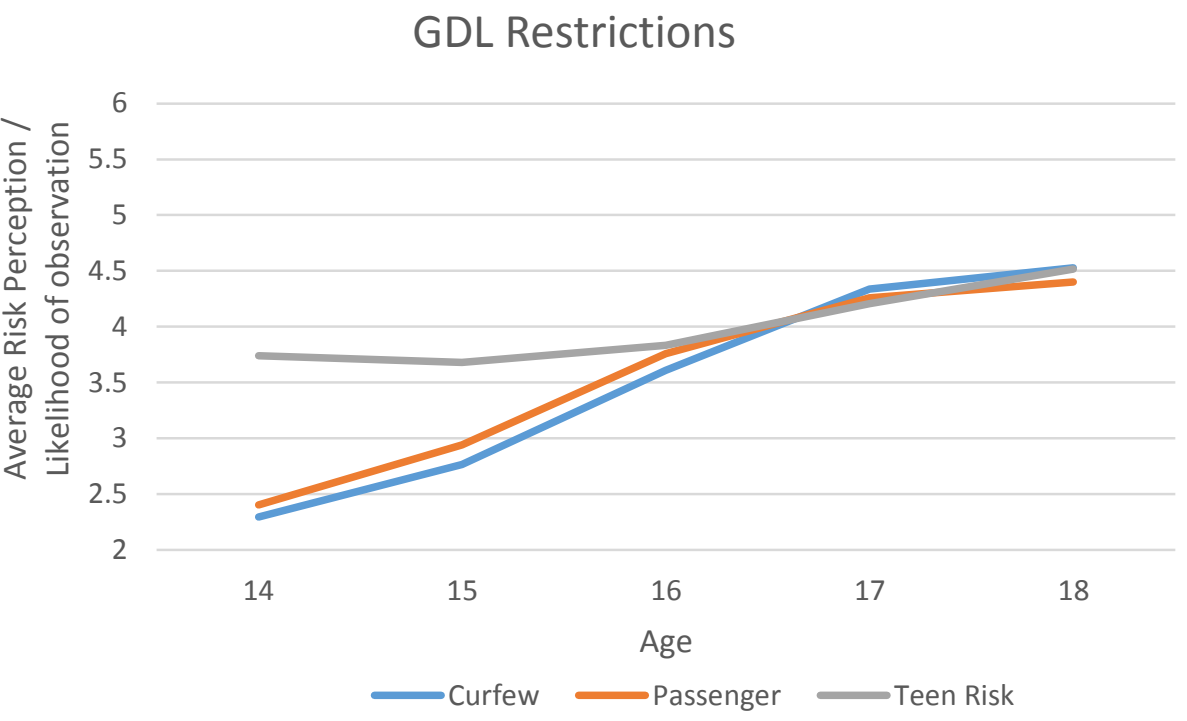

Figure 4-16: Change in the observation of behavior associated with violating GDL and perceived teenage risk 
Table 4-9: Correlation between behavior in violation of GDL and perceived teenage risk

\begin{tabular}{|lr|}
\hline \multicolumn{2}{|c|}{ Spearman Correlation } \\
\hline Curfew to Passenger & $80.2 \%$ \\
Curfew to Teen Risk & $5.1 \%$ \\
Passenger to Teen Risk & $6.7 \%$ \\
\hline
\end{tabular}

\subsection{4: GDL Knowledge and Perceived Risk}

Perceived self-knowledge has a low correlation with perceived teenage and adult risks with a spearman correlation of $27 \%$ and $21 \%$ respectively. However, the average perceived risk for both classifications do show a tendency to increase as the reported knowledge increases.

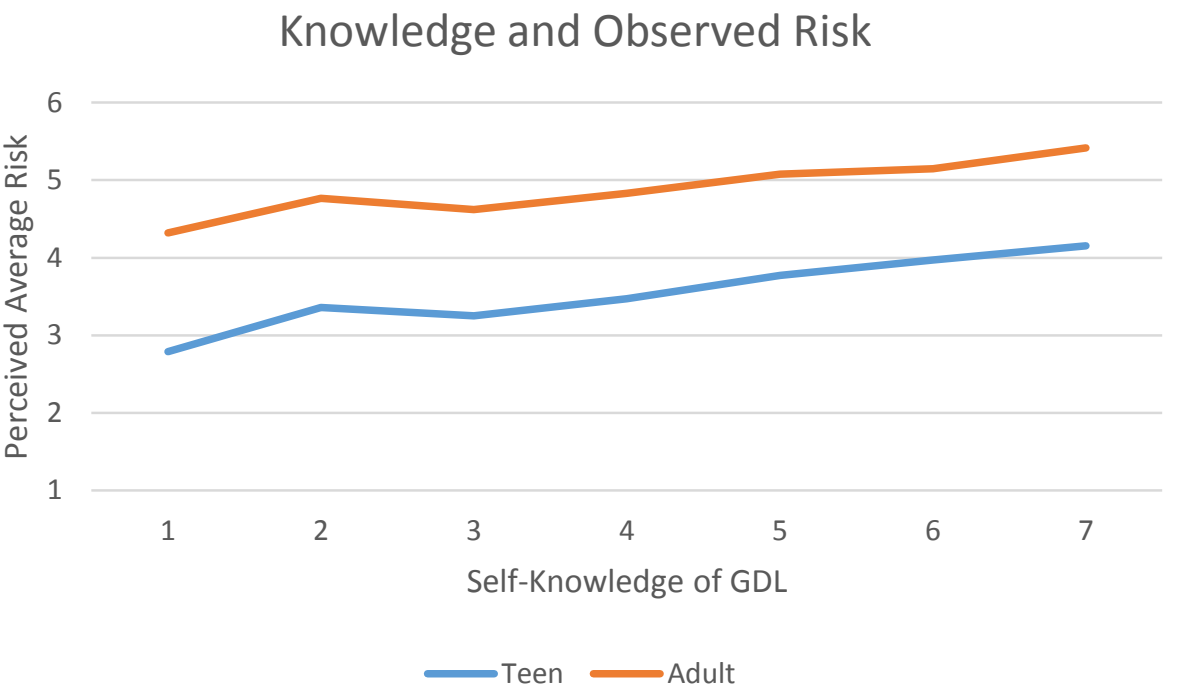

Figure 4-17: The correlation between perceived risk of teenage and adult with the self-assessment of the respondent's GDL knowledge

\section{4: Risky Behavior Correlation}

If teenagers experience one type of risky behavior, they are more likely to experience multiple. Figure 4-18 reiterates the fact that young drivers more frequently view adults engaging in high-risk activities than fellow teenagers. The most frequently observed behavior in adults is talking on the phone with speeding close behind, while the most frequently observed behavior in 
teenagers is speeding with eating being the second most. All categories of the perception of teenagers fall below what would be considered and average frequency of "4" while, across all risk factors, adults show average responses greater than "4".

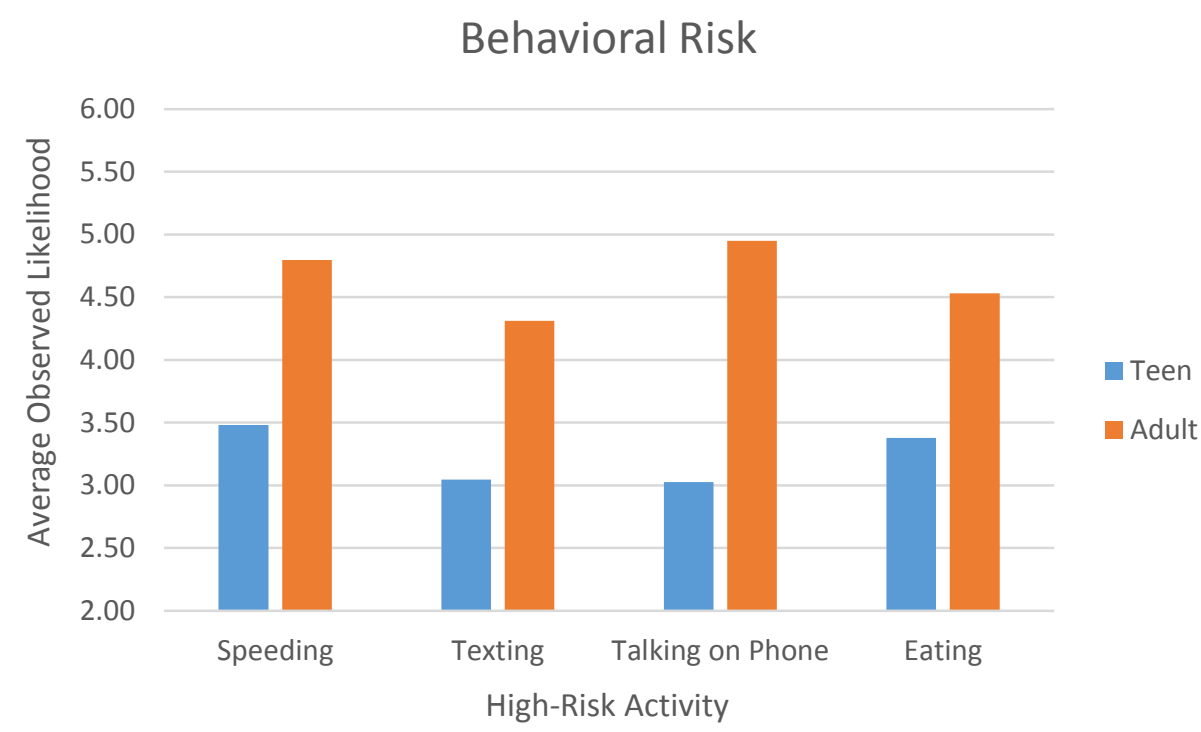

Figure 4-18: Likelihood of observing certain behaviors in teenagers and adults

Figure 4-19 shows a surface map of the number of responses for each correlation of average risk perception for adults and teenagers. Few individual respondents believed that teenagers were more likely to engage in risky behavior compared to their adult counterparts, this is represented by the low responses coming from the top left of the map. Most responses focus around an average risk perception for teenagers with an average to above average risk for adults. The number of responses trails off from there but leads more towards the top left of the map where both groups have a more frequently observed chance of partaking in high risk activities. A t-Test comparing teen and adult average perceived risk validated with $95 \%$ confidence that adults were perceived to take more risks than teenagers from the respondent's perspective. (Table 4-10). 


\section{Corresponding Behavioral Risk}

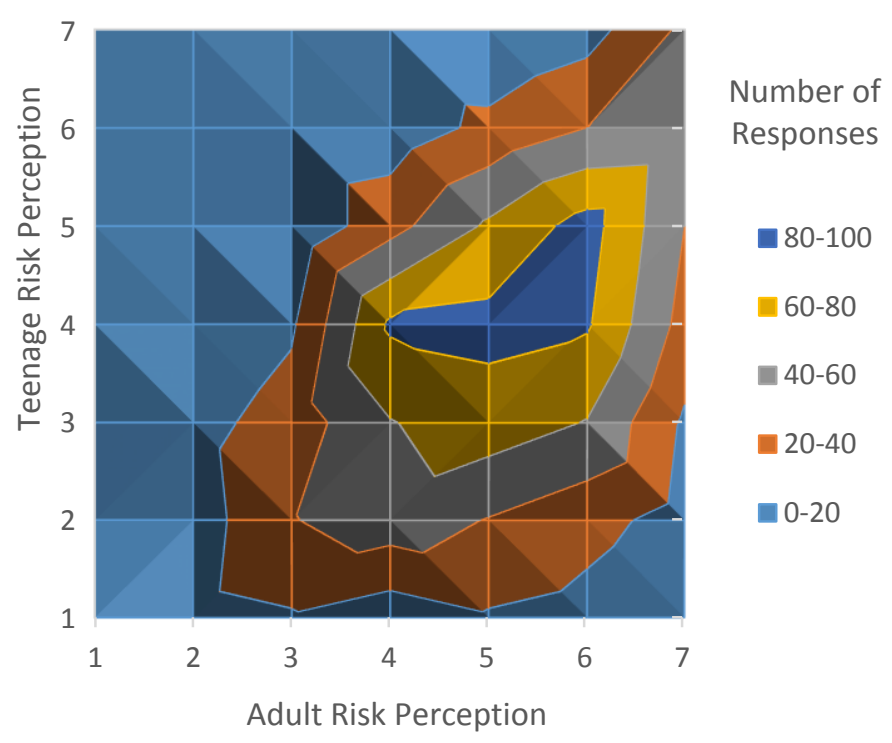

Figure 4-19: Surface map of the correspondence between the perception of teenage and adult drivers

Table 4-10: $t$-Test on the observed likelihood of partaking in risky behavior (teens and adults)

\begin{tabular}{lrr}
\hline \multicolumn{1}{c}{ Behavioral Risk t-Test } & \multicolumn{1}{c}{ Teen } & \multicolumn{1}{c}{ Adult } \\
\hline Mean & 3.23 & 4.66 \\
Variance & 2.54 & 2.28 \\
Observations & 2083 & 2083 \\
Hypothesized Mean Difference & 0 & \\
df & 4152 & \\
t Stat & -29.56 & \\
P(T<=t) one-tail & $9.299 \mathrm{E}-175$ & \\
$\mathrm{t}$ Critical one-tail & 1.65 & \\
$\mathrm{P}(\mathrm{T}<=\mathrm{t})$ two-tail & $1.86 \mathrm{E}-174$ & \\
$\mathrm{t}$ Critical two-tail & 1.96 & \\
\hline
\end{tabular}

A spearman correlation matrix can be found below in Table 4-11. This matrix compares the correlation between the observed frequency of each risky behavior for both adults and teenagers. The analysis indicates that the largest correlation exists for texting and talking for both adults and teenagers at $79 \%$ and $77 \%$ respectively. Overall, the correlation of any one activity for adults to all the others was slightly greater than the correlation of the teenage activities within its 
own categories and there was little correlation across the two separate categories with the highest correlation being eating and driving followed by speeding. Texting and talking on the phone are both risky behaviors that involve the same device, so their strong correlation is to be expected. The correlation between eating and texting for both categories can be explained by both activities requiring additional hand movement within the vehicle that distracts the driver from steering. Speeding is an outlier in this data set, as speeding is not in the same classification as distracted driving.

Table 4-11: Spearman Correlation between likelihood in observing a combination of different behaviors

\begin{tabular}{|c|c|c|c|c|c|c|c|c|c|}
\hline \multirow{2}{*}{\multicolumn{2}{|c|}{$\begin{array}{l}\text { Behavior } \\
\text { Correlation }\end{array}$}} & \multicolumn{4}{|c|}{ Teen } & \multicolumn{4}{|c|}{ Adult } \\
\hline & & \multirow[t]{2}{*}{ Speed } & \multirow{2}{*}{$\begin{array}{l}\text { Text } \\
49 \%\end{array}$} & \multirow{2}{*}{$\frac{\text { Talk }}{47 \%}$} & \multirow{2}{*}{$\frac{\text { Eat }}{46 \%}$} & \multirow{2}{*}{$\frac{\text { Speed }}{40 \%}$} & \multirow{2}{*}{$\begin{array}{l}\text { Text } \\
25 \%\end{array}$} & \multirow{2}{*}{$\frac{\text { Talk }}{29 \%}$} & \multirow{2}{*}{$\frac{\text { Eat }}{26 \%}$} \\
\hline \multirow{4}{*}{ 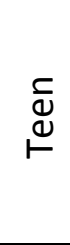 } & Speed & & & & & & & & \\
\hline & Text & $49 \%$ & & $79 \%$ & $64 \%$ & $35 \%$ & $38 \%$ & $35 \%$ & $33 \%$ \\
\hline & Talk & $47 \%$ & $79 \%$ & & $68 \%$ & $32 \%$ & $36 \%$ & $38 \%$ & $34 \%$ \\
\hline & Eat & $46 \%$ & $64 \%$ & $68 \%$ & & $38 \%$ & $35 \%$ & $36 \%$ & $48 \%$ \\
\hline \multirow{4}{*}{$\frac{ \pm}{\frac{5}{3}}$} & Speed & $40 \%$ & $35 \%$ & $32 \%$ & $38 \%$ & & $58 \%$ & $61 \%$ & $53 \%$ \\
\hline & Text & $25 \%$ & $38 \%$ & $36 \%$ & $35 \%$ & $58 \%$ & & $77 \%$ & $59 \%$ \\
\hline & Talk & $29 \%$ & $35 \%$ & $38 \%$ & $36 \%$ & $61 \%$ & $77 \%$ & & $65 \%$ \\
\hline & Eat & $26 \%$ & $33 \%$ & $34 \%$ & $48 \%$ & $53 \%$ & $59 \%$ & $65 \%$ & \\
\hline
\end{tabular}

\section{5: Effects of Loud Music}

The tendency to listen to loud music increases with age during teenage years based on the survey responses. Over time, drivers may become more accustomed to driving and be willing to take the risk of listening to louder music, thus creating more distraction. Both Figure 4-20 and Figure 4-21 support this claim with an overall increase each year. The likelihood to listen to loud music while in a vehicle increases at a rate of $5.5 \%$ per year of age, but $14.5 \%$ with years since acquiring an instructional permit. This lends itself to the idea that more driving experience 
contributes more to your listening habits than age itself since the rate of increased likelihood is steeper for the former.

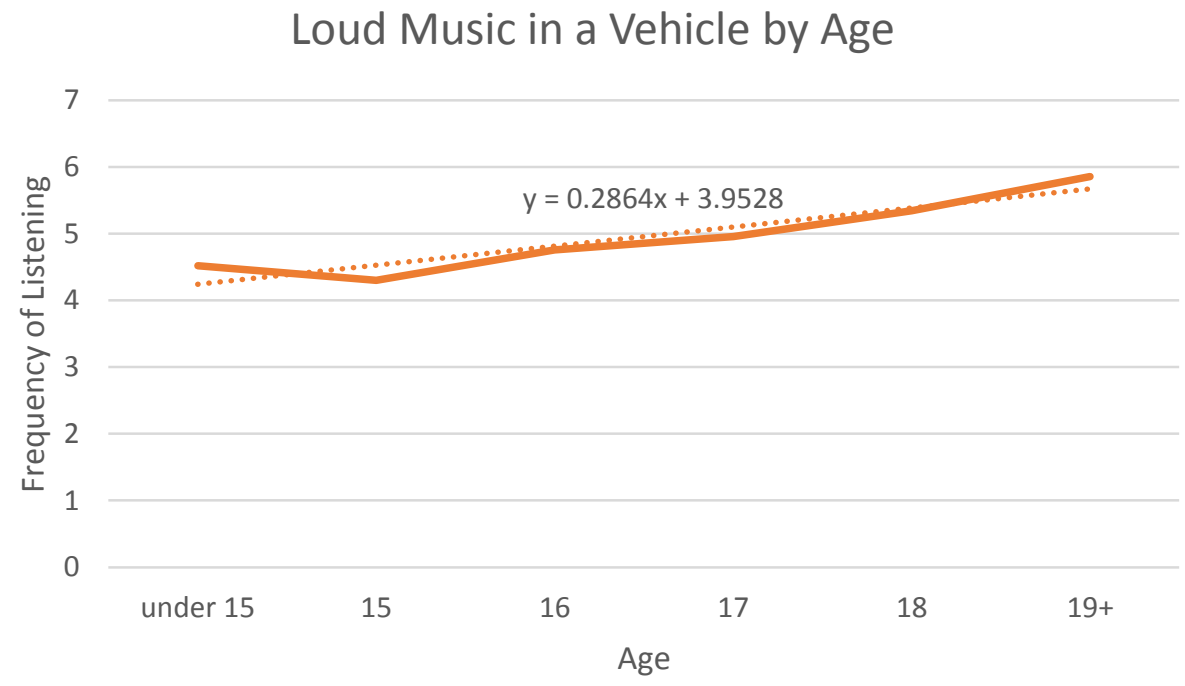

Figure 4-20: Likelihood of listening to loud music while in a vehicle by age

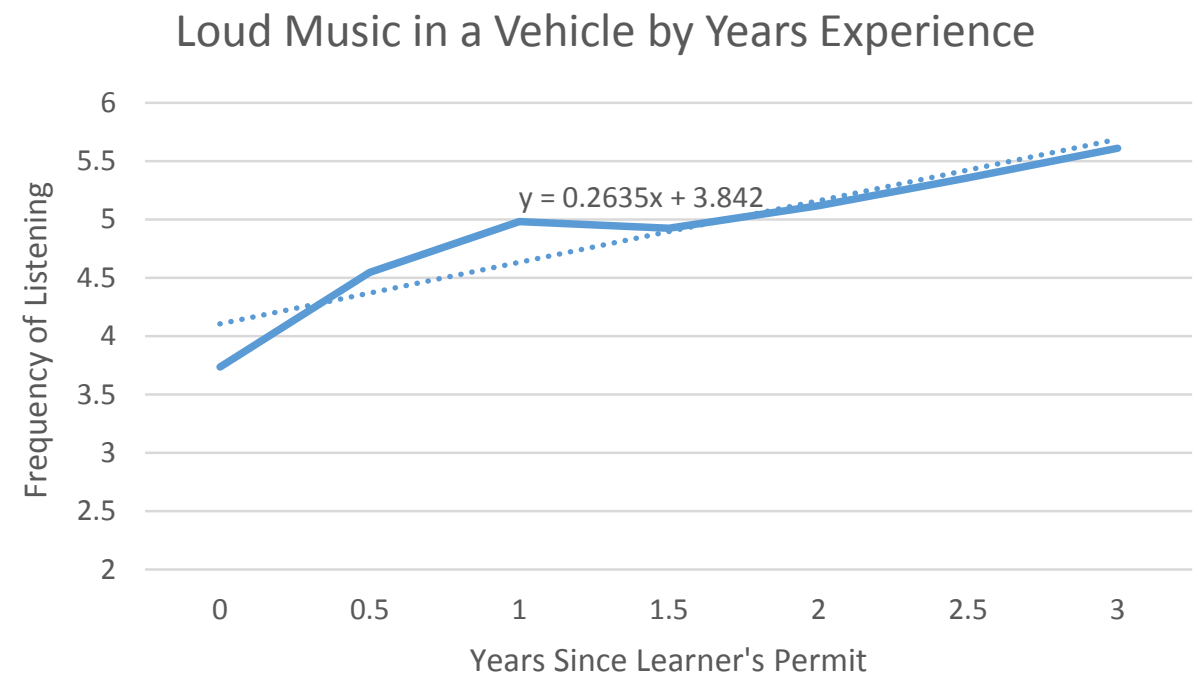

Figure 4-21: Likelihood of listening to loud music while in a vehicle by years driving 


\section{6: Passenger Effects}

The more often teenagers drive other people (especially other teens), the more likely they are to engage in risky behavior (Simons-Morton, Lerner, \& Singer, 2005). Figure 4-22 shows how the combined perceived risk behavior of both teenager passengers and all passengers increased steadily with age. Since the questions were asked in the method of "frequency of all passengers" and "frequency of teen passengers", an estimation of the percent of time students drive other teenagers can be estimated. This was accomplished simply by dividing the average frequency of driving with teenage passengers by the average frequency of driving with all passengers. The result of this suggests that the more frequently teenage drivers drove their peers compared to adults in their life, the more likely they were to observe risky behavior. Since " 1 " is equivalent to never driving with other passengers, it can be considered an outlier in the mentioned trend. Drivers would very infrequently ride with passengers in the car only drove other teenagers $75 \%$ of the time and had overall perceived risk of " 3 " while students who always drove with passengers, drove with other teens $95 \%$ of the time and had a total perceived risk of just under " 6 ". 


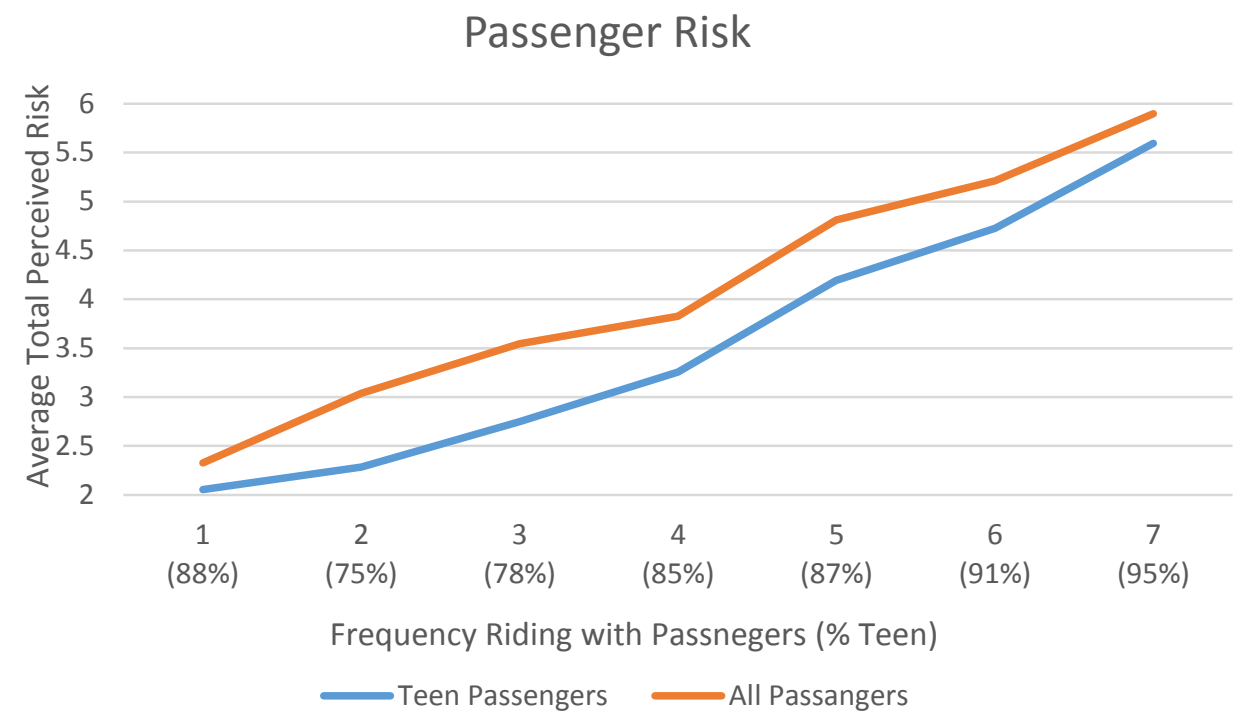

Figure 4-22: Comparison between the frequency one would ride with passengers and combined perceived risk of teens and adults

Correlation rates involving passenger type observed risk were generally low with the highest being the correlation between total perceived risk and teen passengers (Table 4-12). This falls in line with data suggesting that young drivers are at greater risks with teenage passengers (Curry, Mirrman, Kallan, Winston, \& Durbin, 2012).

Table 4-12: Correlation between total observed risk and type of passengers

\begin{tabular}{|lr|}
\hline \multicolumn{2}{|c|}{ Spearman Correlation } \\
\hline & Total Risk \\
All Passengers & $36.1 \%$ \\
Teen Passengers & $40.2 \%$ \\
Ride with Teens & $30.8 \%$ \\
\hline
\end{tabular}

\section{7: Multiple Teenage Driver Household}

Having another teenage driver in the household is associated with safer driving habits. On average, students who have a sibling or other housemate in their teens are $7 \%$ less likely to observe risky behavior. Students who responded "No Teenage Drivers in Household" are 
students who do not drive and have siblings that drive either. These students show a lower perceived risk due to their limited exposure driving Figure 4-23).

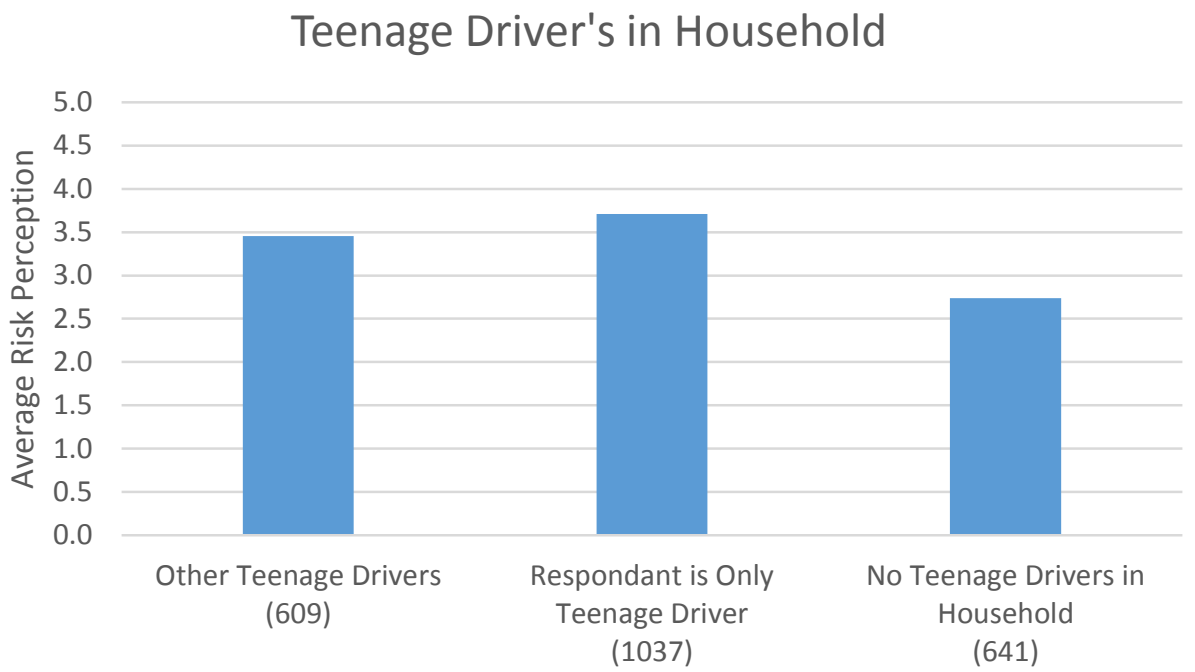

Figure 4-23: Graph of perceived teenage risk by other household young drivers

\section{8: Driving Trip Purpose}

Drivers who primarily drive for social reasons are more likely to engage in behavior which could put them at risk (riding with teenage passengers and speeding). Figure 4-24 shows a detailed breakdown of the driver risk responses separated by primary driving destination. The two categories more likely to have an association with engaging in these behaviors are for social reasons or to and from class. $22 \%$ of the students drove themselves to school while only $32 \%$ had their intermediate license; this indicates that $69 \%$ of students able to drive to school are doing so. Social and recreational reasons are the next most frequent destination with work purposes making up only $8 \%$ of all trips. Those who drove primarily for house hold tasks were the least likely to carry teenage passengers or listen to loud music. The data suggests that students who drive on more of a necessity basis (not for social purposes) could be considered less likely to engage in high risk behaviors. 


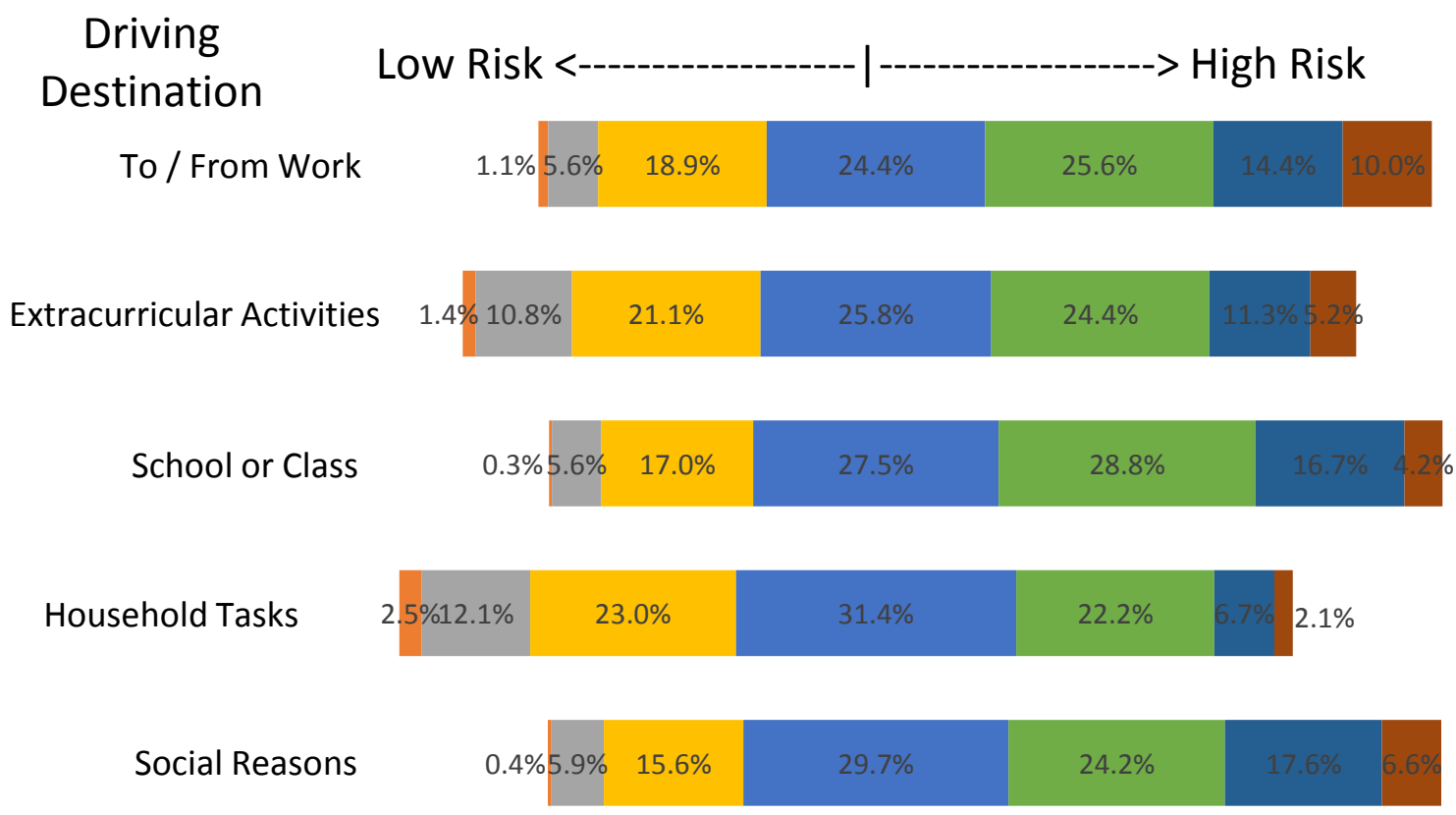

Figure 4-24: self-risk factors by driving destination

\section{9: Vehicle Type}

Vehicle type does not appear to have an influence on likelihood of engaging in high-risk activities (Figure 4-25). When performing a chi squared test, it was determined that there is little significant correlation between self-risk and vehicle type with a result of $p=0.29$. Motorcycles are typically labeled as inherently more dangerous vehicles on their own as they require a separate license endorsement in West Virginia, however the survey was designed to evaluate risk taking and not the nature of the vehicle itself. That being said, motorcycles do tend to fall on the higher end of the driver-risk spectrum compared to vehicle types such as trucks, compact-cars, and vans. Further research would need to be done specifically on how vehicle type impacts likelihood of engaging in high-risk behaviors as it is outside the scope of this survey. 


\section{Driving Risk for Vehicle Type}

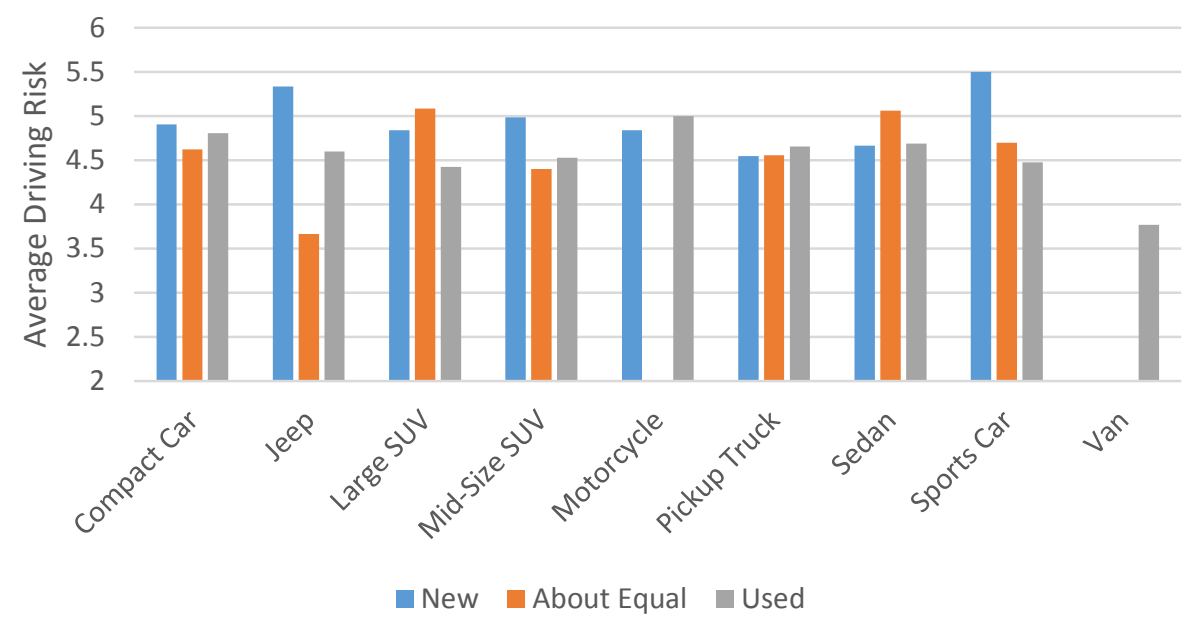

Figure 4-25: Graph of perceived teenage risk by vehicle type and condition 


\section{0: Conclusions}

Many believe the GDL program is sufficient in regards to preparing young drivers for being on the road (Williams, Tefft, \& Grabowski, 2012). However, the GDL relies heavily on parental input and does little to address the behavioral aspect of teenage drivers. These rules and regulation are often ignored by teenage drivers and it becomes more frequent with age. More strikingly, 2 out of 10 law enforcement officers did not know or were unsure about the graduated drivers licensing program and only half of officers knew the specific parameters behind curfew and passengers restrictions (Noble, Martinelli, Unnikrishnan, \& Martinelli, 2012). This, combined with the difficulties to enforce GDL policy, create a system where rules themselves are not necessarily enough to provide young drivers with the safest driving experience.

Another notable the increase of observed high-risk activities with age. Across multiple analyses, this was found to be the strongest factor. As age increased, so did the likelihood of observing high-risk behavior in both teenagers and adults. Also, the older students claimed observations of teenage risk that were more inline, although still below, the frequency of observed risk in adults. This suggests that older students are less susceptible to programs targeted towards the need for further education to improve driving habits since these students may feel that they and their peers are already driving at the same ability level as adults. This isn't to say that programs would be ineffective, it just suggests that the same program model would not be applicable to the entire age range that exists in high school.

Driver Education is an important course, but it is not necessarily offered across the state and, even when implemented, students can have different experiences. West Virginia does not require driver education in order to obtain a driver license, this has potential for the class to fill 
with more senior students. This study suggests that students who take driver education courses are more likely to observe risky behavior in their peers which can be attributed to their increased knowledge and understand of what is high-risk behavior. However, as the students age, this effect becomes significantly reduced. Students who report taking drivers education at age 15 are $14 \%$ more likely to observe risky behavior while those at age 17 show only a $2 \%$ increase. This isn't to say that driver education in this demographic, there just isn't a significant change in perceived risk of peers.

Part of the dilemma with young drivers is that they overestimate the knowledge of adults in their lives. This creates a skewed perspective that can affect the students' learning abilities. Without a proper reference frame, some students may believe that their parents are the ones that are most knowledgeable about the rules and regulations of driving when, in some cases, their classmates may have the better understanding as they are currently going through the same program.

\section{1: Recommendations}

Where the GDL places restrictions on certain high-risk actions, it is important to go beyond the simple restriction and tap into what makes teenagers want to engage in risky behaviors in the first place and reduce those thoughts at the source. Improved early education in middle and high schools and more consistent post-licensing follow-ups are both ways to achieve this. All drivers are susceptible to social influence, this is especially true at a young age; targeting these influences and invoking a responsible attitude will address what the GDL cannot.

Third party counseling is a possible way of influencing the behavior of young drivers beyond parental input. Schools seem to be the most common resource for students when it comes 
to preparing students for the trials of driving, however a recent survey of U.S. pediatricians found that $89 \%$ of these pediatric institutes do counseling about driving to varying degrees (Weiss, O'Neill, Shope, O'Connor, \& Levin, 2012). 41\% touched on the dangers of transporting teen passengers, $23 \%$ spoke about the importance of parental limitation, $21 \%$ about night driving, and only $13 \%$ about GDL.

The most successful program as defined by practicality and widespread use is "Teens in the Driver Seat (TDS)" (Henk \& Fette, 2009). One of the serious problems identified by past research, as well as GDL Phase I, is the limited knowledge students and their parents have on the subject of GDL. This lack of knowledge and misconceptions many students hold would make Monongalia County an ideal location to implement a trial run of such a program for the rest of the state. TDS is a nationwide program which is already designed to be integrated with the school system and has a proven record of reducing incidents and. The appeal of this peer-led program allows students to not only learn more about safe driving, but to become a shaping factor in the best and most efficient way of educating their peers. Getting students involved is one of the biggest strengths of this program, something which traditional GDL education lacks, Implementing the TDS program in select schools will not only be a step in the right direction towards better educating students of the dangers of driving, but a step forward for changing a culture on a peer-to-peer level.

Before the implementation of any state-wide program, an area of study should be selected and properly evaluated. One issue with current research, GDL especially, is that there is little to no research targeted towards before and after effects of program implementation; most existing reports rely heavily on crash data. 
In order to best prepare for the execution of a program such as "Teens in the Driver Seat", target school districts need to be established for the trial and control regions. "After GDL, what's next?" (Henk \& Fette, 2009) excellently outlines a study done with the initial implementation of TDS in 2007 involving two school districts in Texas. A similar study could be done in West Virginia over the course of 3 years, or this trial period could be bypassed altogether operating under the umbrella of tried and proved concept. Regardless of the plan of action, the state of West Virginia needs a system in place to properly monitor the effects of such a program in order to provide a safe future for the teenage drivers of the state.

\section{2: Future Research}

One of the goals of this study was to better understand the behavioral aspect of high school students in West Virginia and how these attitudes related to driving. While the study succeeded at highlighting some important elements such as the misconceptions students have about their parents understanding of driving regulations or the impact of taking driver education earlier in schooling, many things still need to be studied in further detail.

Among these future studies could be a survey that covers a larger portion of the state. Where the existing survey is limited in nature, the ability to work closely with the school did provided high response numbers and a more complete response base. Smaller samples from schools across the state would be able to better confirm the results shown in this study. This would also provide a better base for the population density results that distinguish between rural and urban high schools to see if lower density areas have higher high-risk observance rates across the state. 
Driver education could use a dedicated study to see the exact impact the program is having on the students who enroll in the state of West Virginia. Early signs from this study point towards it being more beneficial at earlier ages, but to what extent? Due to limited state-wide regulations, what is the condition of the program across all schools in the state and what percent of schools actually offer these programs? It is recommended that any study also takes into consideration the behavioral aspect of these students, as knowledge alone is not always an accurate representation of how well a program is functioning.

Several categories shows limited results, such as the effects of driving different vehicles, the types of household environments, and the types of trip the teenage driver is likely to take. If more information is desired about how each of these factors affects the behavior of young driver, more specific research needs to be conducted on each of these factors individually.

Phase I of the GDL study targeted knowledge (Noble, Martinelli, Unnikrishnan, \& Martinelli, 2012) while this study was more focused on the perception of young drivers. Another study could focus on the perspective of parents to see if the same results are encountered or if their truly is a gap in the way teenagers and adults both understand driving. Additionally, future research taking what was learned from both of these studies could implement a two-part survey which evaluates the perception both students and parents have towards driving and then creates a follow-up study on what the actual understanding and adherence to regulation of both parties. Regardless, more needs to be done in the state of West Virginia to better understand the behavioral side of young drivers and adults to better address the engagement in high-risk activities. 


\section{0: References}

Alabama State Data Center. (2015). Urban Rural by State 2010. Retrieved 4 16, 2016, from Center for Business and Economic Research: http://cber.cba.ua.edu/edata/census2010/Urban\%20Rural\%20by\%20State\%202010\%20s hort\%20ver.xls

Brodsky, W. (2002). The effects of music tempo on simulated driving performance and vehicular control. Transportation Research Part F, 219-241.

Brown, R., \& Ogden, J. (2002). Children's eating attitudes and behaviour: a study of the modelling and control theories of parental influence. London, UK: Guys Kings and St Thomas' School of Medicine.

Bukowski, W. M., \& Adams, R. (2005). Peer relationships and psychopathology: Markers, moderators, mediators, mechanisms and meanings. Journal of Clinical Child and Adolescent, 34, 3-10.

CDC, Division of Adolescent and School Health. (2014). 2013 YRBS Data User's Guide. Atlanta, GA: National Center for HIV/AIDS, Viral Hepatitis, STD, and TB Prevention.

Centers for Disease Control and Prevention. (2015, October 14). Injury Prevention \& Control: Motor Vehicle Safety. Retrieved from Centers for Disease Control and Prevention: http://www.cdc.gov/motorvehiclesafety/teen_drivers/teendrivers_factsheet.html

Chambers, R. A., Taylor, J. R., \& Potenza, M. N. (2003). Developmental neurocircuitry of motivation in adolescence: A critical period of addiction vulnerability. American Journal of Psychiatry, 1041-1052. 
Chaudhary, N., Bayer, L., Ledingham, K., \& Casanova, T. (2011). Driver Education Practices In Selected States. Washington, DC: National Highway Traffic Safety Administration Office of Behavioral Safety Research.

Clark-Kevan, M., Hamilton, G., \& Shults, R. A. (2010). Teen Driving: Skills, Responsibilities and Reactions. Centers for Disease Control and Prevention.

Corasaniti, N., \& Williams, J. (2013, March 16). Evolution of the New York Driver's License. The New York Times. New York, NY: The New York Times Company.

Curry, A. E., Mirrman, J. H., Kallan, M. J., Winston, F. K., \& Durbin, D. R. (2012). Peer Passengers: How Do They Affect Teen Crashes? Journal of Adolescent Health.

Dargay, J., Gately, D., \& Sommer, M. (2007). Vehicle Ownership and Income Growth, Worldwide: 1960-2030 . Institute for Transport Studies, University of Leeds .

DiClemente, R. J. (1993). Confronting the challenge of AIDS among adolescents - Directions for future research. The Journal of Adolescent Research, 8, 156-166.

Division of Adolescent and School Health, National Center for HIV/AIDS, Viral Hepatitis, STD, and TB Prevention. (2015, 5 15). Youth Risk Behavior Surveillance System (YRBSS) Overview. Retrieved from Adolescent and School Health: http://www.cdc.gov/healthyyouth/data/yrbs/overview.htm

DMV Practice Tests in West Virginia. (2016). Retrieved from DMV.ORG: http://www.dmv.org/wv-west-virginia/practice-tests/ 
Education, WV Board of. (2011). Next Generation Driver Education Content Standards and Objectives for West Virginia Schools (2520.8). Series 44H. Charleston, WV: WV Board of Education.

FARS. (2012). Federal Analysis Reporting System. Washington, DC: National Highway Traffic Safety Administration.

Goodwin, A. H., O'Brien, N. P., \& Foss, R. D. (2012). Effect of North Carolina's restriction on teenage driver cell phone use two years after implementation. Accident Analysis, 48, 363367.

Governing. (2014). Car Ownership in U.S. Cities Map. Retrieved 4 17, 2016, from Governing the States and Localities: http://www.governing.com/gov-data/car-ownership-numbersof-vehicles-by-city-map.html

Gregersen, N. P., Berg, H. -Y., I., E., S., N., Nyberg, A., \& Rimmo, P. -A. (2000). Sixteen years age limit for learner drivers in Sweden - an evaluation of safety effects. Accident Analysis and Prevention, 25-35.

Gruffyydd, C. (2014, January 17). A Brief History of the American Driver's License. Retrieved from Grounded Parents: https:/groundedparents.com/2014/01/17/a-brief-history-of-theamerican-drivers-license/

Hartos, J., Eitel, P., \& Simons-Morton, B. (2002). Parenting Practices and Adolescent Risky Driving: A Three-Month Prospective Study. Health Education \& Behavior, 194-206.

Hatfield, J., \& Fernandes, R. (2009). The role of risk-propensity in the risky driving of younger drivers. Accident Analysis and Prevention, 25-35. 
Hedlund, J., Shults, R. A., \& Compton, R. (2006). Graduated driver licensing and teenage driving research in 2006. Journal of Safety Research, 37, 107-121.

Henk, R. H., \& Fette, B. (2009). After GDL, what's next? The role of peer influence in reducing car crashes among young drivers. Dallas, TX: Texas Transportation Institute.

IIHS, I. I. (2016). Teenagers. Retrieved from IIHS Highway Loss Data Institute: http://www.iihs.org/iihs/topics/laws/graduatedlicenseintro

Irwin, J. (2011, 12 12). West Virginia population density map. Retrieved 4 17, 2016

Jonah, B. A., \& Dawson, N. E. (1987, July). Youth and Risk: Age Differences in Risky Driving, Risk Perception, and Risk Utility. Alcohol Drugs and Driving, 13-29.

Lautieri, A. (2013). How Gender Affects Auto Insurance Rates. Retrieved from DMV.ORG: http://www.dmv.org/insurance/how-gender-affects-auto-insurance-rates.php

Lotan, T., Toledo, T., Prato, C. G., Yarok, O., \& Hasharon, H. (2010). Modeling the behaviour of novice young drivers using data from in-vehicle data recorders. Proceedings of the Fifth International Driving Symposium on Human Factors in Driver Assessment, Training and Vehicle Design, 491-498.

Manno, M., Maranda, L., Rook, A., Hirschfeld, R., \& Hirsh, M. (2012). The reality of teenage driving: The results of a driving educational experience for teens in the juvenile court system. Philadelphia, PA: Lippincott Williams \& Wilkins.

Mattox, P. A., \& Smith, T. J. (2007). West Virginia Strategic Highway Safety Plan. Charleston, WV: West Virginia Highway Safety Management Task Force. 
Mawson, A. R., \& Walley, E. K. (2014). Toward and Effective Long-Term Strategy for Preventing Motor Vehicle Crashes and Injuries. Basel, Switzerland: MDPI AG.

McCartt, A. T., Shabanova, V. I., \& Leaf, W. A. (2001). Driving experience, crashes and traffic citations of teenage beginning drivers. Trumbull, CT: Preusser Research Group Inc.

McCartt, A. T.; Teoh, E. R.; Fields, M.; Braitman, K. A.; Hellinga, L. A. (2010). Graduated licensing laws and fatal crashes of teenage drivers: a national study. Traffic Injury Prevention, 11, 240-248.

McKnight, A. J., \& McKnight, A. S. (2000). The bahavioral contributiors to highway crashes for youthful drivers. In Proceedings of the 44th Annual Conference of the Association for the Advancement of Automotive Medicine (pp. 321-33). Des Plaines, IL, IL: Association for the Advancement of Automotive Medicine.

Moretti, R., \& Kelly, C. B. (2015). Rural Connections: Challenges and Opportunities in America's Heartland. Washington, DC: TRIP.

National Museum of American History. (n.d.). Americans Adopt the Auto. Retrieved from America on the Move: http://amhistory.si.edu/onthemove/exhibition/exhibition_1_1.html

NHTSA, N. H. (2015). 2014 Crash Data Key Findings. Washington, DC: NHTSA's National Center for Statistics and Analysis.

NHTSA, N. H. (2015). Traffic Safety Facts, Young Drivers. Washington, DC: NHTSA's National Center for Statistics and Analysis.

NHTSA's National Center for Statistical Analysis. (2013). Traffic Safety Facts. Washington, DC: U.S. Department of Transportation. 
NHTSA's National Center for Statistics and Analysis. (2012). Traffic Safety Facts. Washington, DC: U.S. Department of Transportation.

Noble, A. M., Martinelli, D. R., Unnikrishnan, A., \& Martinelli, D. (2012). An Analysis of West Virginia's Graduated Driver Licensing Program. Morgantown, WV: West Virginia University.

North, A., \& Hargreaves, D. (1999). Music and Driving Game Performance. Scandinavian Journal of Psychology, 285-292.

Paris, V. (2008). "It's Not Me Driving Dangerously - It's Them". Erie, PA: Erie Insurance.

Ramirez, M., Yang, J., Young, T., Roth, L., Garinger, A., Snetselaar, L., \& Peek-Asa, C. (2013). Implementation evaluation of steering teens safe: engaging parents to deliver a new parent-based teen driving intervention to their teens. Health Education and Behavior.

Romer, D. (2010). Adolescent Risk Taking, Impulsivity, and Brain Development: Implications for Prevention. Philadelphia, PA: Annenberg Public Policy Center University of Pennsylvania.

Romer, D., \& Hennessy, M. (2007). A biosocial-affect model of adolescent sensation seeking: The role of affect evaluation and peer-group influence in adolescent drug use. Prevention Science, 89-101.

safedriver. (2013, August 22). When does knowledge turn into skill? Retrieved from The Safe Driver: https://safedriving.wordpress.com/2013/08/22/when-does-knowledge-turn-intoskill/ 
Sarkar, S., \& Andreas, M. (2004). Acceptance of and engagement in risky driving behaviors by teenagers. Boca Raton, FL: Florida Atlantic University.

Sela-Shayovitz, R. (2008, March). Young drivers' perceptions of peer pressure, driving under the influence of alcohol and drugs, and involvement in road accidents. Criminal Justice Studies, 21, 3-14.

Sexton, B., \& Grayson, G. (2009). PPR 429. Bracknell, UK: Transportation Research Laboratory.

Shults, R. A., \& Ali, B. (2010). Drivers aged 16 or 17 years involved in fatal crashes-United States, 2004-2008. MMWR Morbidity and Mortality Weekly Report.

Simons-Morton, B., Lerner, N., \& Singer, J. (2005). The observed effects of teenage passengers on the risky driving behavior of teenage drivers. Accidnet Analysis and Prevention, 973982.

Smith, A. (2011). Americans and Text Messaging. Washington, D.C.: Pew Research Center.

St. Martin, V. (2010, 5 5). N.J. teens refuse to use red decal stickers required by Kyleigh's Law. Retrieved 4 16, 2016, from NJ.com: http://www.nj.com/news/index.ssf/2010/05/nj_teens_refuse_to_use_decal_s.html

State of New Jersey Motor Vehicle Commission. (2015). Graduated Driver License. Retrieved 4 16, 2016, from NJ Motor Vehicle Commission: http://www.state.nj.us/mvc/About/safety_gdl.htm 
Taubman, O., Ari, B., Kaplan, S., Lotan, T., \& Prato, C. G. (2015). Parents' and peers' contribution to risky driving of male teen drivers. Accident Analysis and Prevention, 8186.

Teens in the Driver Seat. (2016). About Us. Retrieved 4 15, 2016, from Teens in the Driver Seat: http://www.t-driver.com/

Teens in the Driver Seat. (2016). Steps to Starting TDS at Your School. Retrieved 4 16, 2016, from Teens in the Driver Seat: http://www.t-driver.com/be-involved/start-tds/

University of Iowa College of Public Health. (2014). What is 'Steering Teens Safe'? Retrieved 4 16, 2016, from Steering Teens Safe A Parent Guide for Safe Teen Driving: https://www.public-health.uiowa.edu/driving/learnmore.php

US DOT FHA. (2014). Statista. Retrieved 4 17, 2016, from Number of vehicles registered in the United States from 1990 to 2013 (in 1,000s): http://www.statista.com/statistics/183505/number-of-vehicles-in-the-united-states-since1990/

Voas, R. B., Torres, P., Romano, E., \& Lacey, J. H. (2012). Alcohol-Related Risk of Driver Fatalities: An Update Using 2007 Data. Calverton, MD: Impaired Driving Center, Pacific Institute for Research and Evaluation.

Weiss, J. C., O'Neill, J., Shope, J. T., O'Connor, K. G., \& Levin, R. A. (2012). Paediatrician knowledge, attitudes and counselling patterns on teen driving. Journal of the International Society for Child and Adolescent Injury, 18, 5-10. 
West Virgina DMV. (2016). State of West Virginia Driver's Licensing Handbook. Charlestion, WV: Department of Transportation Division of Motor Vehicles.

West Virginia Department of Education, Office of Research. (2015). 2013 West Virginia Youth Risk Behavior Survey Results of High School Students. Ripley, WV: West Virginia Department of Education.

West Virginia Graduated Driver Licensing. (2011). Retrieved from Graduated Driver Licensing: http://www.graduateddriverlicensing.com/states/westvirginia.php

Wheaton, A. G., Shults, R. A., Chapman, D. P., Ford, E. S., \& Croft, J. B. (2014, July 4). Drowsy Driving and Risk Behaviors — 10 States and Puerto Rico, 2011-2012. Morbidity and Mortality Weekly Report.

William, A. F., Shults, R. A., \& Ali, B. (2012). Fatal crashes of 16-to 17-year-old drivers involving alcohol, nighttime driving, and passengers. Traffic Injury, 13, 1-6.

Williams, A. F., Tefft, B. C., \& Grabowski, J. G. (2012). Graduated Driver Licensing Research Review, 2010-Present (November 2012). Washington, DC: AAA Foundation for Traffic Safety.

Winston, F. K., Kallan, M. J., Senserrick, T. M., \& Elliott, M. R. (2008). Risk factors for death among older child and teenaged motor vehicle passengers. Arch Pedoatr Adolesc Med.

WV DOT. (2016). Driver's Licenses and ID Cards. Retrieved 4 27, 2016, from WV DMV: http://www.transportation.wv.gov/DMV/Drivers/Pages/Drivers-Licenses.aspx

Zhu, M., Cummings, P., Chu, H., Coben, J., \& Li, G. (2012). Graduated licensing and motor vehicle crashes involving teenage drivers: an age-stratified meta-analysis. Morgantown, 
WV: Department of Community Medicine and Injury Control Research, West Viginia University. 


\section{0: Appendix}

The appendix contains a complete copy of the paper version of the survey administered to Morgantown High, University High, and Clay-Battelle Middle/High Schools. The responses to each question are shown in a graphical representation as well as a tabulated breakdown.

\section{1: Complete GDL Survey}




\section{Assent Form}

Principal Investigator

Department

Protocol Number

Study Title

Co-Investigator(s)
David Martinelli, Ph.D.

Civil and Environmental Engineering

1503639282

Knowledge, Attitudes and Behaviors toward the WV GDL

Avinash Annikrishnan, Ph.D., Diana Martinelli, Ph.D.

\section{Contact Persons}

If you have any questions, concerns or complaints about this research study or questionnaire, you should contact Dr. David Martinelli at 304-293-9936 or david.martinelli@mail.wvu.edu. For information regarding your rights as a person in research or to talk about the research, call the Office of Research Integrity \& Compliance at (304) 293-7073.

\section{Introduction}

You,_[write your name here: have been asked to participate in this research study, which has been explained to you by

\section{Purpose(s) of the Study}

The purpose of this research is to better understand teenagers' knowledge about, attitude toward and observed behaviors regarding the West Virginia Graduated Driver's License. Therefore, we hope you will participate so that your feelings and ideas are included.

\section{Description of Procedures}

This survey is anonymous. No identifying information will be gathered; therefore, there is no way to connect your responses to you. The survey will take approximately 12 minutes to answer. Your participation is strictly voluntary and you may skip any question or stop responding at any time.

\section{Discomforts}

None of the questions should cause discomfort on your behalf. If you experience discomfort, you are free to stop the survey at any time.

Phone: 304-293-7073

Fax: 304-293-3098 http://oric.research.wvu.edu
Chestnut Ridge Research Building

886 Chestnut Ridge Road

PO Box 6845

Morgantown, WV 26506-6845
$P$ a g e | 1

Subject's Initials Date 


\section{Benefits}

This study may not help you directly, but what we learn from the study may help other people.

\section{Confidentiality}

We promise that anything we learn about you in this study will be kept as secret as possible. It is an anonymous survey, so you will not put your name on it, and your identity will not be connected to your responses.

\section{Voluntary Participation}

You do not have to do this. No one will be mad at you if you refuse to do this or if you decide to quit. You have been allowed to ask questions about the research, and all of your questions were answered.

I willingly agree to be in this research.

\section{Signatures}

Your Signature

$\begin{array}{lll}\text { Printed Name } & \text { Date Time }\end{array}$

The minor has had the opportunity to have questions addressed. The minor willingly agrees to be in the study.

Signature of Investigator or Co-Investigator

\begin{tabular}{lll}
\hline Printed Name & Date
\end{tabular}

Phone: $304-293-7073$

Fax: 304-293-3098 http://oric.research.wvu.edu
Chestnut Ridge Research Building

886 Chestnut Ridge Road

PO Box 6845

Morgantown, WV 26506-6845
Pag e | 2

Subject's Initials

Date 


\section{Knowledge, Attitudes, and Behaviors toward the WV Graduated Driver Licensing (GDL)}

Please answer each question to the best of your ability. If a question does not apply or you are uncomfortable answering then skip the question. "West Virginia Graduated Driver Licensing is a system for phasing in on-road driving, allowing beginners to get their initial experience under conditions that involve lower risk and introducing them in stages to more complex driving situations". (Instruction Permit > Intermediate Driver's License > Full Class E License)

1. How do you most often get to school?

Mark only one oval.

$\bigcirc$ Bus

$\longrightarrow$ Drive yourself

Carpool with another student

Carpool with adult who works at or near the school

Driven by adult family member

Walk

Other

2. What do you think the speed limit is in your designated school zone?

Mark only one oval.

15 miles per hour ( $\mathrm{mph}$ )

$\Longrightarrow 20 \mathrm{mph}$

$25 \mathrm{mph}$

$30 \mathrm{mph}$

$\Longrightarrow 35 \mathrm{mph}$

Something else

$\Longrightarrow$ Not sure

3. What is your current age?

Mark only one oval.

under 15

15

16

17

18

$19+$ 
4. At what age did you get your learner's permit?

Mark only one oval.

C 15

$\longrightarrow 151 / 2$

16

17 or older

Don't have my learner's permit

5. At what age did you get your driver's license?

Mark only one oval.

16

$161 / 2$

17

18 or older

Don't have my license

6. If you have a license or a learner's permit, what type of vehicle do you typically drive? Mark only one oval.

Compact Car

Sports Car

$\bigcirc$ Sedan

$\bigcirc$ Pickup Truck

$\bigcirc$ Mid-Size SUV

Large SUV

$\bigcirc \operatorname{Van}$

$\longrightarrow$ Motorcycle

$\longrightarrow$ Other:

7. The vehicle you usually drive is...

Mark only one oval.

$\bigcirc$ New (less than a year old)

$\Longrightarrow$ Used (more than a year old)

I drive both new and used about the same

$\Longrightarrow$ I don't drive 
8. Are you the only teenage driver in your household?

Mark only one oval.

Yes

$\longrightarrow$ No

There are no teenage drivers in my household

9. About how many hours did you spend driving with a licensed adult before you started driving on your own?

Mark only one oval.

less than 30 hours

31- 60 hours

61 - 90 hours

more than 90 hours

Don't yet drive on my own

10. Are you currently in or have you ever completed a driver's education course?

Mark only one oval.

Yes

$\bigcirc$ No

11. For which ONE of the following activities do you most often drive?

Mark only one oval.

To / from school or class

To / from school-related activities (sports, other extracurricular events)

To / from work

For social or recreational activities

Household / family tasks or activities

I don't drive

Other:

12. What is the most common GDL violation you see among your friends/classmates? Mark only one oval.

curfew

number of passengers

age of passengers

not finishing required practice hours

Other: 
13. In your opinion, what are the benefits of the GDL?

Check all that apply.

helps teens gain driving confidence

increases public safety

makes teens feel safer when riding with other teens

allows teens to start driving at an earlier age

helps parents feel better

I don't see any benefits of the GDL

not sure / don't know

14. What do you believe is the BEST way to improve GDL compliance among teens? Mark only one oval.

More GDL education in school

More GDL education for parents

More police enforcement/ penalties for violations

More severe penalties by parents for GDL violations

Peer pressure / influence to comply with GDL restrictions

Increase insurance rates for GDL offenders

Decrease insurance rates for GDL compliance

Unsure / don't know

Other:

15. Based on your previous knowledge, please write down what you believe to be the MOST useful GDL requirement in terms of driver safety?

16. Based on your previous knowledge, please write down what you believe to be the LEAST useful GDL requirement in terms of driver safety? 
Please fill in the circle that best represents your opinion on each of the following statements.

(Select one per row)
1
2
3
4
5
6
7
Students drive just as safely as adults.

Strongly

Disagree

O 0

$\bigcirc \quad \bigcirc$

$\bigcirc$

$\bigcirc$

Strongly Agree

Your school zone area is safe for vehicles to travel.

Strongly

Disagree

$\mathrm{O}$

O

O

O

$\bigcirc$

$\bigcirc$

$\bigcirc$ Strongly Agree

Your school zone area is safe for pedestrians to travel.

Strongly

Disagree

O

$\bigcirc$

0

○

0

$\bigcirc$

Strongly Agree

The traffic signs in and around your school zone are clear.

Strongly

Disagree

O

O

O

O

O

O

Strongly Agree

In your opinion, the school zone speed limit is too slow.

Strongly

Disagree

Strongly

Disagree

Strongly

Disagree

Strongly

Disagree

○

O

O

0

0

$\bigcirc$

Strongly Agree

Speeding is a problem in your school zone.

-

Drivers use designated school pick-up and drop-off locations appropriately.

\section{Orivers use designated school pick-up and drop-off locations appropriately.}

Drivers who don't pay full attention to their driving (distracted drivers) are a problem in and around your school zone.

\section{Strongly \\ Disagree \\ Disagree}

Disagree

Strongly

Disagree

Strongly

Disagree
○

○

$\bigcirc$

O

$\bigcirc$

Strongly Agree

Student drivers with passengers are more likely to be distracted in and around school zones.
$\bigcirc$
$\bigcirc$
$\bigcirc$
$\bigcirc$
$\bigcirc$
$\bigcirc$
Strongly Agree

There are more traffic problems in and around your school zone in the morning than in the afternoon.

$\begin{array}{llllllll} & 0 & 0 & 0 & 0 & & & \end{array} \quad$ Strongly Agree

The person who drives you to school obeys the speed limit while in and around the school zone.

(Continue on back) 


\section{$\begin{array}{lllllll}1 & 2 & 3 & 4 & 5 & 6 & 7\end{array}$}

How well do you know Graduated Driver's License (GDL) restrictions?

Not well at all

Not well at all

Never

Not at all Likely

Not at all Likely

Not at all Likely

Not at all Likely

None of them

Never

Never

Never

Never

Never

Never

Never

Never

Never $\bigcirc$

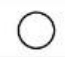

$O$

O

$\bigcirc$

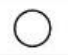

0

Extremely well

How well does your most knowledgeable guardian know GDL restrictions?

How often did/does your parent/guardian use $\mathrm{GDL}$ restrictions as a reason to
O
O
O
$O$
O
O

How likely are you to drive other with passengers in your vehicle?

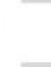

$\bigcirc \quad \bigcirc$

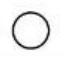

$\bigcirc$

O

0

$\bigcirc$

How likely are you to drive other teens in your vehicle?

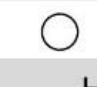

$\mathrm{O}$

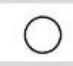

0

$\bigcirc$

$\bigcirc \bigcirc$

How likely are you to ride (be a passenger) with a teenage driver?

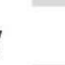

$O$
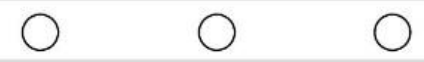

O

$O$

$\mathrm{O}$

How likely are you to listen to loud music while in a vehicle?

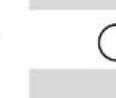

Extremely well

Always

Very Likely

Very Likely

Very Likely

Very Likely

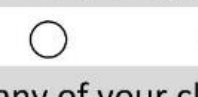

How many of your closest friends regularly exceed the speed limit?
O
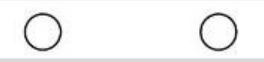
$\bigcirc$
$\bigcirc$

How often do you see friends ignore the GDL curfew restriction?

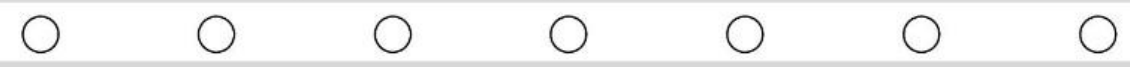

How often do you see friends ignore the GDL passenger limit restriction?

All of them

Always

Always

How often do you see friends or classmates texting while driving?

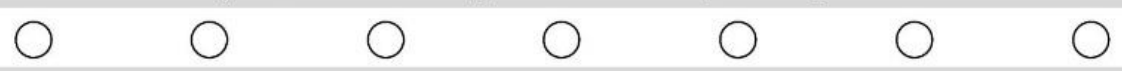

Always

How often do you see friends talking on the phone while driving?

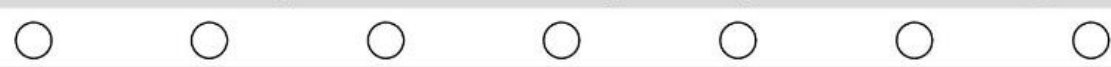

Always

How often do you see friends or classmates eat while driving?

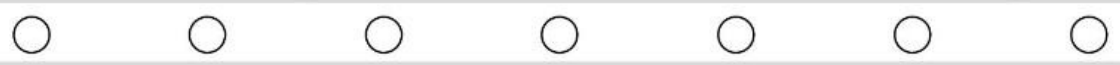

How often do you see adults exceed the speed limit?

Always

Always

How often do you see adults text while driving?

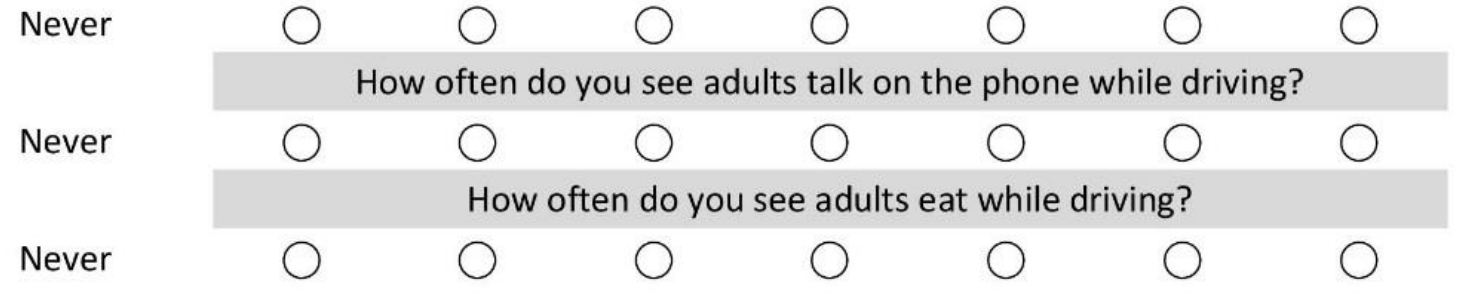

Always

Always

Always

Thank you for your time! Please wait for further instructions from the survey administrator. 
7.2: Graphical Breakdown of Responses by Question

\subsection{1: Categorical}

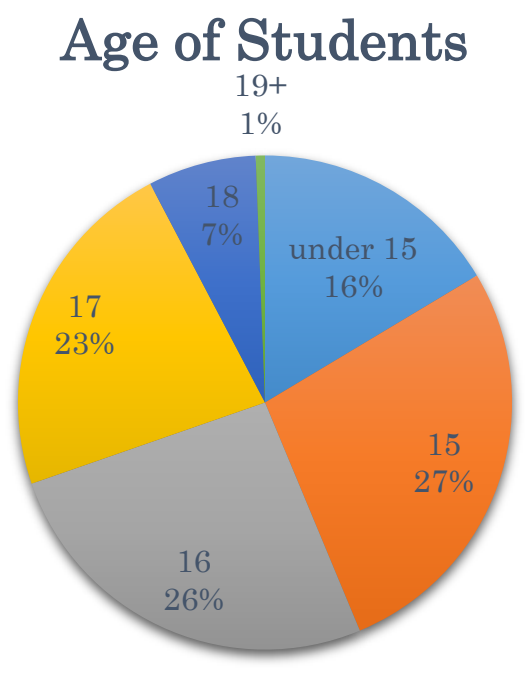

\section{Age of Instructional Permit}

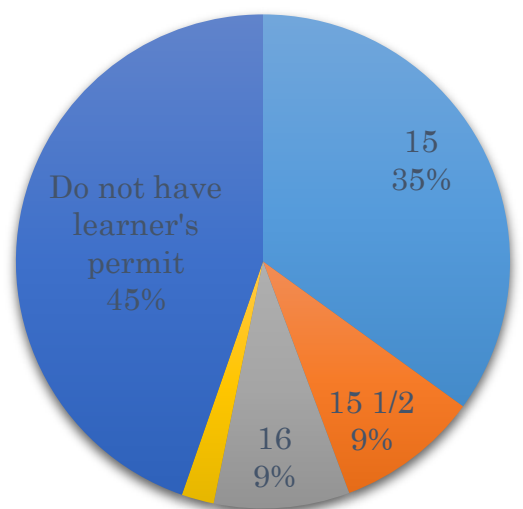

17 or older

$2 \%$

\section{Method of Getting to School}

Walk Other

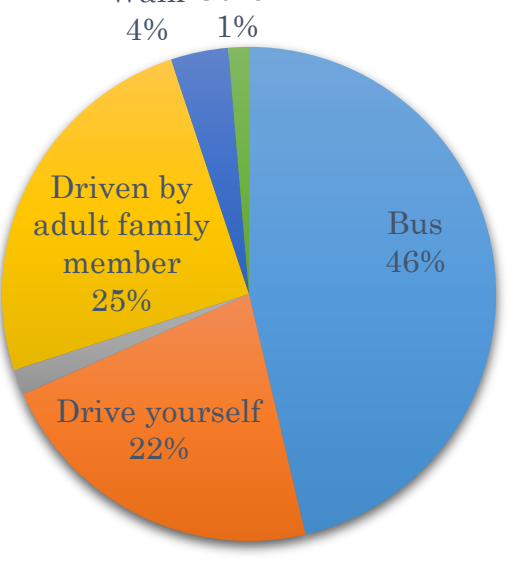

Carpool with adult who

works at or near the school $2 \%$

\section{Age of Intermediate License}

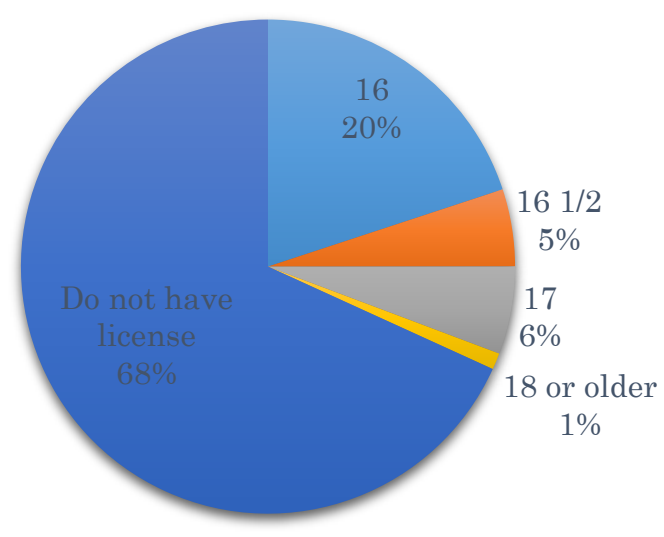




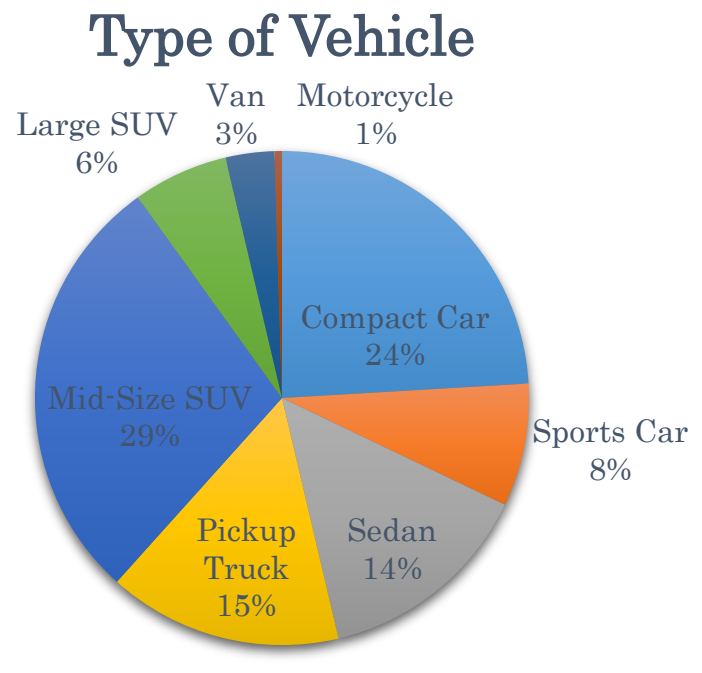

\section{Age of Vehicle}

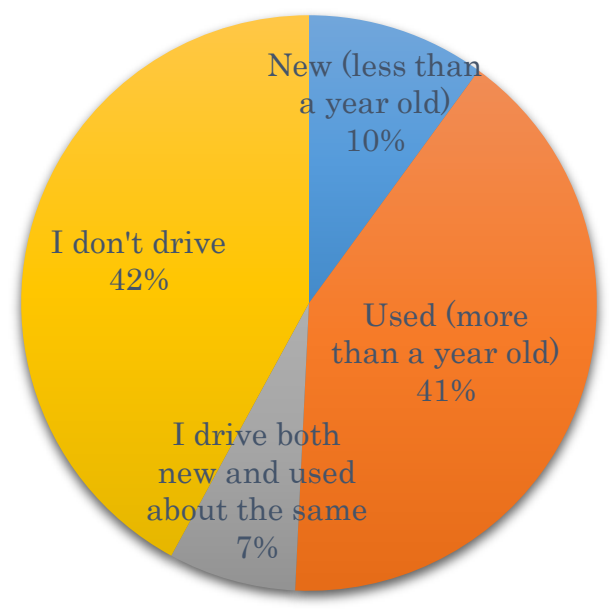

Only Teenage Driver in Household
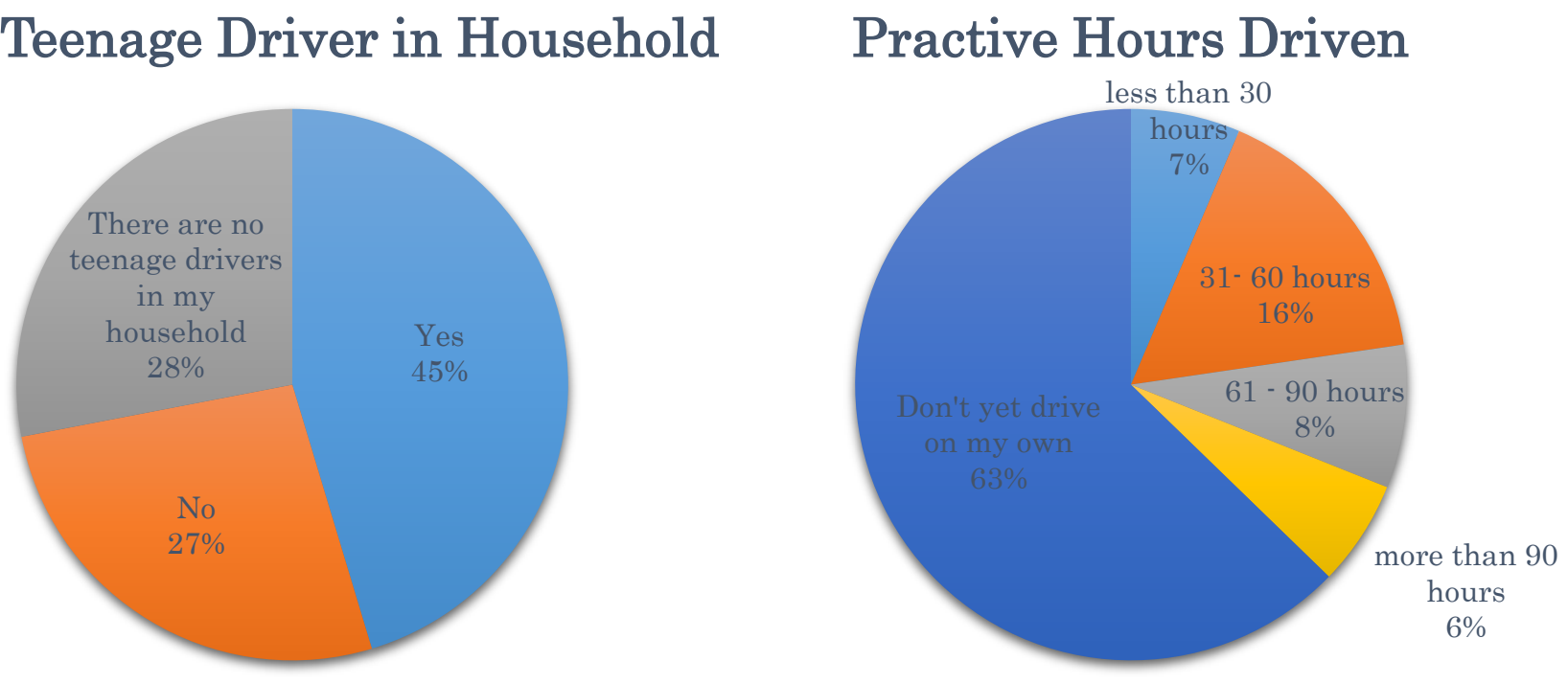

Have Taken Driver's Education

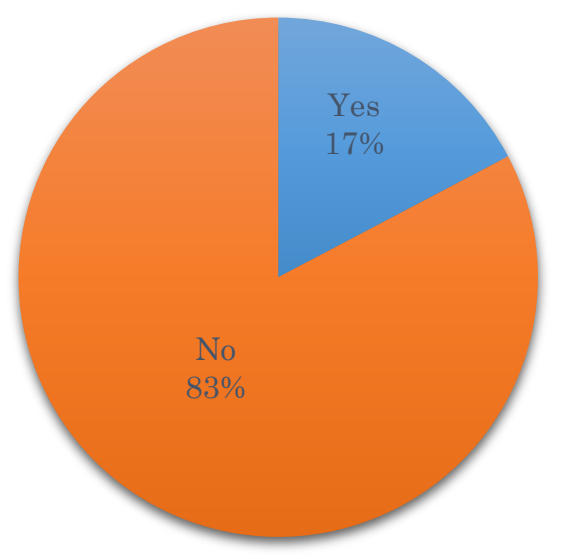




\section{Most Common Driving Destination}

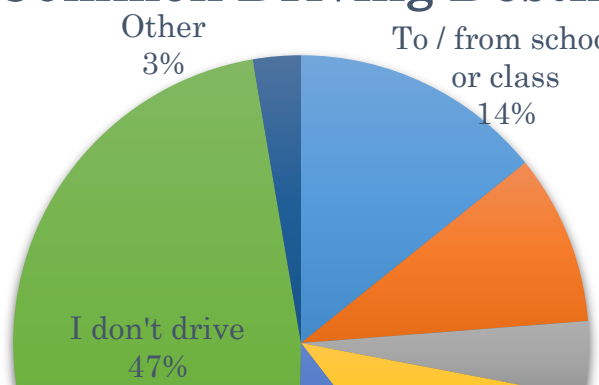

For social or recreational activities $11 \%$

Household / family tasks or activities $11 \%$

\section{Benefits of the GDL}

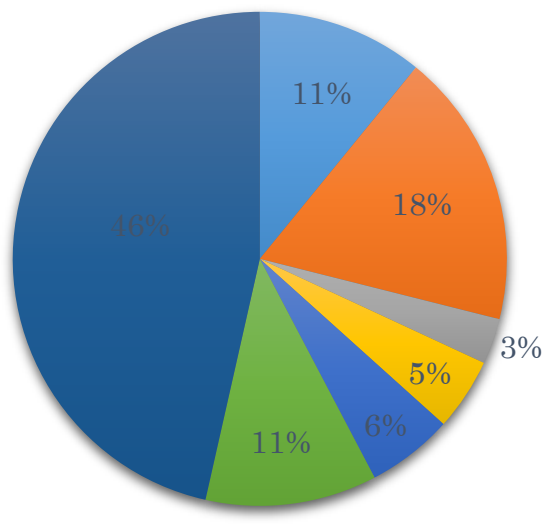

- helps teens gain driving confidence

- increases public safety

makes teens feel safer when riding with other teens

- allows teens to start driving at an earlier age

- helps parents feel better

I don't see any benefits of the GDL

not sure / don't know

\section{Most Commonly Seen GDL Violation}

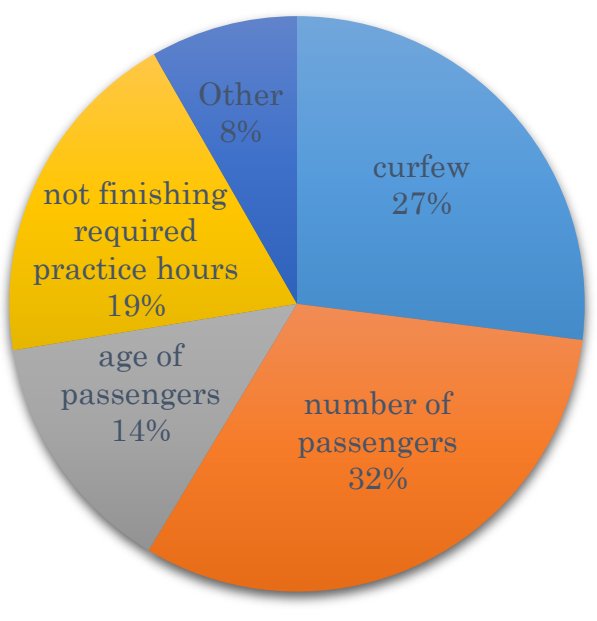

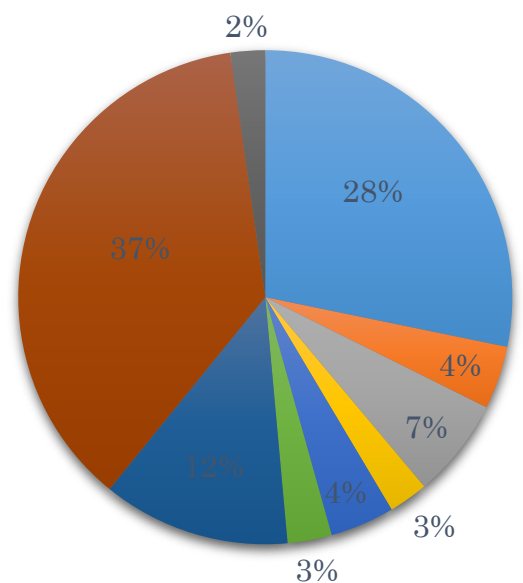

- More GDL education in school

More GDL education for parents

- More police enforcement/ penalties for violations

- More severe penalties by parents for GDL violations

- Peer pressure / influence to comply with GDL restrictions

- Increase insurance rates for GDL offenders

- Decrease insurance rates for GDL compliance

- Unsure / don't know 


\subsection{2: Scaled}

\subsubsection{1: GLD}

Extremely Low Extremely High

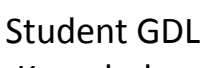

Knowledge
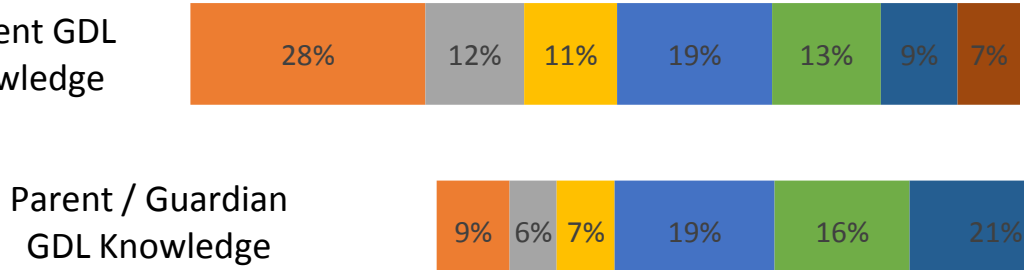

Frequency of Partental GDL Enforcement
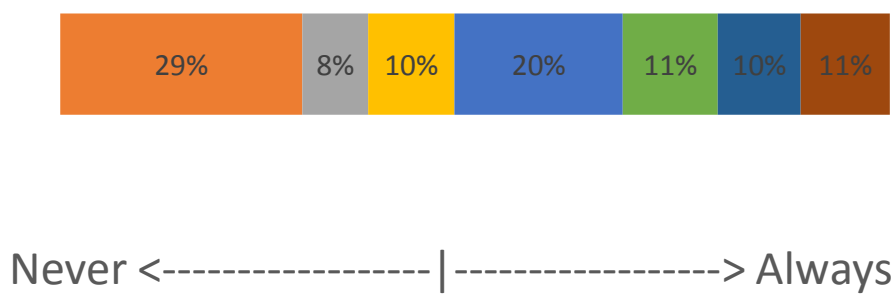

Observe Teens

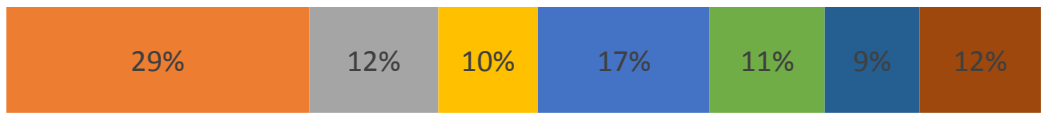

Observe Teens Ignoring Passenger Limit

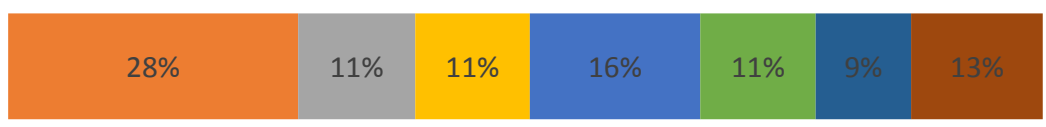

\subsubsection{2: Self-Habits}

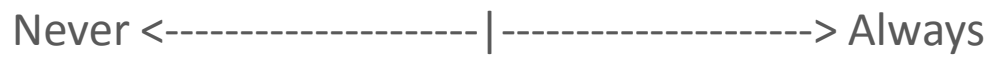

Driving with Passengers

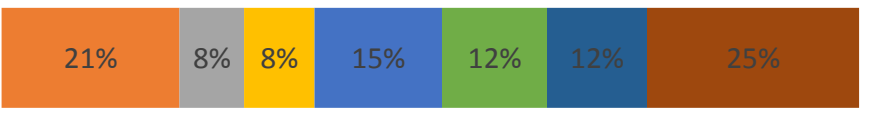

\section{Driving with Teenage Passengers}

Be a Passenger of a Teenage Driver

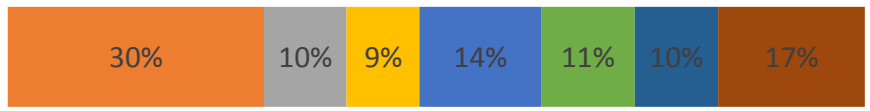

Listening to Loud Music
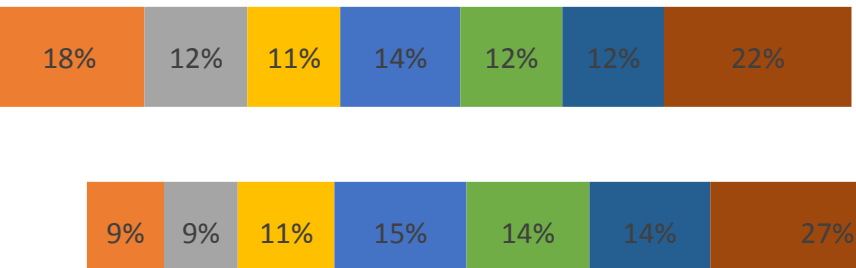
7.2.2.3: Teen/Adult Perspective

Never <---------------------------- |--------------------------> Always

Teen Speeding

\begin{tabular}{|l|l|l|l|l|l|l|}
\hline $24 \%$ & $14 \%$ & $12 \%$ & $18 \%$ & $13 \%$ & $10 \%$ & $10 \%$ \\
\hline
\end{tabular}

Adult Speeding

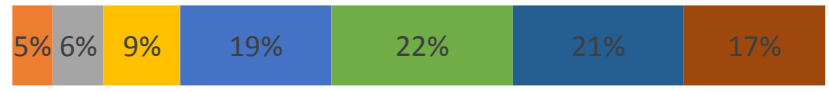

Teen Texting

$32 \%$

$17 \% \quad 11 \%$

$15 \%$

Adult Texting

$10 \% \quad 11 \% \quad 11 \%$

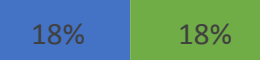

$8 \%$

Teen Talking

\begin{tabular}{|l|l|l|l|l|l|}
\hline $31 \%$ & $17 \%$ & $14 \%$ & $16 \%$ & $11 \%$ & $6 \%$
\end{tabular}

Adult Talking

$$
5 \% \quad 6 \% \quad 8 \%
$$

$16 \%$

Teen Eating

\begin{tabular}{|l|l|l|l|l|l|l|}
\hline $25 \%$ & $14 \%$ & $13 \%$ & $19 \%$ & $13 \%$ & $9 \%$ & $8 \%$ \\
\hline
\end{tabular}

Adult Eating

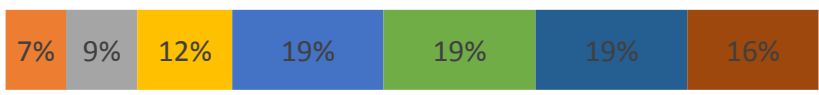




\section{3: Detailed Summary of Responses by Question}

Q1. How do you most often get to school?

\section{Category}

Bus

Drive yourself

Carpool with adult who works at or near the school

Driven by adult family member

Walk

Other

Total
Number of Responses Response Percentage 998

474

36

$22 \%$

$2 \%$

$\begin{array}{cc}536 & 25 \% \\ 81 & 4 \% \\ 29 & 1 \% \\ 2154 & \end{array}$

Q2. What do you think the speed limit is in your designated school zone?

\section{Category}

15 miles per hour (mph)

$20 \mathrm{mph}$

$25 \mathrm{mph}$

$30 \mathrm{mph}$

$35 \mathrm{mph}$

Something else

Not sure

Total
Number of Responses

1874

160

110

13

24

25

122

2328
Response Percentage $80 \%$

$7 \%$

$5 \%$

$1 \%$

$1 \%$

$1 \%$

$5 \%$

Q3. What is your current age?

\section{Category}

under 15

15

16

17

18

19+

Total
Number of Responses

382

636

604

527

165

14

2328

\section{Response Percentage}

$16 \%$

$27 \%$

$26 \%$

$23 \%$

$7 \%$

$1 \%$ 
Q4. At what age did you get your learner's permit?

\section{Category}

15

15.5

16

17 or older

Do not have learner's permit

Total
Number of Responses

808

216

205

49

1032

2310
Response Percentage

$35 \%$

$9 \%$

$9 \%$

$2 \%$

$45 \%$

Q5. At what age did you get your driver's license?

\section{Category}

16

16.5

17

18 or older

Do not have license

Total
Number of Responses

462

117

133

25

1580

2317
Response Percentage

$20 \%$

$5 \%$

$6 \%$

$1 \%$

$68 \%$

Q6. If you have a license or a learner's permit, what type of vehicle do you typically drive?

\section{Category}

Compact Car

Sports Car

Sedan

Pickup Truck

Mid-Size SUV

Large SUV

Van

Motorcycle

Other

Total
Number of Responses

347

116

205

221

410

90

46

7

217

1659
Response Percentage

$21 \%$

$7 \%$

$12 \%$

$13 \%$

$25 \%$

$5 \%$

$3 \%$

$0 \%$

$13 \%$

Q7. The vehicle you usually drive is...

\section{Category}

New (less than a year old)

Used (more than a year old)

I drive both new and used about the same

I don't drive

Total
Number of Responses

228

926

163

956

2273
Response Percentage

$10 \%$

$41 \%$

$7 \%$

$42 \%$ 
Q8. Are you the only teenage driver in your household?

\section{Category}

Yes

No

There are no teenage drivers in my household

Total
Number of Responses

1037

609

641

2287
Response Percentage

$45 \%$

$27 \%$

$28 \%$

Q9. About how many hours did you spend driving with a licensed adult before you started driving on your own?

Category

less than 30 hours

31- 60 hours

61 - 90 hours

more than 90 hours

Don't yet drive on my own

Total
Number of Responses

146

370

191

141

1428

2276
Response Percentage $6 \%$

$16 \%$

$8 \%$

$6 \%$

$63 \%$

Q10. Are you currently in or have you ever completed a driver's education course?

\section{Category}

Yes

No

Total
Number of Responses

398

1903

2301
Response Percentage

$17 \%$

$83 \%$

Q11. For which ONE of the following activities do you most often drive?

\section{Category}

To / from school or class

To / from school-related activities (sports, other extracurricular events)

To / from work

For social or recreational activities

Household / family tasks or activities

I don't drive

Other

Total
Number of Responses

323

217

96

262

245

1067

61

2271
Response Percentage

$14 \%$

$10 \%$

$4 \%$

$12 \%$

$11 \%$

$47 \%$

$3 \%$ 
Q12. What is the most common GDL violation you see among your friends/classmates?

\section{Category \\ curfew}

number of passengers

age of passengers

not finishing required practice hours

Other

Total
Number of Responses

564

660

288

403

173

2088
Response Percentage

$27 \%$

$32 \%$

$14 \%$

$19 \%$

$8 \%$

Q13. In your opinion, what are the benefits of the GDL?

\section{Category}

helps teens gain driving confidence

increases public safety

makes teens feel safer when riding with other

teens

allows teens to start driving at an earlier age

helps parents feel better

I don't see any benefits of the GDL

not sure / don't know

Total
Number of Responses

131

217

36

57

68

135

559

2283
Response Percentage

$6 \%$

$10 \%$

$2 \%$

$2 \%$

$3 \%$

$6 \%$

$24 \%$

Q14. What do you believe is the BEST way to improve GDL compliance among teens?

\section{Category}

More GDL education in school

More GDL education for parents

More police enforcement/ penalties for violations

More severe penalties by parents for GDL

violations

Peer pressure / influence to comply with GDL

restrictions

Increase insurance rates for GDL offenders

Decrease insurance rates for GDL compliance

Unsure / don't know

Other

Total
Number of Responses

636

93

147

58

95

65

277

831

51

2253
Response Percentage

$28 \%$

$4 \%$

$7 \%$

$3 \%$

$4 \%$

$3 \%$

$12 \%$

$37 \%$

$2 \%$ 
Q15. Based on your previous knowledge, please write down what you believe to be the MOST useful GDL requirement in terms of driver safety?

*Short Answer Responses*

Q16. Based on your previous knowledge, please write down what you believe to be the LEAST useful GDL requirement in terms of driver safety?

\section{*Short Answer Responses*}

Q17-27. These questions were asked in junction with a separate study through West Virginia University.

Q28. How well do you know Graduated Driver's License (GDL) driving restrictions?

\begin{tabular}{|c|c|c|c|c|}
\hline Category & & $\mathrm{Nu}$ & Responses & Response Percentage \\
\hline Not well at all & & & & $28 \%$ \\
\hline 2 & & & & $12 \%$ \\
\hline 3 & & & & $11 \%$ \\
\hline 4 & & & & $19 \%$ \\
\hline 5 & & & & $13 \%$ \\
\hline 6 & & & & $9 \%$ \\
\hline Extremely well & & & & $7 \%$ \\
\hline Total & & & & \\
\hline sum & mean & variance & std. dev. & skew \\
\hline 2202 & 3.34 & 3.88 & 1.97 & 0.28 \\
\hline
\end{tabular}

Q29. How well does your most knowledgeable parent/guardian know GDL driving restrictions?

\begin{tabular}{|c|c|c|c|c|}
\hline Category & & $\mathbf{N u}$ & Responses & Response Percentage \\
\hline Not well at all & & & & $9 \%$ \\
\hline 2 & & & & $6 \%$ \\
\hline 3 & & & & $7 \%$ \\
\hline 4 & & & & $19 \%$ \\
\hline 5 & & & & $16 \%$ \\
\hline 6 & & & & $21 \%$ \\
\hline Extremely well & & & & $22 \%$ \\
\hline Total & & & & \\
\hline sum & mean & variance & std. dev. & skew \\
\hline 2184 & 4.80 & 3.45 & 1.86 & -0.60 \\
\hline
\end{tabular}


Q30. How often did/do your parent or guardian use GDL restrictions as a reason to limit your driving activities?

$\begin{array}{lcc}\text { Category } & \text { Number of Responses } & \text { Response Percentage } \\ \text { Never } & 621 & 29 \% \\ \mathbf{2} & 168 & 8 \% \\ \mathbf{3} & 221 & 10 \% \\ \mathbf{4} & 432 & 20 \% \\ \mathbf{5} & 243 & 11 \% \\ \mathbf{6} & 213 & 10 \% \\ \text { Always } & 228 & 11 \% \\ \text { Total } & 2126 & \end{array}$

\begin{tabular}{|c|c|c|c|c|}
\hline sum & mean & variance & std. dev. & skew \\
\hline $\mathbf{2 1 2 6}$ & 3.50 & 4.28 & 2.07 & 0.20 \\
\hline
\end{tabular}

Q31. On any given day, how likely are you to drive with passengers in your vehicle?

$\begin{array}{lcc}\text { Category } & \text { Number of Responses } & \text { Response Percentage } \\ \text { Not at all Likely } & 447 & 21 \% \\ \mathbf{2} & 162 & 8 \% \\ \mathbf{3} & 177 & 8 \% \\ \mathbf{4} & 321 & 15 \% \\ \mathbf{5} & 263 & 12 \% \\ \mathbf{6} & 252 & 12 \% \\ \text { Very Likely } & 533 & 25 \% \\ \text { Total } & 2155 & \end{array}$

\begin{tabular}{|c|c|c|c|c|}
\hline sum & mean & variance & std. dev. & skew \\
\hline $\mathbf{2 1 5 5}$ & 4.24 & 5.01 & 2.24 & -0.20 \\
\hline
\end{tabular}


Q32. On any given day, how likely are you to drive other teens in your vehicle?

\section{Category}

Not at all Likely

2

3

4

5

6

Very Likely

Total
Number of Responses

644

207

183

305

235

209

369

2152
Response Percentage $30 \%$

$10 \%$

$9 \%$

$14 \%$

$11 \%$

$10 \%$

$17 \%$

\begin{tabular}{|c|c|c|c|c|}
\hline sum & mean & variance & std. dev. & skew \\
\hline $\mathbf{2 1 5 2}$ & 3.64 & 5.08 & 2.25 & 0.18 \\
\hline
\end{tabular}

Q33. On any given day, how likely are you to ride (be a passenger) with a teenage driver?

$\begin{array}{lcc}\text { Category } & \text { Number of Responses } & \text { Response Percentage } \\ \text { Not at all Likely } & 385 & 18 \% \\ \mathbf{2} & 264 & 12 \% \\ \mathbf{3} & 238 & 11 \% \\ \mathbf{4} & 308 & 14 \% \\ \mathbf{5} & 261 & 12 \% \\ \mathbf{6} & 261 & 12 \% \\ \text { Very Likely } & 480 & 22 \% \\ \text { Total } & 2197 & \end{array}$

\begin{tabular}{|c|c|c|c|c|}
\hline Sum & mean & variance & std. dev. & skew \\
\hline $\mathbf{2 1 9 7}$ & 4.14 & 4.71 & 2.17 & -0.08 \\
\hline
\end{tabular}


Q34. On any given day, how likely are you to listen to loud music while in a vehicle?

\section{Category}

Not at all Likely

2

3

4

5

6

Very Likely

Total
Number of Responses

197

190

247

339

315

310

601

2199
Response Percentage

$9 \%$

$9 \%$

$11 \%$

$15 \%$

$14 \%$

$14 \%$

$27 \%$

\begin{tabular}{|c|c|c|c|c|}
\hline sum & mean & variance & std. dev. & skew \\
\hline $\mathbf{2 1 9 9}$ & 4.69 & 3.95 & 1.99 & -0.39 \\
\hline
\end{tabular}

Q35. Think of your closest friends in school. About how many of them would you say regularly exceed the speed limit?

\section{Category}

None of them

2

3

4

5

6

All of them

Total
Number of Responses

521

308

254

396

274

208

206

2167

\section{Response Percentage} $24 \%$

$14 \%$

$12 \%$

$18 \%$

$13 \%$

$10 \%$

$10 \%$

\begin{tabular}{|c|c|c|c|c|}
\hline sum & mean & variance & std. dev. & skew \\
\hline $\mathbf{2 1 6 7}$ & 3.48 & 3.95 & 1.99 & 0.26 \\
\hline
\end{tabular}


Q36. How often do you see friends or classmates ignore Graduated Driver's License (GDL) curfew restrictions?

$\begin{array}{lcc}\text { Category } & \text { Number of Responses } & \text { Response Percentage } \\ \text { Never } & 631 & 29 \% \\ \mathbf{2} & 269 & 12 \% \\ \mathbf{3} & 208 & 10 \% \\ \mathbf{4} & 358 & 17 \% \\ \mathbf{5} & 239 & 11 \% \\ \mathbf{6} & 198 & 9 \% \\ \text { Always } & 253 & 12 \% \\ \text { Total } & 2156 & \end{array}$

\begin{tabular}{|c|c|c|c|c|}
\hline sum & mean & variance & std. dev. & skew \\
\hline $\mathbf{2 1 5 6}$ & 3.42 & 4.43 & 2.10 & 0.31 \\
\hline
\end{tabular}

Q37. How often do you see friends or classmates ignore GDL passenger limit restrictions?

$\begin{array}{lcc}\text { Category } & \text { Number of Responses } & \text { Response Percentage } \\ \text { Never } & 603 & 28 \% \\ \mathbf{2} & 244 & 11 \% \\ \mathbf{3} & 238 & 11 \% \\ \mathbf{4} & 355 & 16 \% \\ \mathbf{5} & 240 & 11 \% \\ \mathbf{6} & 199 & 9 \% \\ \text { Always } & 274 & 13 \% \\ \text { Total } & 2153 & \end{array}$

\begin{tabular}{|c|c|c|c|c|}
\hline sum & mean & variance & std. dev. & skew \\
\hline $\mathbf{2 1 5 3}$ & 3.50 & 4.46 & 2.11 & 0.27 \\
\hline
\end{tabular}


Q39. How often do you see friends or classmates texting while driving?

\section{Category}

Never

2

3

4

5

6

Always

Total
Number of Responses

689

374

244

329

259

151

138

2184
Response Percentage $32 \%$

$17 \%$

$11 \%$

$15 \%$

$12 \%$

$7 \%$

$6 \%$

\begin{tabular}{|c|c|c|c|c|}
\hline sum & mean & variance & std. dev. & skew \\
\hline $\mathbf{2 1 8 4}$ & 3.05 & 3.69 & 1.92 & 0.54 \\
\hline
\end{tabular}

Q40. How often do you see friends or classmates talk on the phone while driving?

\section{Category}

Never

2

3

4

5

6

Always

Total
Number of Responses 665

362

303

340

238

136

132

2176
Response Percentage $31 \%$

$17 \%$

$14 \%$

$16 \%$

$11 \%$

$6 \%$

$6 \%$

\begin{tabular}{|c|c|c|c|c|}
\hline sum & mean & variance & std. dev. & skew \\
\hline $\mathbf{2 1 7 6}$ & 3.03 & 3.51 & 1.87 & 0.56 \\
\hline
\end{tabular}


Q41. How often do you see friends or classmates eat while driving?

\section{Category}

Never

2

3

4

5

6

Always

Total
Number of Responses

545

299

280

414

278

186

170

2172
Response Percentage $25 \%$

$14 \%$

$13 \%$

$19 \%$

$13 \%$

$9 \%$

$8 \%$

\begin{tabular}{|c|c|c|c|c|}
\hline sum & mean & variance & std. dev. & skew \\
\hline $\mathbf{2 1 7 2}$ & 3.38 & 3.72 & 1.93 & 0.30 \\
\hline
\end{tabular}

Q42. How often do you see adults exceed the speed limit?

\section{Category}

Never

2

3

4

5

6

Always

Total
Number of Responses 109

137

206

406

488

458

382

2186
Response Percentage

$5 \%$

$6 \%$

$9 \%$

$19 \%$

$22 \%$

$21 \%$

$17 \%$

\begin{tabular}{|c|c|c|c|c|}
\hline sum & mean & variance & std. dev. & skew \\
\hline $\mathbf{2 1 8 6}$ & 4.80 & 2.79 & 1.67 & -0.54 \\
\hline
\end{tabular}


Q43. How often do you see adults text while driving?

\section{Category}

Never

2

3

4

5

6

Always

Total
Number of Responses 226

250

244

391

403

343

340

2197
Response Percentage $10 \%$

$11 \%$

$11 \%$

$18 \%$

$18 \%$

$16 \%$

$15 \%$

\begin{tabular}{|c|c|c|c|c|}
\hline sum & mean & variance & std. dev. & skew \\
\hline $\mathbf{2 1 9 7}$ & 4.31 & 3.59 & 1.90 & -0.23 \\
\hline
\end{tabular}

Q44. How often do you see adults talk on the phone while driving?

\section{Category}

Never

2

3

4

5

6

Always

Total
Number of Responses

116

131

183

356

428

504

480

2198
Response Percentage

$5 \%$

$6 \%$

$8 \%$

$16 \%$

$19 \%$

$23 \%$

$22 \%$

\begin{tabular}{|c|c|c|c|c|}
\hline sum & mean & variance & std. dev. & skew \\
\hline $\mathbf{2 1 9 8}$ & 4.95 & 2.98 & 1.73 & -0.66 \\
\hline
\end{tabular}


Q45. How often do you see adults eat while driving?

\section{Category}

Never

2

3

4

5

6

Always

Total
Number of Responses

164

192

257

408

411

410

355

2197
Response Percentage

$7 \%$

$9 \%$

$12 \%$

$19 \%$

$19 \%$

$19 \%$

$16 \%$

\begin{tabular}{|c|c|c|c|c|}
\hline sum & mean & variance & std. dev. & skew \\
\hline $\mathbf{2 1 9 7}$ & 4.53 & 3.25 & 1.80 & -0.36 \\
\hline
\end{tabular}

